\title{
ADVOCACY AND ACCOUNTABILITY IN SCHOOL COUNSELING: ASSESSING THE USE OF DATA AS RELATED TO PROFESSIONAL SELF-EFFICACY
}

\author{
A Dissertation \\ presented to \\ the Faculty of the Graduate School \\ at the University of Missouri-Columbia \\ In Partial Fulfillment \\ of the Requirements for the Degree \\ Doctor of Education \\ by \\ SUSAN EVANS MATTHEWS
}

Dr. Sarah Diem, Dissertation Supervisor

MAY 2020 
The undersigned, appointed by the dean of the Graduate School, have examined the dissertation entitled

\section{ADVOCACY AND ACCOUNTABILITY IN SCHOOL COUNSELING: ASSESSING THE USE OF DATA AS RELATED TO PROFESSIONAL SELF-EFFICACY}

Presented by Susan Evans Matthews,

a candidate for the degree of doctor of education, and hereby certify that, in their opinion, it is worthy of acceptance.

Dr. Sarah Diem, Advisor

Dr. Jennifer Fellabaum-Toston

Dr. Keith Herman

Dr. James Sebastian 


\section{DEDICATION}

With the end still months away, I decided to take some time to consider to whom I owe a deep gratitude for the journey that is this dissertation. Albert Bandura (1986), the theorist upon whose work this dissertation is built, once wrote in a dedication, "It is with profound gratitude that I dedicate this volume to my family, who have put up with me during this extended venture. They are good companions to have on a long journey" (p.xiii). And, once again, my sage speaks for me.

So, to my good companions:

- Marty and the children for the hurried dinners, shortened conversations, homework sessions that were more about me getting stuff done than learning middle and high school concepts, I thank you so very much. Now is when you must start calling me Dr. Mom. Scarlett Grace, I hope you enjoy this work because it is your younger sibling.

- To my beacons and depth markers, my parents. You instilled a natural curiosity and nurtured my drive. I cannot imagine a better way for you to parent me and to tell me "I love you" than through these acts. It couldn't have been easy.

- To my sister for her well placed, "Dayum"s when she was impressed. I'll never stop looking up to you for validation since you are my "much" older sister.

- For the extended family that knows me from the inside out and loves me nonethe-less. Education has always been a value and I know that each of you has supported me in small and big ways since birth. What would Gramma and Daddy think of us now?

- My family of choice is also quite large and fiercely passionate and protective of me. For Gay and Kim, you sheltered and comforted me through writing. For my Hickman family: Tracey and your encouragement, Eric and your laughter, Tony and your reminders to be bold, Counseling at Hickman and our perfectly dysfunctional family. Your accountability and support made this less of a trial.

- Cohort 8 - Mizzou group. Y'all rock and Mintzberg rules, even if I couldn't figure out a way to get him in this dang research. And, believe me, I tried. I mean, seriously, who wouldn't love an inside joke mixed in with a dissertation? 


\section{ACKNOWLEDGEMENTS}

It is completely appropriate to pause and acknowledge my new companions on this extended venture: my committee.

Patience is surely a virtue held with a firm grasp by Dr. Sarah Diem. The fits and starts of this process are not unique to me - I hope - but have been nurtured with the patience and grace of my amazing advisor. You have supported my work with grace and strength. I appreciate your forthrightness and accountability. Thank you.

When asked to be on the committee, Dr. Jennifer Fellabaum-Toston did not hesitate. She asked what role I needed and wanted from her and I got just what I wanted: a cheerleader who points out APA errors. The time and energy you've supplied through the bootcamps over the years was seen and appreciated deeply. It doesn't put too fine a point on things to say I don't know how I would be at this point without your efforts. Thank you.

If mathematics is a language, then statistics must be one of the most nuanced of dialects. Dr. James Sebastian, thank you for the roadmap and consistent rephrasing as I refreshed my decades old course work and took understanding of statistical concepts to a new level. Thank you.

It was important to me that a member of this committee be connected to School Counseling and have an understanding, in a somewhat concrete way, of what it is that I do day in and day out for the students at Hickman. Dr. Keith Herman, I appreciate your willingness to step out of your department and be part of this process. I look forward to continuing to work with you toward same goals of mental health for the children and adolescents in Columbia Public Schools and Boone County. Thank you. 


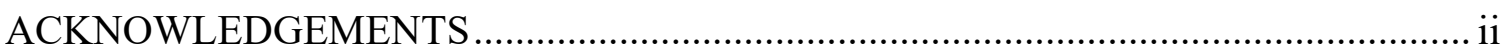

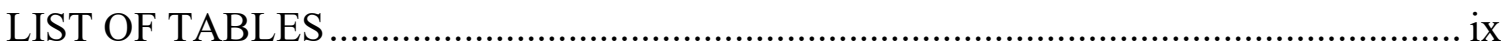

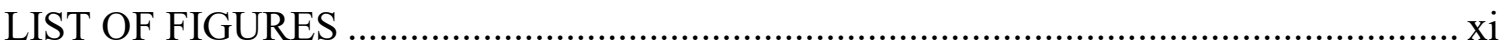

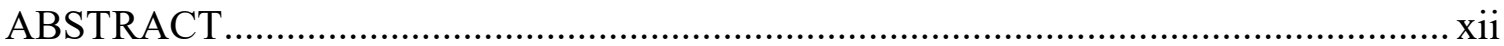

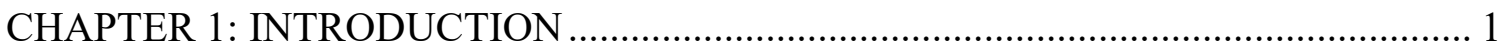

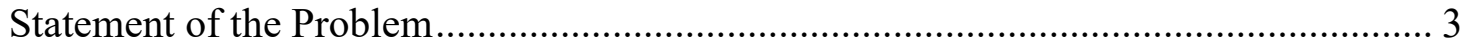

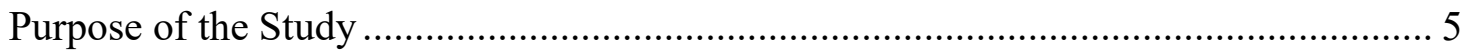

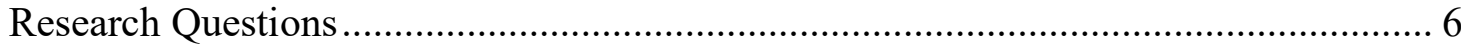

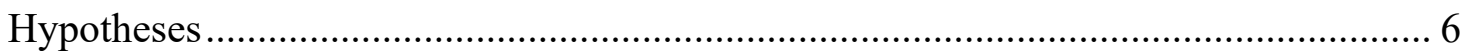

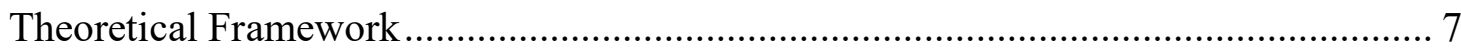

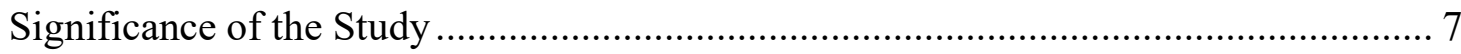

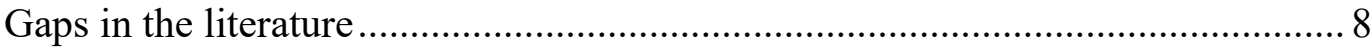

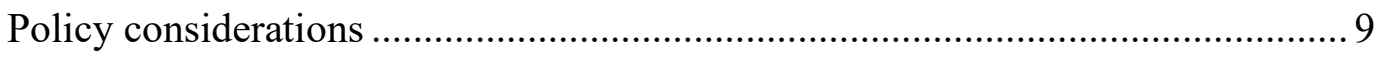

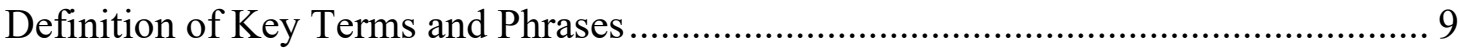

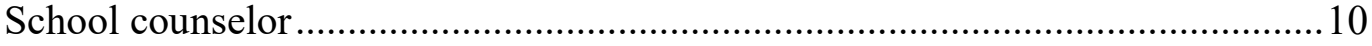

ASCA National Model.............................................................................. 10

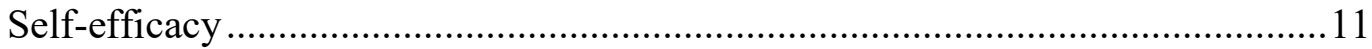

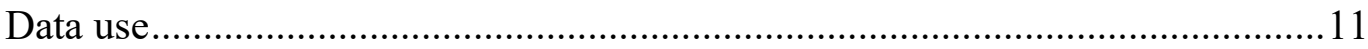

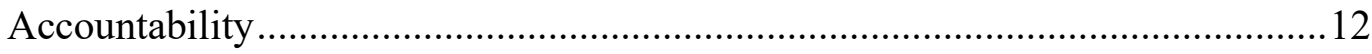

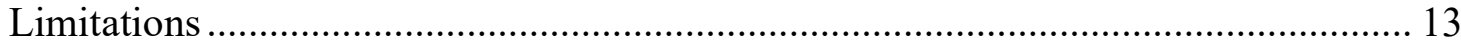

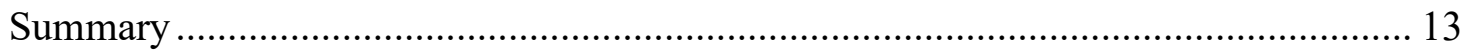




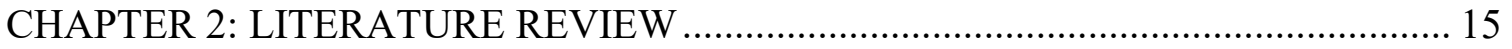

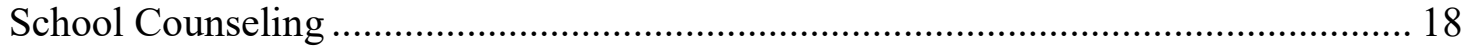

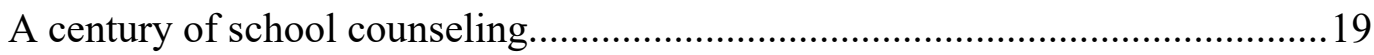

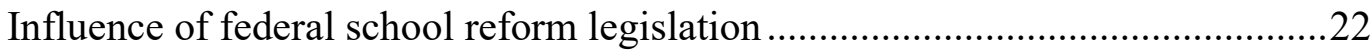

National Defense Education Act.......................................................23

Elementary and Secondary Education Act .......................................24

No Child Left Behind...................................................................25

Every Student Succeeds Act ..........................................................26

Current conceptualization of school counseling .........................................28

Components of the National Model .....................................................30

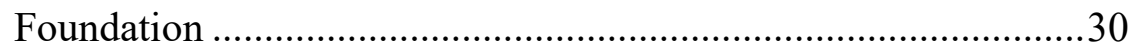

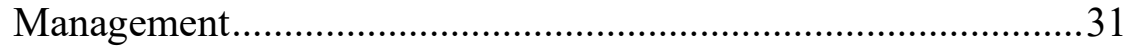

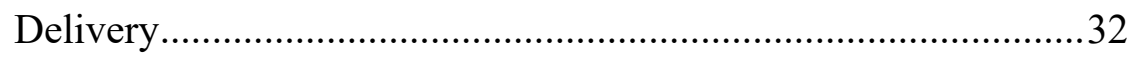

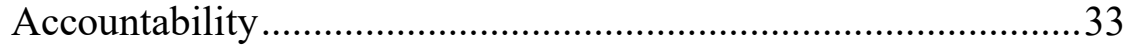

Themes that govern the National Model..............................................34

Leadership ................................................................. 34

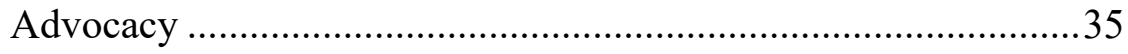

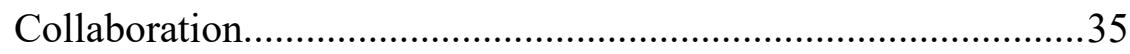

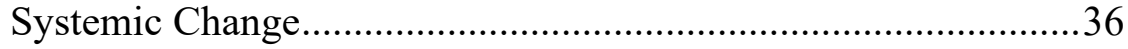

Social Cognitive Theory, Self-Efficacy, and the School Counselor............................ 38

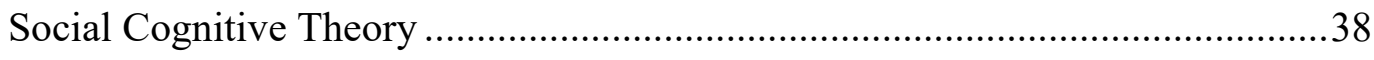

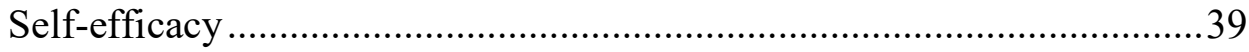

School counselor's self-efficacy.......................................... 40 


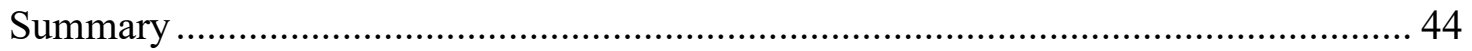

CHAPTER 3: RESEARCH DESIGN AND METHODOLOGY ................................... 45

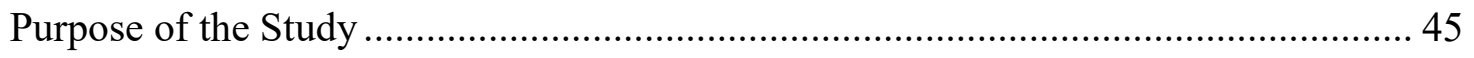

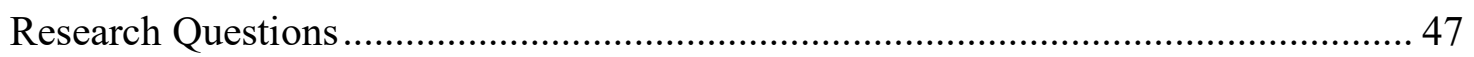

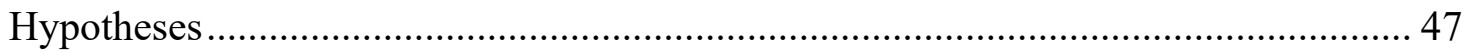

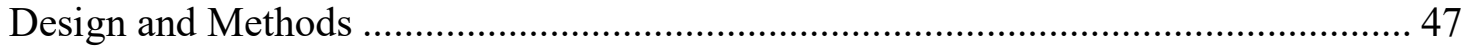

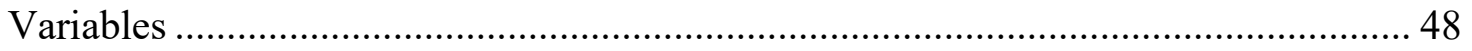

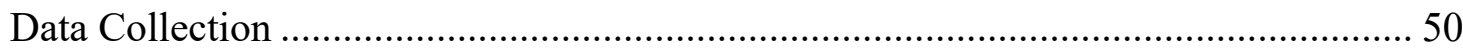

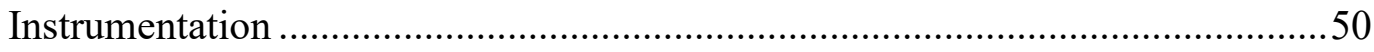

School Counselor Self-Efficacy Scale …………………………...............51

Bodenhorn \& Skaggs Study One ...................................................51

Bodenhorn \& Skaggs Study Two ………………………….......52

Bodenhorn \& Skaggs Study Three .............................................55

Bodenhorn \& Skaggs Study Four ................................................56

School Counseling Accountability Needs Assessment...............................57

Items related to math self-efficacy.........................................................59

Demographic information tool..................................................................60

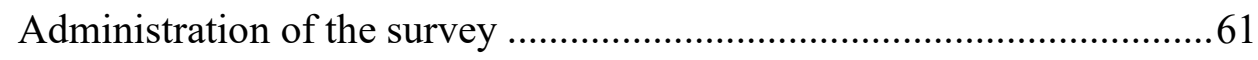

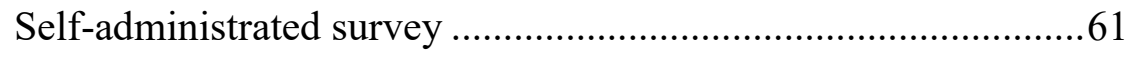

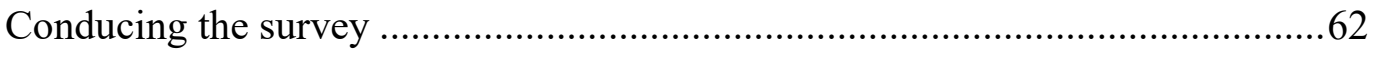

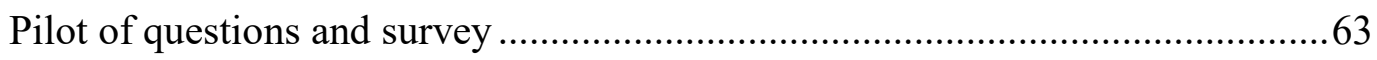

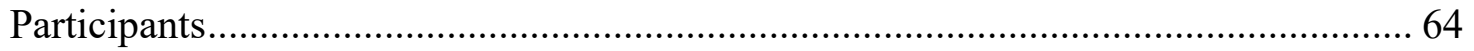




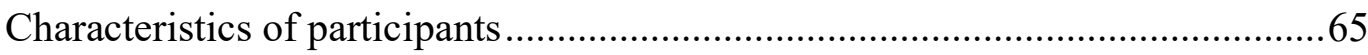

Consent, access, and the use of human subjects ..................................68

Informed consent ............................................................... 68

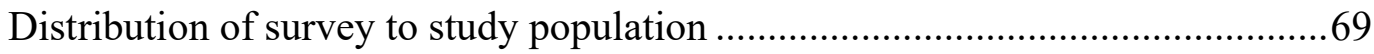

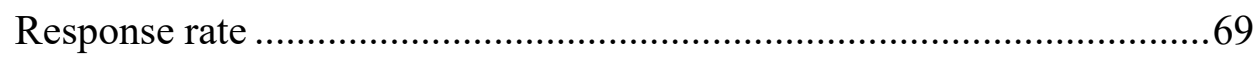

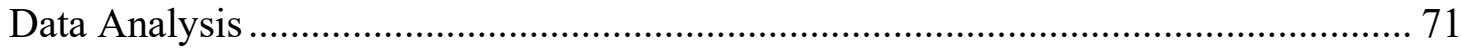

Statistical procedures for the study ........................................................... 71

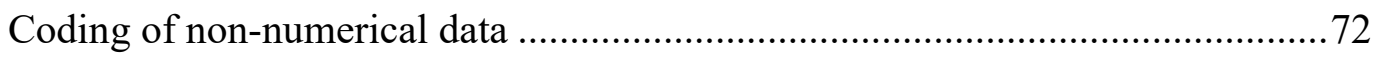

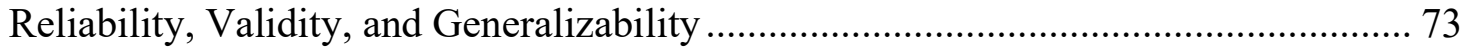

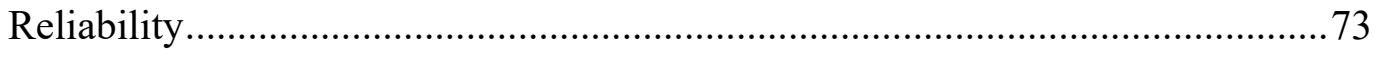

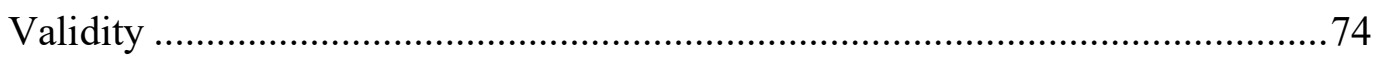

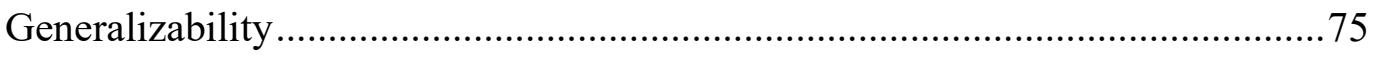

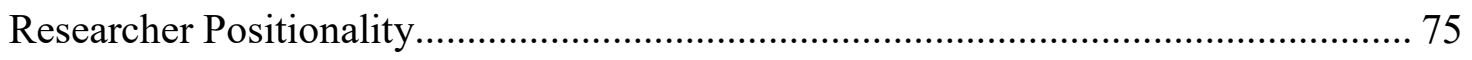

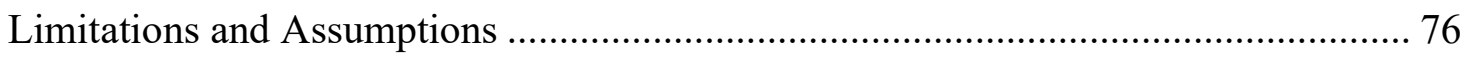

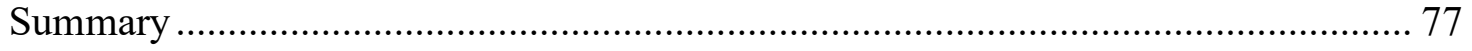

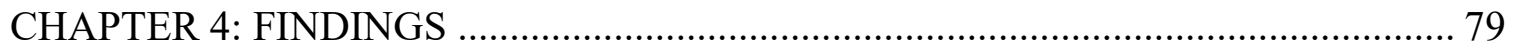

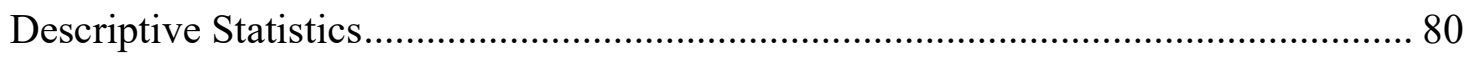

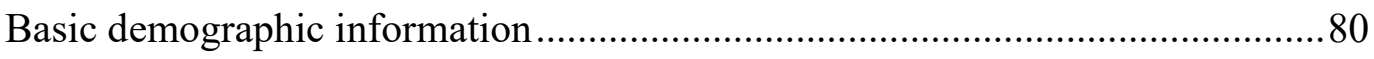

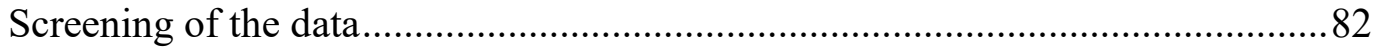

Check for normality, homogeneity of variance, and multicollinearity .....82

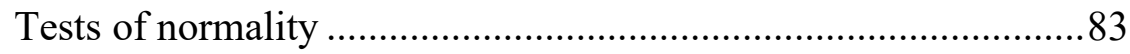

Tests for homogeneity of variance ....................................... 85 
Test for multicollinearity ................................................ 87

Creating dummy variables to support analysis ........................................... 87

Significant correlations of demographic statistics ............................... 88

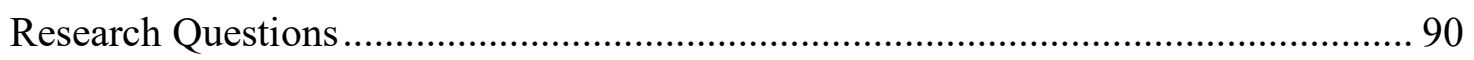

The primary research question ............................................................ 90

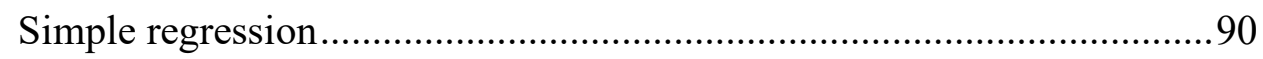

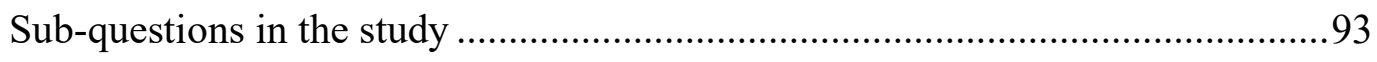

Adding covariates to the model .....................................................94

Sequential multiple regression .................................................. 95

Changes in the model by adding demographic variables.............95

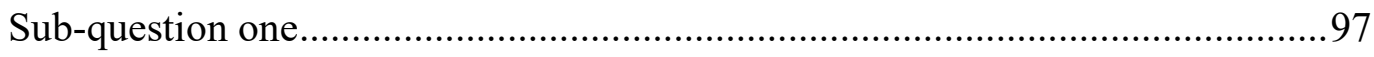

Math items created for this study ................................................. 97

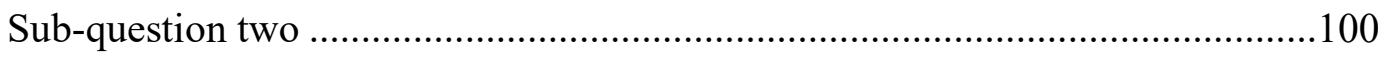

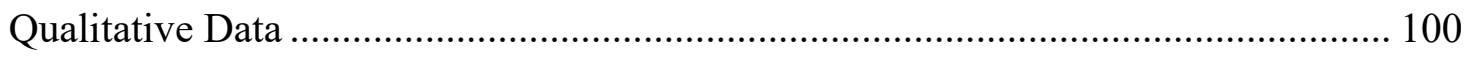

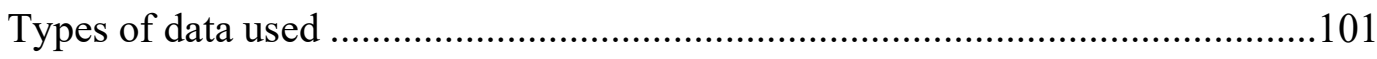

Opinions, thoughts, and feelings shared on data type question ..............103

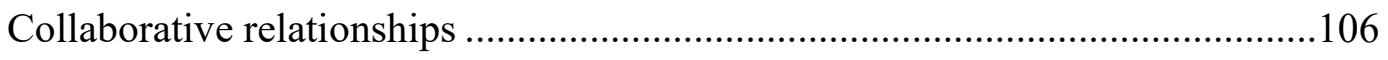

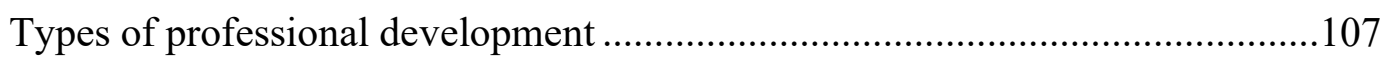

Where school counselors receive professional development..................108

Professional development topic and scope .......................................108

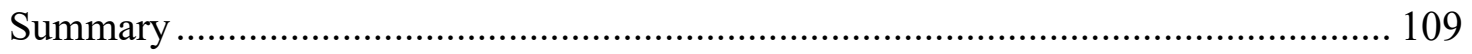

CHAPTER 5: DISSCUSSION, CONCLUSIONS, AND IMPLICATIONS ................ 111

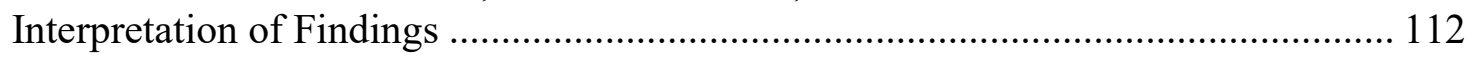




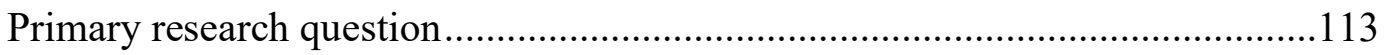

Self-efficacy in mathematical concepts ...........................................................114

Participation in targeted professional development...............................................115

More than half of the variance remains unattributed ..........................................117

Targeted professional development, diverse collaboration, and identified

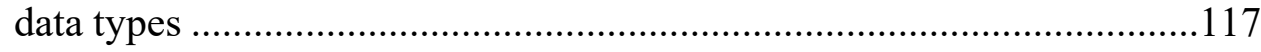

Implications for Practice .................................................................................... 119

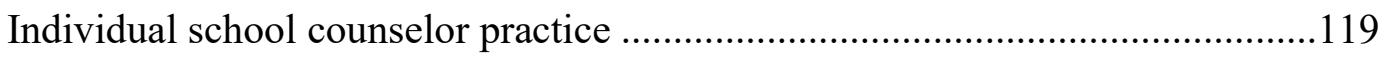

Implications for those involved in training school counselors .............................120

Implications for those working alongside school counselors ...............................121

Implications for advocacy groups focused on school counselors ........................122

Implications for school counselors and leadership ……….................................123

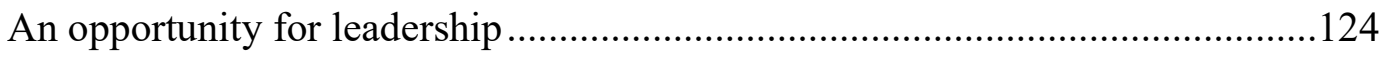

Recommendations for Further Research............................................................... 125

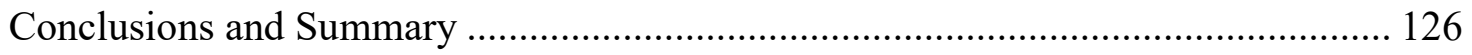

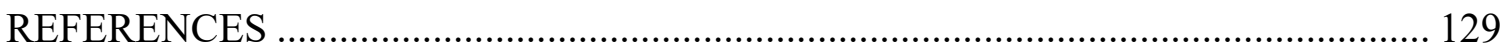

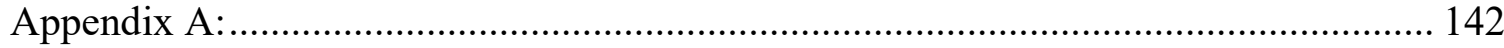

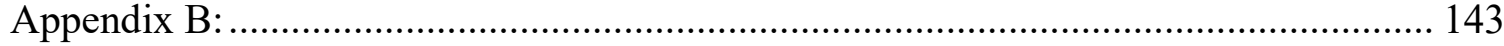

Appendix C:

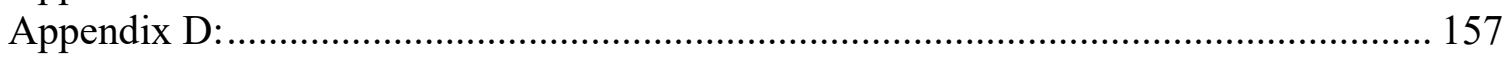

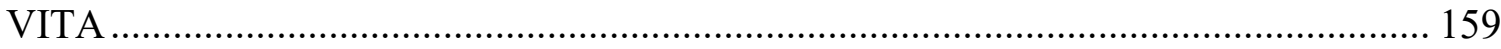




\section{LIST OF TABLES}

Table 1. Survey items from the School Counselor Self-Efficacy Scale (SCSE) 53

Table 2. Survey items from the School Counselor Accountability Needs Assessment (SCANA)

Table 3. Survey items reltated to mathematical self-efficacy 60

Table 4. Participant numbers and percentages by group 67

Table 5. Homogeneity of variance for SCSE and SCANA 86

Table 6. Descriptive statistics and correlations 89

Table 7. Results of simple regression analysis 92

Table 8. Sequential multiple regression analysis 96

Table 9. Summary of exploratory factor analysis 98

Table 10. Regression analysis results for data use regressed on self-efficacy with math and professional development 
Table 11. Free-response items included in the survey ............................................. 101

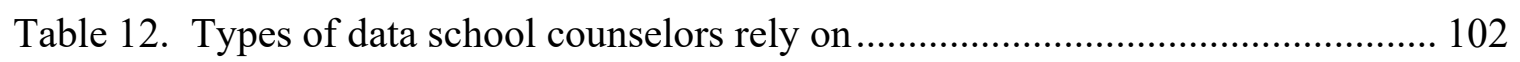

Table 13. Qualitative responses indicating opinion, thought, or feeling of school

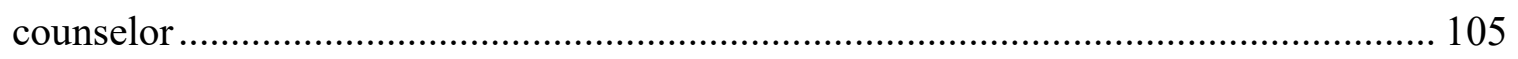

Table 14. Who school counselors collaborate with by group .................................... 107

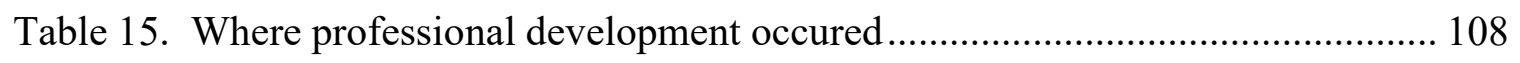

Table 16. Topic or focus of professional development............................................ 109 


\section{LIST OF FIGURES}

Figure 1. ASCA National Model Diamond.. ................................................................. 2

Figure 2. Simple scatterplot of SCANA Mean by SCSE Total with Regression Line.... 82

Figure 3. Histogram of SCANA mean scores......................................................... 83

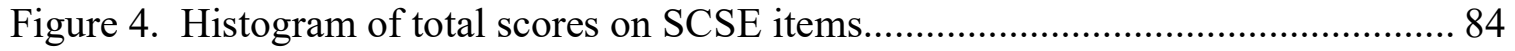

Figure 5. Histogram of mean scores for participants on self-efficacy in math items..... 85 
ADVOCACY AND ACCOUNTABILITY IN SCHOOL COUNSELING: ASSESSING THE USE OF DATA AS RELATED TO PROFESSIONAL SELF-EFFICACY

\author{
Susan Evans Matthews
}

Dr. Sarah Diem, Dissertation Supervisor

\begin{abstract}
School counselors are uniquely trained and positioned within schools to use data for the purpose of addressing opportunity and achievement gaps present in many schools. Even with this position, the literature for school counseling remains focused on reasons to use data rather than how to use data within a school counseling program.

This study examines the relationship between professional self-efficacy and levels of data use to understand an aspect of why school counselors might not use data to promote school counseling program goals and advocacy. Participants are 426 public school counselors from Missouri. Participants are mostly female (89.4\%) and have 7-18 years of experience as school counselors (44.8\%). Simple and multiple regression analysis is used to examine the relationship between self-efficacy and data use.

Additional factors are self-efficacy in mathematical concepts and the involvement of participants in continued training on the use of data.

Statistically significant variation in school counselor's data use is attributed to self-efficacy $\left(\mathrm{R}^{2}=0.247, p<.01\right)$. The addition of higher self-efficacy in math concepts $\left(\mathrm{R}^{2}=0.370\right)$ and participation in professional development $\left(\mathrm{R}^{2}=0.40\right)$ increases the strength of the model $(p<.01)$. Recommendations for future research offers suggestions for additional covariates to analyze. Implications for practicing school counselors as well as those who train, support, and evaluate them are also addressed.
\end{abstract}




\section{CHAPTER 1: INTRODUCTION}

School counseling has a rich history that directly connects with educational and societal reform in the United States. Early in the 20th century, reform agents sought to modify schooling by selecting teachers who connected with students to explore vocational interests and goals (Cinotti, 2014; Erford, House, \& Martin, 2003; Gysbers, 2010; Herr, 2003; Sink, 2005). As the conceptualization of schooling evolved so, too, did the role of these teacher-leaders. The advancement of school counseling mirrors the timeline of educational reform. The current conceptualization of school counseling also follows the lead of reform. In the late 21 st century, school personnel are accountable to various stakeholders in concrete ways. Parents, taxpayers, and politicians desire specific data to explain the performance of students of all demographics (Carey \& Dimmitt, 2006; Dahir \& Stone, 2003, 2009; Education Trust, 2007; National Commission on Excellence in Education, 1983; Smith, 2005). This desire to understand student performance provides an opportunity for specialized professionals, within the structure of the school setting, to use data to tell the story of student achievement and performance.

School counselors, one such group of specialized educators, have at their disposal, the ASCA National Model: A Framework for School Counseling Programs (2012; Figure 1, Appendix A) as a blueprint for implementing comprehensive and developmental programs of counseling in schools. Produced by the American School Counselor Association (ASCA), the skills, competencies, and standards within the National Model inform the training of counselors as well as their daily professional role. Counselor education programs across the United States use the National Model structure to design course maps that include instruction in the areas of foundational counseling and 
organizational theories, systems of delivery, program management, as well as program evaluation and accountability.

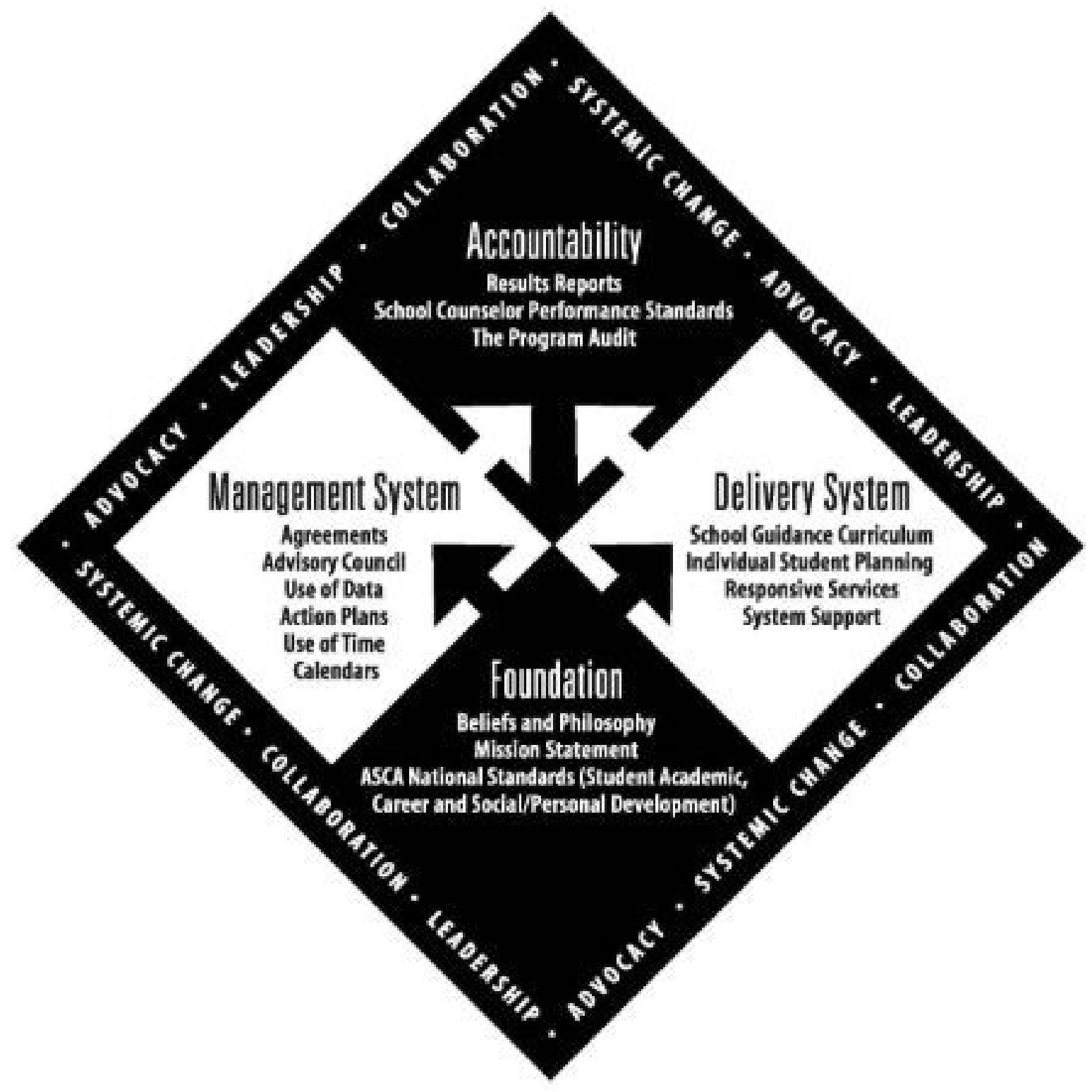

Figure 1 ASCA National Model Diamond. The diamond visually describes the interplay of the four elements: Foundation, Management, Delivery, and Accountability as well as the themes of Leadership, Advocacy, Collaboration and Systemic Change. From ASCA National Model: A Framework for School Counseling Programs by American School Counselors Association (2012) Alexandria, VA: Author, Copyright 2012 by American School Counselor Association. Reprinted with permission. 
Utilizing data within the educational setting is not a new endeavor. This study explored how one distinct role within the school setting used student level data to support work that addressed both achievement and opportunity gaps within the student population.

\section{Statement of the Problem}

Approximately a decade ago the school where I work began an intentional journey to address concerns of equity in access and success for students. Simultaneously, our district highlighted the need to be data-driven in every decision made. These initiatives, along with the revision of the American School Counselor Association (ASCA) National Model, fed a personal and professional interest in the role of school counselors within the spheres of accountability and advocacy.

From early in my training I was encouraged to be mindful of the tasks I did as well as those assigned to me. As is explored in the literature review, school counselors have a history of tasks that are not strictly within the purview of the role. That is, there are many "non-guidance" tasks that are accomplished by school counselors. At times, the function of a school counselor may look like a job where the only line in the description reads "all other duties as assigned" (ASCA, 2012; Gysbers, 2010; Gysbers \& Henderson, 2005; Lambie \& Williamson, 2004; Paisley, 2001; Sink, 2005).

However, I noticed that I, and many of my colleagues, were often more comfortable in the completion of these somewhat mundane administrative tasks that were not directly tied to professional training than we were to engage in activities that more completely fit the changing view of the school counselor as promoted by ASCA. I began 
to ask myself, how did we get to this point? Was it an issue of being in a spot of comfort or even complacency? Was it a lack of professional development regarding the developing vision of the profession and the discrete skills associated with the new functions? If it was the latter, would principals and other leaders in the school and district need to have professional development to better understand what school counselors should and could accomplish? Were my observations valid of just my interaction with the profession or were others feeling a similar ennui? Were there other counselors in the state and nation that felt a similar push and pull between what "they've always done" and what we are called to do?

With these questions in my mind I realized that I had the perfect problem to examine in a dissertation. As I read more about the role of school counselors, as a lead member of data teams in schools, and as a proactive part of the closing of achievement and opportunity gaps I noticed that many of these articles had a "how-to" nature. That is, the articles were not focused on what was working in these situations, but rather spent time on why it is important for school counselors to engage in this work and the beginning steps of how to use and interpret data for other stakeholders Adelman \& Taylor, 2002; ASCA, 2012; Astromovich \& Coker, 2007; Bemak, 2000; CACREP, 2016; Dahir \& Stone, 2009; Dimmit, 2009; Holcomb-McCoy, Gonzalez \& Johnston, 2009; House \& Hayes, 2002).

This, then, is the essential problem of this research. School counselors, a specialized profession within public schools in the United States, are trained in their master's level educational programs on the basics of mining, interpreting, and communicating about data (ASCA, 2018; CACREP, 2016). Additionally, school 
counselors are trained in using the data package to develop and implement strategies to facilitate the continued success of students. Even with this training the literature of the profession continues to advocate and evangelize about the need for this work. Why might school counselors be hesitant to engage in this process? Might it be connected to self-efficacy, the belief in one's own abilities to perform specific tasks?

\section{Purpose of the Study}

The purpose of this quantitative survey study is to examine if there is a relationship between school counselor self-efficacy and school counselor's utilization of data to support a comprehensive school counseling program. Chapter Two reviews literature that looks at these concepts singularly as well as a few limited studies that examine the relationship. Young and Kaffenberger $(2011,2015)$ are leading the research on data use with Bodenhorn and Skaggs (2005) as well as Bodenhorn, Wolfe, and Airen (2010) examining self-efficacy in school counselors.

It is my contention that looking at data usage for the nearly 2,700 school counselors in the state of Missouri along with their reports of self-efficacy describes another factor within the broader topic. Specifically, I believe my study furthers Young and Kaffenberger's $(2011,2015)$ work by looking through the lens of one's belief about one's own ability. Further, describing this relationship provides information that can form recommendations to my own practice, the comprehensive school counseling program at my school and district, as well as state initiatives and counselor education programs. 
School counselor input was solicited through an online survey that contained questions from two established surveys: School Counselor Accountability Needs Assessment (SCANA, Young \& Kaffenberger, 2015) and the School Counselor SelfEfficacy Scale (SCSE, Bodenhorn \& Skaggs, 2005). The online survey was conducted following Dillman's (2007) Tailored Design Method. Data collected from the survey underwent statistical analysis using basic descriptive statistics as well as multiple linear regression.

\section{Research Questions}

The primary question guiding this study is: are there relationships between school counselor self-efficacy and the use of data to drive program advocacy and accountability? Additional questions, to further understand the relationship were: does the direction and strength of the relationship, if one was found to be present, change (1) with report of greater self-efficacy in mathematical processes and (2) depending upon the experience of professional development focused on the topic of data use?

\section{Hypotheses}

For purposes of this study there was one hypothesis set. For the primary question:

1. $\mathrm{H}_{0}=$ No relationship exists between school counselor data usage and the use of data to drive program advocacy and accountability.

2. $\mathrm{H}_{1}=\mathrm{A}$ relationship does exist between school counselor data usage and the use of data to drive program advocacy and accountability. 


\section{Theoretical Framework}

Researchers utilize theoretical frameworks that best align with their views on epistemology and ontology. I believe knowledge is constructed and reality is developed through experience. I further acknowledge that reality is a personal construct and therefore multiple realities exist. My experience working within public education for the last decade along with my training as a school counselor lends to this bias and directly informs each choice made in the design and implementation of this study. I specifically utilize a theory in this study that explains the structures that create and support the construction of knowledge, specifically the knowledge and beliefs surrounding one's own abilities, also known as self-efficacy as defined in Bandura's social cognitive theory. Bandura $(1986,1993,1995,2001,2012)$ presents a model of humanity where factors such as environment, personal traits, and behaviors interact and inform each other. He further states that humans are the primary agent of their functioning and, as such, are active players in their creation of reality.

\section{Significance of the Study}

Robson and McCartan (2016) indicate that the pragmatic approach includes the view that knowledge is constructed and experienced. They further argue that knowledge can change as experiences change. Research, therefore, should be interpreted as

provisional truth. It is within this mindset that I conducted this study into the relationship between self-efficacy in school counselors and their use of student data to inform their practice. This section outlines the gaps in literature and potential outcomes available from this study. 


\section{Gaps in the Literature}

First, Young and Kaffenberger (2011) looked at the data usage of school counselors in Recognized ASCA Model Program (RAMP) designated schools. The recipients of this award have validated use of data. To be considered for the recognition, the schools must demonstrate skills in program evaluation. The application for the award requires the school counselor to submit 12 components, each including a significant amount of data to support claims and decisions. In fall of 2012, 631 schools, or $0.0066 \%$, of schools in the United States, held RAMP designation (ASCA, 2017; Kena, et al., 2015). The highly specialized sample does not allow for much generalization to other school counselors. Likewise, the same authors in 2015 conducted a study focusing on counselors in the state of Iowa (Young \& Kaffenberger, 2015). The authors examined data use as connected to professional development. They found a significant relationship between frequency of professional development and use of data to increase college and career readiness in students. Two factors were identified that could contribute to higher data use: participation in professional development and years in the profession. Again, this limited sample places limitations and gaps when trying to understand the larger phenomena of school counselors and their data use.

In a dissertation published in 2016, Miller expanded upon the original research of Young and Kaffenberger $(2011,2015)$ and examined data use of school counselors from both RAMP and non-RAMP designated schools in eight states. This data set yielded a possible confirmation of Young and Kaffenberger's (2011) original study that RAMP recognition does lead to higher levels of data use. Miller (2016) cites neutral and/or lower ratings on common survey items when comparing results from Young and 
Kaffenberger's (2011) sample and Miller's (2016) sample. The sample, however, only included school counselors holding membership in ASCA.

The present study adds to the research by looking at how counselors work with data regardless of professional affiliation and/or program recognition. The sample is limited by the inclusion of only school counselors from Missouri. However, the present study does include the added questions regarding self-efficacy.

\section{Policy Considerations}

Accountability in education is the job of every member of a school staff. School counselors, as specialized members of this community, have standards through ASCA and the Council for Accreditation of Counseling and Related Educational Programs (CACREP) that call for work in this area. Even with calls for accountability, why does there seem to be a lack of data use on the part of school counselors? Researchers (Blacher, Murray-Ward, \& Uellendahl, 2005; Isaacs, 2003; Militello \& Janson, 2014; Poynton, 2009; Poynton \& Carey, 2006) point to many reasons. If a relationship exists between self-efficacy and data usage for school counselors, it could have implications for the professional acceptance of this role on a macro-level. Additionally, the present study could inspire individual school counselors to look at their own use of data and how it may relate to their program advocacy thus influencing the micro-level support of practitioners.

\section{Definition of Key Terms and Phrases}

Certain terms are utilized throughout this study. What follows are definitions for these content specific terms and how they are conceptualized within the present study. These definitions are offered to orient the reader to a full understanding of the findings. 


\section{School Counselor}

Comprehensive schools employ these educators that offer specialized services in the areas of academic planning, social and emotional welfare, and career development. State Departments of Education set parameters for the certification of school counselors. In the State of Missouri these include completion of a master's degree-level program of study in student services from an approved college or university and passing a content assessment. Training for school counselor programs includes the following topics: human growth and development; social and cultural diversity; assessment; career development and planning; helping relationships; group work; professional relationship, identity, and well-being; legal and ethical standards; professional orientation; and counseling program development, implementation, evaluation, and enhancement (Missouri Department of Elementary and Secondary Education, n.d.).School counselors engage in direct services with students, such as individual advisement and counseling, as well as indirect services that support advocacy on behalf of students in various systems: classroom, building, district, and community. Many school counselors utilize the American School Counselor Association's (ASCA) National Model as the guide for the comprehensive and developmental program of counseling.

\section{ASCA National Model}

Consisting of four elements with four themes, the National Model provides a blueprint of how school counseling might operate in a comprehensive way that is also developmentally appropriate for students. The four elements are: Foundation, Management, Delivery, and Accountability. The four themes are: Leadership, Advocacy, 
Collaboration, and Systemic Change. Additional details about the model are discussed in the next chapter.

\section{Self-efficacy}

For this study, I borrow the definition of self-efficacy as seen in Bodenhorn and Skaggs (2005): “...defined as beliefs about one's own ability to successfully perform a given behavior..." (p.14). This definition is based on Bandura's (1986, 1993, 1995, 2001,2012 ) work on social cognitive theory. Self-efficacy, then, is the collection of thoughts and beliefs that inform a person's actions and choices. Literature regarding selfefficacy is included in the following chapter.

\section{Data Use}

For purposes of this study, the phrase data use combines concepts of program development as well as program evaluation. Standards from both ASCA and CACREP are clear that utilizing skills pertaining to data (i.e., collection, analysis, and description) are critical to the school counseling profession (ASCA, 2012; CACREP, 2016). This is echoed in literature regarding data use (Blacher, Murray-Ward, \& Uellendahl, 2005; Isaacs, 2003; Militello \& Janson, 2014; Poynton, 2009; Poynton \& Carey, 2006). These authors agree that the ongoing and deliberate collection of student data followed by the analysis of data leads to the ability to address issues of academic and opportunity gaps. The ultimate goal of data use is the transformation of student learning and achievement. For school counselors data use is specifically tied to needs assessment, program design and development, and evaluation of outcome data. Data use is, therefore, cyclical in nature as each evaluation begins the process of needs assessment to develop new interventions. Program development relies on the collection and analysis of student data 
(ASCA, 2012). The data is typically disaggregated and used to create universal interventions such as grade level curriculum and special events. This data also reveals any inconsistencies along student groups and may lead to new understandings about inequities for members of the student population. Data is often used with specific students and student groups to provide targeted interventions with a goal to close achievement and opportunity gaps.Program evaluation is defined by Dimmitt (2009) as the

purposeful and systematic collection and analysis of data or information used for the purpose of documenting the effectiveness, impact, and outcomes of programs, establishing accountability, and identifying areas needing change and improvement (p. 395)

Once a program is implemented by a school counselor, the outcome data is collected and analyzed to discover effectiveness of the intervention and, ultimately, of the school counselor.

\section{Accountability}

According to the Education Trust (2014), accountability is a process of regulation and performance within schools. The regulatory systems, created by stakeholders at the national, state, and local level, set goals for student performance that are meaningful, achievable, and rigorous. Information about these goals and student progress toward the goals are used to communicate with stakeholders and set up systems of intervention and support for students who do not meet the necessary achievement levels. The definition of accountability for this study follows this example. When discussing the process of accountability, I refer to guidelines set by state and national governmental bodies as well 
as local school districts and the subsequent reporting of student performance data for compliance and communication.

\section{Limitations}

Limitations to the present study are discussed in the third chapter. These include the selection of participants, social desirability of participants when completing the survey tool, and my own bias as a school counselor. Decisions made in the process of designing the study addressed these potential limitations.

\section{Summary}

A specialized educator, the school counselor is trained in the tenets of counseling psychology as well as educational theory. It is this training that provides the context for work with all stakeholders in the school and community. Within the umbrella of educational theory, the school counselor is also trained in the use of data to identify achievement and opportunity gaps present as well as the skills of consultation and collaboration necessary to lead teams of educators to develop interventions and evaluations to address these needs.

To adequately set the context of this study, the following chapters include a literature review as well a detailed description of the research design and method. The final two chapters focus on the findings and analysis of data and their meaning and significance. In the literature review I offer a history of school counseling and show how it mirrors the development of educational reform. The literature review chapter also includes information regarding self-efficacy and the work of Albert Bandura. In the third chapter information is included regarding the research design and methodology of 
this study. Information regarding the measurement tool as well as data collection processes and protocols are also included in this chapter. Chapter Four describes the data generated from the survey and flows into a discussion of meaning and significance in Chapter Five. 


\section{CHAPTER 2: LITERATURE REVIEW}

As education has evolved, so has the profession of school counseling. What started as a response to the Industrial Revolution and the desire to connect school children with vocational opportunities has morphed into a profession that, while still responding to the needs of the society and the edicts of the political system, offers schoolbased mental health, academic coaching, and career development (Gysbers, 2010; Herr, 2003; House \& Hayes, 2002; Paisley \& Borders, 1995). School counselors are specially trained members of a school community and their training focuses on collaboration, consultation, counseling, and leadership. Program components and themes found in the American School Counselor Association's (ASCA) National Model inform the practice of school counselors and counselor educators across the United States (ASCA, 2012; Cinotti, 2014; Herr, 2003; Paisley \& Borders, 1995). The four components of the National Model are: Foundation, Management, Delivery, and Accountability. The four themes are: Leadership, Advocacy, Collaboration, and Systemic Change. Together, these elements combine to create the lens used by school counselors to develop, implement, and evaluate comprehensive and developmental school counseling programs (ASCA, 2012). According to Dahir and Stone (2009) and Martin and House (2002), the combination of these elements directly links school counselors and their work to the promotion of student achievement and equity in access that, in turn, addresses achievement and opportunity gaps present in education today.

Current statistics regarding school-age children and their education and general welfare are too grim to be ignored. There are 73.6 million children aged $0-17$ in the United States (Federal Interagency Forum on Child and Family Statistics, 2016). Using 
data from the 2010 Census, researchers estimate the racial and ethnic diversity of this segment of the population will be the most diverse of the total population within a decade. Youth of color in that year will constitute the majority of the population and by 2060; Hispanic children are expected to be $34 \%$ of the total youth population (ACT for Youth, 2016). The needs of students and families is in a nearly constant state of change. Economically, nearly a quarter of families with children live at the poverty level, face issues with secure parental employment, and are classified by the USDA as "food insecure" (FIFCFS, 2016).

Additionally, mental health concerns, including, but not limited to, substance abuse and suicide rates, are troubling as indicated in the following studies. In 2010, a study found that $50 \%$ of youth in the United States report having mental health symptoms. The study looked at adolescents in the 13-18 age range. They reported anxiety disorders at $32 \%$, mood disorders at $14 \%$, and substance abuse disorders at $11 \%$ (ACT for Youth, 2016). In 2015, almost 10\% of students reported attempting suicide with the rate for students who are lesbian, gay, queer, and questioning even higher at $29 \%$ (ACT for Youth, 2016). The Centers for Disease Control and Prevention (CDC) in 2013 summarized information from ongoing mental health surveillance systems between 2005 and 2011. In the CDC report, childhood mental illness was found to be on the rise. One study, within this meta-analysis, indicated that the increase for inpatient treatment was $24 \%$ between 2007 and 2010. The summary continues that even when hospitalization is not part of the equation, mental illness in children and adolescents accounts for serious difficulties at home, school, and in the larger community (CDC, 2013). According to the CDC (2013), drug and alcohol abuse as well as criminal acts and other high-risk 
behaviors are comorbid with mental illness. Incidents of substance abuse increase nearly $10 \%$ from 10th grade to 12th grade for both alcohol and illicit drugs (FIFCFS, 2016). Nearly 3.8 million adolescents have a substance abuse disorder which is often comorbid with a major depressive episode (ACT for Youth, 2016).

Educational attainment is also a statistic that points to the health of young people in the United States. In 2014, the dropout rate for youth ages 16-24 was 7-8\% (ACT for Youth, 2016; FIFCFS, 2016). Hispanic youth were most likely to dropout at $11 \%$ and males are $55 \%$ of the total dropout populations (ACT for Youth, 2016). Students not enrolled in school and not working, leading to a further disengagement and disenfranchisement, are $9 \%$ of the youth population (FIFCFS, 2016).

Erford, House, and Martin (2003) point out that as often happens when societal ills become quite grim, governments and citizens turn to educational communities for the solutions. As a result, they contend, there is a call for urgency within the school counseling field. As the needs of society change and more is expected of recent graduates, Erford, House, and Martin maintain that not adjusting to meet these needs is tantamount to "benign neglect" (p. 11). School counselors have a role that allows them to be at the center of school reform that addresses the emotional, social, and academic concerns of students while acknowledging cultural differences (Erford, House, \& Martin, 2003; Paisley, 2001).

School counselors, therefore, rely upon the National Model (ASCA, 2012) to specifically develop, maintain, and evaluate programs that address these identified needs. The present study focused on the evaluation piece of this equation and sought to discover what, if any, relationships exist between school counselor self-efficacy and the utilization 
of data for program evaluation around the concept of efficacy. This literature review provides a base of knowledge along several strands. First, the history of school counseling is addressed. Intertwined in this review of history is literature featuring the history of school reform efforts. School reform, I contend, informs the rationale for program evaluation and the use of data on the part of school counselors. Next, the literature connected with the use of data within a comprehensive school counseling program is reviewed. Following this, I include a brief section that provides context for how the use of data is critical to the continued success of the profession. I conclude with articles and studies inspired by Bandura's (1986) work on Social Cognitive Theory and connected to the self-efficacy of school counselors (Bodenhorn \& Skaggs, 2005; Bodenhorn, Wolfe \& Airen, 2010).

\section{School Counseling}

The role of school counselor has expanded since the first introduction in the 1900s (Herr, 2003; Paisley \& Borders, 1995) and is concomitant with educational reform (Gysbers, 2010). The history is a tale of calls for reform from society and response to these calls within a student services model. As the country issued reforms for education, one of the major responses in public education included the expansion of school counseling as a profession. In this section, the history of school counselors and their roles is discussed. Topics include the beginning of vocational guidance, school reform efforts and federal legislation that shaped school counseling, and the current conceptualization of the school counselor. 


\section{A Century of School Counseling}

When first introduced, the role of school counselor was given to teacher-leaders who offered vocational assistance as an add-on to their classroom duties (Cinotti, 2014; Gysbers, 2010; Herr, 2003; Lambie \& Williamson, 2004). This was a response to the factory model of education that was prevalent in schools in the United States beginning in the Industrial Revolution and continuing into the 1980s (National Commission on Excellence in Education, 1983). In the formative era of school counseling, working with students was limited to identifying the vocational needs of students. Herr (2003) indicates the main focus of the teacher-leaders was on nonacademic services such as admission, orientation, financial aid, and placement. Cinotti (2014) expands this picture to say that these services were in addition to classroom roles and responsibilities. These teacher-leaders had little additional training. This model quickly became insufficient to meet the needs of all students. Concerns about the need for specialized training and supervision were raised in 1924 (Cinotti, 2014). In the 1930s, the profession incorporated student assessment, centralized leadership of a program, and the application of scientific techniques. By necessity, teacher-leaders received training in assessment and clinical services (Herr, 2003; Lambie \& Williamson, 2004; Sink, 2005).

As the country moved out of the mindset of World War II, counselors became even more specialized within the educational arena and added the role of community liaison (Herr, 2003). The 1950s saw a shift in professional roles from vocational interests to pupil services. School counselors focused on clinical skills and moved counseling to the forefront of the profession which allowed for a personalization of education (Herr, 2003; Sink, 2005). It was at this time that "guidance" counselors coordinated student 
planning for courses, assisted with academic development, discovered student aptitudes, and facilitated all of the services that connected with the student (Herr, 2003; Lambie \& Williamson, 2004). These new responsibilities were linked to the National Defense Education Act of 1958.

In the second half of the 20th century, pupil services encompassed more than school counselors. School psychologists, social workers, administration, and nursing professionals all fell under the umbrella of student services (Gysbers, 2010; Sink, 2005). This updated the conceptualization of the school counselor to include a focus on the developmental needs of students. Theory and practice in the counseling field, specifically Carl Roger's person-centered theories, were translated for use in the school setting (Gysbers, 2010). This was accomplished through the creation of comprehensive programs that were developmental in nature and included both direct and indirect services to students. Direct services include those tasks associated with the counselor's work with students such as individual planning for college and career options, small group counseling sessions promoting self-adjustment and/or improvement, and implementation of curriculum provided either by the school counselor or another educator in the building (ASCA, 2012; Gysbers \& Henderson, 2005; Sink, 2005). Indirect services, on the other hand, were tasks associated with the nuts and bolts of programmatic support such as designing the curriculum and interventions as well as establishing collaborative relationships with community organizations and professionals to provide extended support for students and families (ASCA, 2012; Gysbers \& Henderson, 2005; Sink, 2005). 
In the 1970s, according to Lambie and Williamson (2004), financial support from local and state funding sources dwindled as the ability to show effectiveness in school counseling was difficult. The authors indicate this led to the addition of non-guidance jobs to the portfolios of school counselors. The majority of these duties were administrative in nature. From the 1970s through 1990s, school counseling became issue driven. It was not uncommon for counselors to spend time with students on topics and issues such as decision-making strategies, career education, drug abuse prevention, selfdevelopment, child abuse prevention, and drop-out rates (Herr, 2003).

Full implementation of comprehensive and developmental school counseling programs is a work in progress. In the 1980s, under the pall of A Nation at Risk (The National Commission on Excellence in Education, 1983), school counseling literature begins to focus on standards for the profession. Cinotti (2014) marks this as the beginning of the culture of assessment in public education. It was also in the early 1980s when developmentally appropriate programs that were comprehensive of academic, vocational, and social/emotional needs were piloted. These three-pronged models as well as a re-visioning of school counseling by The Education Trust (2007) provide the foundation for today's National Model from the American School Counselor Association (ASCA, 2012). The model's purpose is to support school counselors to design, coordinate, implement, manage, and evaluate programs to lead to greater student success (Sink, 2005). The four components of the ASCA (2012) model are: Foundation, Management, Delivery, and Accountability. The four themes are: Leadership, Advocacy, Collaboration, and Systemic Change. The components and themes are discussed in greater depth in subsequent sections of this chapter. 


\section{Influence of Federal School Reform Legislation}

As the decades changed, so did the role of the counselor within the school. Many of these changes are directly linked to legislation that sparked educational reform in the United States (Gysbers, 2010). With the understanding that an educated populace is a foundation of a democratic society, the policy and law makers of the United States often place education reform on the policy agenda. In the course of history of educational reforms there are several places where federal funds have been allocated to reach the aims of the particular legislation. The influence of federal reform is salient in this study because many of the initiatives, design of programs, and accountability measures found in education generally, and school counseling specifically, are directly linked to reform.

Erford, House, and Martin (2003) as well as Young and Kaffenberger (2015) suggest that school counselors have a solid position within educational reform. It is their opinion that accountability is the responsibility of everyone within the system of education and that school counselors should become proactive leaders and advocates. Ideally, they contend, school counselors are positioned in schools to serve as disseminators of information to promote school wide success for all students. That is, in using data, school counselors are able to articulate the equity, opportunity, and achievement gaps while simultaneously mobilizing supports within and outside of the school building to address these concerns. This opinion is also advanced by House and Hayes (2002), who posit that school counselors, as a critical link between student dreams and realized success, must be proactive in their leadership within accountability measures. Thus, the school counselor must be able to advocate for students and their professional role simultaneously. 
Conceptualizations of school counseling in the past show a dynamic history. In the relatively short story that is modern day counseling, the profession moved from an add-on duty for a teacher-leader into a specialized discipline providing a unique set of skills to school-aged children in the United States (Lambie \& Williamson, 2004). This section expands on the purpose of some of the educational reforms in the United States the resulting changes in the profession of school counseling.

National Defense Education Act ([NDEA], 1958). In the time after the Soviet Union launched the Sputnik satellite, the United States looked for a way to enhance the identification and training of scientists and mathematicians and raise the general education of the populace. Leadership in Congress passed a bill, The National Defense Education Act of 1958, to provide financial support to create a system of early identification of talented young people as a response to the perceived threat from the Soviet Union as well as a concern in the gap of knowledge and interest in science, math, and technology on the part of students in the United States (NDEA, 1965; U.S. Senate, n.d.). Title $\mathrm{V}$ of this Act was a major stimulus in the guidance profession because it allocated funds for states to hire and train counselors who could help with the identification of young talent. The legislation allocated $\$ 88$ million over 4 years for this purpose. It required states to match funds, so the final amount was in excess of $\$ 130$ million for just Title $\mathrm{V}$ of the Act (NDEA, 1958). At its end, guidance counselors were strongly entrenched in high schools across the country (Herr, 2003; Paisley \& Borders, 1995). This allowed for the continuance of the profession in areas of the country that previously did not employ school counselors. As described previously, the 1950s and 1960s conceptualization of school counseling included a focus on individual student 
abilities and interests. This was facilitated through federally mandated aptitude testing and more individualized advising of course selections and met the provisions of Title $\mathrm{V}$ of the NDEA.

Elementary and Secondary Education Act ([ESEA], 1965). As part of what was known as "Great Society" legislation, the Elementary and Secondary Education Act (ESEA) was proposed by President Lyndon Johnson. Education was seen as a way to fix societal ills and in so doing the ESEA advocated for vocational support for disadvantaged groups (Herr, 2003; Lambie \& Williamson, 2004; Paisley \& Borders, 1995). ESEA also serves as the foundation of most educational reform in the subsequent years as the language in the legislation requires a reauthorization to occur periodically. In the history of the legislation there have been seven reauthorizations. Two of the more notable are the No Child Left Behind Act (NCLB, 2001) and most recently, the Every Student Succeeds Act (ESSA, 2015) (U.S. Department of Education, 2016).

When originally passed, the ESEA was a change in previous federal operations regarding federal funding for public education. ESEA created a funding stream from the federal government to state and local educational authorities. Previously, under NDEA, the only federal funding was specifically for prescribed content areas (e.g., science, math, and world languages along with counseling) (1958). With ESEA, the funds focused on specific students and their success. It is interesting to note that Title VI of ESEA specifically states that the legislation does not and will not result in federal oversight of local school systems and institutions (ESEA, 1965).

States and local schools opting to participate in these funds directed efforts to support students in poverty (ESEA, 1965). After receiving funds, schools and states were 
to report achievement of the targeted student population annually. Under ESEA schools were integrated, funds were available for the neediest children, and education gained a solid foothold in the public agenda.

No Child Left Behind (NCLB, 2001). In the early part of the 21 st century, under President George W. Bush, legislators passed a reauthorization of the ESEA, called No Child Left Behind (NCLB, 2001). The purpose statement of the Act read: "To close the achievement gap with accountability, flexibility, and choice, so that no child is left behind" (NCLB, 2001). According to Section I of the Fiscal Year 2009 Budget Summary of the U. S. Department of Education, NCLB was “... based on a simple premise and a big idea" (U.S. Department of Education, 2008). The summary expanded this notion to explain that NCLB designed a path to show return on federal financial investment in public education through accountability measures while contending that all children can learn and be proficient in reading and math by 2014 (Kim \& Sunderman, 2005; Smith, 2005; U.S. Department of Education, 2008, 2012). The initial investment in NCLB was $\$ 17.4$ billion and by fiscal year 2008 had increased to $\$ 24.4$ billion, an estimated $8.9 \%$ of total funds spent on public education in the United States (Smith, 2005; U.S. Department of Education, 2008).

NCLB sought to hold school districts accountable for the improvement of the academic achievement of disadvantaged students, qualification of teachers, content standards, and safe and drug-free schools. Specifically, NCLB made federal funding contingent on states demonstrating the achievement of students. Of particular focus was the achievement of particular sub-groups of students: income disadvantaged, limited English proficient learners, minorities, and students with disabilities. Standards of 
achievement for all students were defined along three markers: Advanced, Proficient, and Basic (NCLB, 2001; Smith, 2005). Once defined, the states had to develop assessments that all students took to measure the school and district performance in closing the achievement gaps present in the identified sub-groups. In the initial version of the Act, NCLB set the deadline of 2014 for all students to reach proficient levels in reading and math. Schools were also measured on Annual Yearly Progress (AYP) and lack of progress on this measure resulted in sanctions from state and local educational authorities (Education Week, 2011; Kim \& Sunderman, 2005; Linn, 2003; Smith, 2005). AYP was determined through student performance on state-developed assessments that resulted in the categorization of students along the advanced, proficient, and basic delineations (Kim \& Sunderman, 2005; Smith, 2005).

Dahir and Stone (2009) framed NCLB as a call to every member of the educational community to be accountable for the work accomplished for students in public education. Within this regimented culture of accountability, the professional organization for school counselors, American School Counselor Association (ASCA) proposed a national template for the implementation of school counseling programs. NCLB was a catalyst for this development. That is, school counselors, as with every educational professional in public schools, needed to advocate for, and show, student development as a function of their work.

Every Student Succeeds Act ([ESSA], 2015). Just shy of the 50th anniversary of ESEA, President Barack Obama signed a rewrite of the law called the Every Student Succeeds Act (ESSA). This reauthorization of the ESEA revised portions of NCLB and is the current understanding of public education accountability in the United States 
(Education Trust, 2016a, 2016b; Klein, 2015). The budget allocations for Title I of ESSA is just over $\$ 60$ billion over 4 years (ESSA, 2015).

As with the original law, ESEA, this reauthorization continues the vision of serving disadvantaged students while keeping some components found in NCLB. For example, states are still required to meet goals and set content standards that are measured through state-wide assessments as set by NCLB. The difference in ESSA is in the mechanics of how these goals are developed and the addition of other measures to assess if progress is made. To further explain, ESSA keeps the NCLB requirement for states to meet achievement goals for students. These goals, however, are no longer selected from a list of mandated federal goals. Rather, states have the responsibility and autonomy to set goals on their own (Education Trust, 2016b; Klein, 2015).

ESSA goals must address three main elements: proficiency on the annual assessments, English-language proficiency, and graduation rates. The goals have two timeframes: long term large goals and shorter-term, interim targets (Education Trust, 2016b; Klein, 2015). At the heart of the goal must be an acknowledgment that those student groups furthest behind make gains and close the gaps in both achievement and graduation (Education Trust, 2016b; Klein, 2015).

Additionally, under ESSA, the state's content standards must align with admission requirements for the public higher education systems within the state (Education Trust, 2016a, 2016b, 2016c). As with NCLB, content and performance standards must be applied to all students and be at high levels of rigor (Education Trust, 2016b, 2016c). 
Accountability continues to be a theme of the legislation and the ESSA reauthorization adds a fourth indicator of progress. Assessments remain annual requirements that are aligned with state content standards. Likewise, the states must still report on English-language proficiency and choose one other academic indicator (Education Trust, 2016b, 2016d; Klein, 2015). ESSA adds the requirement of an additional indicator of the state's choosing. This fourth indicator may be: (1) data on teacher or student engagement, (2) opportunity to participate in and completion of advanced courses, (3) school climate, or (4) other data points that contribute to student success and/or school quality (Education Trust, 2016b, 2016e; Klein, 2015). These indicators are the same for elementary and middle schools. High schools must also report on graduation rates in place of the second academic indicator (Klein, 2015). Each indicator must be reported for identified groups; states and districts can no longer rely on statistical groupings termed super subgroups (Education Trust, 2016e; Klein, 2015). Finally, interventions for underperforming schools under ESSA are tailored by the states rather than specific action plans as NCLB required (Klein, 2015).

The flexibility that is introduced in ESSA in terms of accountability indicators provides another entry point for school counselors to support school-, district-, and statewide efforts to improve student outcomes. As ESSA becomes fully implemented the conceptualization of school counselors and their role will likely see revisions if the past experiences hold true.

\section{Current Conceptualization of School Counseling.}

With over a century of change and development as a response to changing mindsets and reforms in the United States, school counseling morphed and changed from 
a teacher-leader to a specialized position within the school culture. With the second authorization of NCLB and our most current understanding of federal public education law, it is important to ask specific questions which allow for a modern conceptualization of school counseling. Those questions, according to Herr (2003) are: (1) what do school counselors do best?, (2) for what should they be accountable?, (3) which duties should be eliminated?, (4) which duties should be emphasized?, and (5) how can responsibilities be made explicit and achievable? These questions, and their accompanying answers, can happen at building, district, and national levels. The answers will define how the next generation of school children will interact with their education (Herr, 2003).

In addition to Herr's (2003) questions, Shillingford and Lambie (2010) also encourage school counselors to advocate for their program within the school by making direct connections to the mission and vision of the school and district in the design, implementation, and evaluation of the counseling program. Additionally, they call for school counselors to nurture collaborative relationships and coalitions that will aide in the advocacy of the counseling program. It is through data use and program evaluation, according to Lapan, Gysbers, and Sun (1997), that the continued health and relevance of school counseling is realized. Erford, House, and Martin (2003) share this view and challenge counselors to use leadership, advocacy, and collaboration as the main tools to support educational reform within their schools. The result of these efforts, then, supports the fulfilment of Herr's (2003) challenge for school counseling to be relevant, broad-based, and effective.

The questions posed by Herr (2003), Shillingford and Lambie (2010), and others are answered through the ASCA National Model (2012). This template of best practices 
designed by the national organization for school counselors provides a structure and defines the role of school counselors. Through this model, according to Cinotti (2014), school counselors are positioned to answer questions about their role in schools as well as provide evidence to address questions of their effectiveness.

Components of the National Model. With the 2012 revision of the ASCA National Model (Appendix A), there are four basic elements of the framework:

Foundation. At the macro level, school counselors work to design, implement, manage, and evaluate a comprehensive counseling and guidance program that is developmental in nature. According to ASCA (2012), the Foundation element describes the "what" of a school counseling program. This coordination is a complex task that requires many resources including time and leadership. It is at this level that school counselors can mobilize others to be involved in the implementation of the guidance and counseling program. Crosswalking, the practice of teaming with other educators in the building to co-facilitate learning objectives, with other content areas allows for the program to reach all students within the school. It is within this coordination that the school counselor provides data, interpretation, and perspective to the wider school community. The school counselor, then, can design and facilitate school reform that leads to greater accountability (Sink, 2005).

Erford, House, and Martin (2003) discuss the elements of a comprehensive school counseling program within the culture of educational reform. They outline that for a program to be considered well-defined, it must be equitable, accessible, and supportive of all students. The school counselor at the helm of this program must, they continue, use data to analyze and continually improve the program. The authors speak of progress 
monitoring that facilitates proactive interventions and assists in the targeting of the students most disadvantaged in opportunity and achievement. Systems of support can then be developed through coordination of the school counselor. When school counselors take this role within a school they have membership in leadership teams and directly feed all activities into the mission and vision of the school (Erford, House, \& Martin, 2003).

Management. The current understanding of the school counselor role is complex and requires individuals who hold many levels of knowledge and abilities to address the needs of the evolving student population (Lambie \& Williamson, 2004). The Management component of the National Model consists of a plan to use assessments and other tools to organize, develop, implement, and evaluate the school counseling program. Examples of these assessments and tools are: program assessment, use-of-time assessment, an advisory council, use of data, and action/lesson plans.

It is the use of data that is of particular salience to the present study. Use of data, as defined by the ASCA National Model, is measuring results of a program while also promoting change within a school system and preparing students to be college- and career-ready. The data that is used falls into several categories: academic achievement, attendance, behavior incidents, and demographic points. Data is measured along shortand long- term timelines. Program results data is also critical and falls into process, perception, and outcome data sets. Process data answers the "what" and "for whom" of the counseling program. Perceptual data is collected through pre- and post-tests as well as surveys of stakeholders. This data answers questions about beliefs and knowledge held by respondents. Finally, outcome data answers the question "so what?" The data 
provided by this data set informs school counselors on the impact of the comprehensive program. This data allows the school counselor to return to original data sets and compare and contrast how the student and school data changed as a result or in connection with the elements of the comprehensive school counseling program (ASCA, 2012).

Erford, House, and Martin (2003) advocate for a broadening of the roles to include evaluation and the use of data as well as leadership and collaboration. It is their contention that this data-driven advocacy will support success in the three domains school counselors focus their attention: academic, career, and personal development. Militello and Janson (2014) agree, pinpointing the use of data as a key element in supporting the work of modern school counselors. Data facilitates the intentional work of counselors as they work to find and eradicate gaps in achievement and opportunity for students. School counselors are engaged in data use with little frequency and that examples of using data are often shallow in that they are intended for a very limited audience and have only surface level interpretations (Militello \& Janson, 2014). Dimmitt (2009) agrees and sees evaluation and the use of data as the way to determine what works and with whom. Dahir and Stone (2009) as well as these other authors promote the tools of data use and program evaluation as the way for school counselors to meet the ethical obligations to close the gaps and barriers for students.

Delivery. This component of the National Model varies depending upon the level (e.g., elementary, middle, secondary) of the students. Delivery comprises $80 \%$ of the recommended use of time for all school counselors. Within delivery are both direct and indirect services. Direct services are those tasks that are in-person interactions between 
counselor and student. Curriculum, individual planning, and responsive services are the bulk of the work. It is through counseling curricula that many of the universal goals of a comprehensive and developmental counseling program are met (Gysbers \& Henderson, 2005). Individual planning is accomplished through conversations around individual goals for students in the domains of academic, career, and personal/social growth. Under the umbrella of responsive services, school counselors provide first level mental health support as well as small-group and individual counseling that is brief in nature and focused on behavior change (ASCA, 2012).

As students present more complex concerns that are not able to be addressed within the confines of the school day, school counselors become a resource for available resources in the community (Sink, 2005). This is an example of indirect services. These services are those activities that are completed on behalf of students. This includes the referral example as well as collaboration and consultation conducted through the school and externally in the community (ASCA, 2012).

Accountability. Much of the final component of the National Model mirrors the description of Management. The key difference is that under the Accountability portion of the model is where the analysis of the management data, as well as the broadcast and advocacy of results, occurs. The process of accountability is reiterative. The nature of public education is such that school counselors review data points to answer current needs and set future goals (ASCA, 2012). Dahir and Stone (2003) further the understanding by describing accountability as the systematic collection and analysis of data to develop strategies and measurements to impact student achievement. Accountability is the process of intentional and proactive efforts to remove gaps in 
achievement and opportunity. It is within this component of the National Model, where school counselor roles and the reporting of student data to state and federal agencies collide. Dahir and Stone further explain when school counselors understand the role of accountability within a systemic context they are viewed as integral to the overall picture of student success (Dahir \& Stone, 2003).

Data answering process, perceptual and outcome questions provide school counselors with information to present to all stakeholders. Results from the analysis of these data are available through web sites, handouts, presentations, and state reports (ASCA, 2012). Therefore, with the analysis of program data, the school counselor can contribute to school and district measures of student achievement and progress measured by state reports and submitted for review under ESSA.

Themes that govern the National Model. In addition to the framework, there are four themes that occur throughout the model (Appendix A). The following section explains the themes with greater depth.

Leadership. Within the school context counselors hold a unique position (Adelman \& Taylor, 2002; ASCA, 2012). This perspective allows for a "balcony" view of many concerns within the school. Under the theme of leadership, this perspective contributes to individual work for the school counselor as well as the facilitation of work within smaller teacher groups where a holistic perspective is needed. School counselors, according to ASCA (2012), must have the ability to operate through a variety of leadership lenses as identified in Bolman and Deal (2008). Those are: structural, human resource, political, and symbolic. 
Advocacy. School counselors operating under the comprehensive nature of the National Model hold the belief that all students can achieve at high levels. Advocacy, then, is a natural offshoot of this understanding in that counselors promote every student's opportunity to demonstrate success and college- and career-readiness. It is within the advocacy theme that school counselors are placed at the forefront of school reform measures (ASCA, 2012). Advocacy occurs at the student level with the school as well as at the micro- and macro- level on behalf of students. The micro-level includes internal advocacy efforts within a school or district. Macro-level advocacy includes public avenues of social and/or political advocacy (ASCA, 2012).

Collaboration. When a school counselor views their role as a consultant, it can lead to partnerships with people in the school with the greatest contact with students. Inherent in the role of consultation is the skill of collaboration (Keys, Green, Lockhart, \& Luongo, 2003). There are several models that can be employed by the school counselor. In a dependent model, the consultant is viewed as an expert; this is an indirect method where teachers and parents are the consultee who then implement the suggestions offered by the expert. A second model, collaborative, the counselor is one of many experts. The knowledge of each member of the interaction is acknowledged as important to finding a solution. As with the first model, the consultee rather than the counselor implements the plan. Within collaborative models the problem can be at the individual and/or the systemic levels. The final model is also collaborative but is understood as interdependent. All members of the team are involved in every step of the process: (1) identification of problem, (2) development of a plan, (3) implementation of a plan, and (4) evaluation of the plan (Keys et al., 2003). 
Understanding the process of collaboration is key to the process of addressing the achievement gap and the response to educational reform (Adelman \& Taylor, 2002). It necessitates a flexible mindset, a commitment to collaboration, parity within the group, and shared accountability (Keys et al., 2003). School counselors receive training that is connected to the goals of consultation and collaboration. Within this process of problemsolving and change initiation, the school counselor can exhibit leadership in data collection and interpretation as well as in the ability to think systemically. Counselors often have the access to data that can help with problem and need identification as well as the tools to help interpret those data in a way that can help frame an action plan (Keys et al., 2003). Finally, school counselors, as the connection to larger society, can lead collaborations with the broader community through core social institutions such as Division of Family Services, Juvenile Justice Officers, and mental health providers. The engagement of these groups allows for an integrative and community-based approach with shared responsibility.

Systemic change. The accountability movement in public education that started in the 1980s (Cinotti, 2014) evolved and strengthened to the current climate where a greater awareness of opportunity and achievement gaps in education in the United States propels much of the work in schools (Carey \& Dimmitt, 2006; Dimmitt \& Carey, 2007). Systemic change is necessary to address these gaps. Adelman and Taylor (2002) as well as House and Hayes (2002) report that school counselors, often the "eyes and ears" of a school, are best positioned to identify gaps and barriers for students. According to House and Hayes, "An effective school counselor hears more, knows more, and understands more about teachers, parents, students, and the community than anyone in the school" (p. 
252). This knowledge is why the ASCA Model includes systemic change as a theme to guide the work of school counselors. Yet the literature around school reform often neglects to address the role of school counselors which, in turn, leaves these professionals a step removed from critical conversations (Carey \& Dimmitt, 2006; Dimmitt \& Carey, 2007). Counselors utilize data, through program and school evaluation, to address inequities and barriers within the dual systems of school and community with the goal of promoting success for all students (Carey \& Dimmitt, 2006; Dimmitt \& Carey, 2007; Lapan, 2005).

As school counselors and the understanding of their role broadens, so, too, does the need to communicate professional needs, efficiency, and efficacy. Efficacy is of particular importance because it relates to not only program efficacy - the ways the school counseling program changes students - but also the self-efficacy of the school counselor. The former, according to Bodenhorn, Wolfe, and Airen (2010), depends upon the levels of the latter. The authors highlight the use of data, levels of self-efficacy in school counselors, and having a clear programmatic approach as indicators for strength of school counseling to address the achievement and equity gaps in schools. Several studies (Astramovich \& Coker, 2007; Dahir \& Stone, 2009; Dimmitt, 2009; Mitiello \& Janson, 2014) suggest that use of data within a school counseling program is not prevalent in the current practice of some school counselors. The studies offer some possible explanations. Self-efficacy, as described by Bandura (1986, 1993, 1995, 2000, 2001, 2012) and other authors highlighted in the following section, may be a factor. For example, Bodenhorn, Wolfe, and Airen (2010) as well as Bodenhorn and Skaggs (2005) 
use Bandura's work with Social Cognitive Theory, specifically the concept of selfefficacy, as a foundation for their subsequent work in school counseling.

The next section of the literature review fully describes these aspects of Social Cognitive Theory and the application used in school counseling work. These topics are included to support the understanding of the present study.

\section{Social Cognitive Theory, Self-Efficacy, and the School Counselor}

To maintain relevance - and funding - in the school system, school counselors must measure efficacy within their program and profession and communicate these outcomes with stakeholders (Erford, House \& Martin, 2003; Herr, 2003; Lapan, Gysvers \& Sun, 1997). For purposes of this study it is helpful to conceptualize this through the lens of self-efficacy and social cognitive theory. This section provides information about Bandura's $(1986,1995)$ Social Cognitive Theory with the tenets of self-efficacy and human agency as well as how these concepts connect to counselor roles in general and within schools specifically.

\section{Social Cognitive Theory}

Described by Albert Bandura (1986) as a foundation for thought and action, social cognitive theory explains a model of human nature where the environment, personal factors, and behaviors interact and determine each other. The theory is further based on the perspective that people are agents of their own life and functioning (Bandura, 2012). "The human mind is generative, creative, proactive, and reflective, not just reactive" (Bandura, 2001, p. 4). This means that people play a part in their creation of self, adaptation to new stimuli, and self-development as times change (Bandura, 2001). This 
model is more specifically called triadic reciprocality (Bandura, 1977, 1989, 1995, 1997; Larson, 1998; Larson \& Daniels, 1998).

There are six constructs found within Social Cognitive Theory that help to explain the regulation of behavior of people through control and reinforcement. Those constructs are: (1) reciprocal determinism, (2) behavioral capability, (3) observational learning, (4) reinforcements, (5) expectations, and (6) self-efficacy. These basic constructs describe an understanding of human behavior that allows for the interplay of person, environment, and behavior. It is influenced by a person's actual ability within a certain action, the opportunities for observing others engaging in the preferred behavior, as well as the resulting reinforcements and expectations. Reinforcements are those things that happeninternally and externally - to a person that affect the likelihood of a behavior continuing or discontinuing. Expectations, then, are held by the person and are based upon past experiences - including those gained through observation - about likely consequences of a person's behavior. Reinforcements and expectations play a particularly important role in the setting and attaining of goals. The final construct identified in Social Cognitive Theory is self-efficacy, a focus of the present study.

Self-Efficacy. According to Bandura (1986, 1993, 1995, 1997, 2001, 2012), the central mechanism of human agency is the individual's belief about their capacity to exercise control over situations. This phenomenon is known as efficacy beliefs, or selfefficacy. These beliefs influence all aspects of life: feelings, thoughts, and motivations. Self-efficacy can be defined more succinctly as the collection of beliefs one holds regarding one's abilities and personal capacity to exert influence on situations. Several 
authors agree with this basic definition (Bodenhorn, Wolfe, \& Airen, 2010; Gibson \& Dembo 1984; Larson, 1998; Larson \& Daniels, 1998).

As the central mechanism of human agency, these beliefs inform every action and performance. Therefore, good and poor outcomes lie not only in the individual's abilities or familiarity with the action, but also with the held beliefs in their self-efficacy (Bandura, 1993, 1995, 1997). As people experience new situations determinations are made through the influence of self-efficacy. People select environments and opportunities based on how well they believe they can be successful (Bandura, 1993). Sutton and Fall (1995) further this understanding of Bandura's two types of expectancies: efficacy and outcome. These concepts have an interplay that allows individuals to assess one's own ability to execute a task as well as the likelihood that a desired outcome will be achieved. This concept is also noted in Gibson and Dembo (1984) under the term "two-factor theoretical model."

Bandura $(1997,2009,2012)$ indicated four ways to develop capabilities that support the growth of self-efficacy. First, allowing for mastery experiences with early success. These experiences should increase in difficulty to develop a concomitant quality of resilience. Second, creating efficacy beliefs through social modeling, or observational learning. Social persuasion is the third way to develop self-efficacy capabilities. This is where trusted or valued mentors or peers persuade individuals to increase beliefs of self. Finally, the process of choice builds self-efficacy. This is the ability people have to create environments and choice in their actions.

School counselor's self-efficacy. Self-efficacy, as a major construct of social cognitive theory, informs how and why people select careers, connect with one another, 
and complete tasks (Bandura, 1993, 2009). Within counseling psychology, self-efficacy is critical to the interactions between counselor and client. Research indicates that levels of self-efficacy of the adults within a school sets the tone for the building culture and the academic gains of the students (Bandura, 1993; 1995; Gibson \& Dembo, 1984). Teachers with higher levels of instructional self-efficacy, the authors suggest, increase the academic gains of students. Conversely, when teacher efficacy is low, academic gains do not exist regardless of the students' starting point (Bandura, 1995). Gibson and Dembo (1984) went a step further and measured teacher personal efficacy. They hypothesize that as teachers believed in their ability to control the learning environment through effective teaching while holding a strong belief in personal skills the persistence and outcomes of the teaching would be greater. The converse would also be true. The study found the hypothesis to be accurate. School counselors, as a specialized role within the school environment, can feasibly be included in their conclusions.

For counselors then, it stands to reason that professional duties are perceived as easier or harder based on the individual's self-efficacy beliefs. Continuing and expanding upon the work of Gibson and Dembo's (1984) teacher efficacy scale, Sutton and Fall (1995) sought to create a self-efficacy scale for school counselors. The Counselor Self-Efficacy Scale (CSS) has 33 items. The authors performed a factor analysis and identified three factors that help define self-efficacy within the role of school counselor: (1) efficacy expectancy for being a school counselor, (2) efficacy expectancy for the role of counseling in school, and (3) outcome expectancy.

In 2010, Bodenhorn, Wolf, and Airen furthered research in this area. The study found that school counselors with higher self-efficacy also reported higher levels of 
awareness in areas of achievement gaps. Additionally, the study found that school counselors with higher levels of self-efficacy seem to have a different - a deeper impact on the students they serve. This study also provides a connection to the importance of data awareness and use in the professional work of school counselors.

Even with studies such as this, school counselors, according to Astramovich and Coker (2007) as well as Holcomb-McCoy, Gonzalez, and Johnston (2009), do not consistently engage in the use of data to inform practice. The authors give several examples of why school counselors may not engage in using data for evaluation and accountability. These include: lack of training, lack of confidence, concern that results will not be favorable, cultural resistance, time constraints, and fear of reprisal. People, according to Social Cognitive Theory, fashion an environment that plays to their strengths and allows for higher levels of personal control (Bandura, 2012). The agentic nature of Bandura's theory (2001) indicates that self-efficacy beliefs are determinants in goal setting, expectations, commitment, effort, perseverance, and accomplishments.

In their 2016 study, Mullen and Lambie examined the frequency of program delivery for school counselors in relation to self-efficacy. The authors utilized the School Counselor Self-Efficacy Scale developed by Bodenhorn and Skaggs (2005). They found that school counselors with higher levels of self-efficacy had higher rates of program delivery geared toward students' personal, social, academic, and career development.

As indicated in the section on the National Model (ASCA, 2012), school counselors must engage in the evaluation of program which ties to the theme of advocacy. This process is seen as vital to the continued progression of the school counseling profession for it is through evaluation that counselors can communicate with 
stakeholders (e.g., administrators, parents, boards of education) about the benefits of a fully funded and fully implemented comprehensive school counseling program (Erford, House, \& Martin, 2003; Gysbers \& Henderson, 2005; Lapan, 2005; Lapan, Gysbers, \& Sun, 1997; Maras, Coleman, Gysbers, Herman, \& Stanley, 2013). To be fully effective in this part of professional duties, the school counselor utilizes four processes: (1) planning, (2) designing, (3) implementing, and (4) evaluating. According to Lapan (2005),

[r]esults-based systems challenge counselors not to lapse into outdated, rigid, and marginally effective work roles. Instead, attainment of outcomes is consistently evaluated, and on the basis of this information counselor roles and work tasks are adapted to better help students. (p. 261)

It is important to highlight the reiterative nature of this process. By continually assessing needs, designing and/or selecting interventions, and monitoring the progress toward goals, a school counselor utilizing program evaluation is consistently able to show the value of the program (Erford, House, \& Martin, 2003; Lapan, 2005). When school counselors regularly engage in this process, according to Gysbers and Henderson (2005), they are also able to provide outcome information at three points in time. Program evaluation can operate at the immediate, intermediate, and long-range time frames. This allows school counselors to participate in efforts to address mandates connected with educational reform (Astramovich \& Coker, 2007; Lapan, Gysbers, \& Sun, 1997). Having outcome data with this level of depth is helpful to promote and advocate for school counseling programs. Erford, House, and Martin (2003) indicate school counselors' ability to examine data that communicates what is happening in the school, assists in the 
explanation to stakeholders, and can facilitate change within the system. "Professional school counselors will be valued when they demonstrate effectiveness in making systemic changes that allow all students access to rigorous programs and equity in academic success" (p. 11). The use of data is critical to the continued health of the profession as well as individual programs within schools (Astramovich \& Coker, 2007; Dahir \& Stone, 2009; Dimmitt, 2009; Erford, House, \& Martin, 2003; Holcomb-McCoy, Gonzalez, \& Johnston, 2009; Lapan, Gysbers, \& Sun, 1997).

\section{Summary}

The century-long history of school counseling is filled with calls for reform and response from within the professional. This literature review recounts the history of school counseling and the ways that legislative initiatives in the United States have influenced the conceptualization of the profession. Information regarding the most current understanding of the professional duties, the ASCA (2012) National Model is included as literature related to self-efficacy in general and how the concepts in Bandura's social cognitive theory connect with the work of the school counselor in particular. Finally, the chapter provided context for school counselors utilizing data in program evaluation for the purposes of personal reflection as well as advocacy for students and professional roles. 


\section{CHAPTER 3: RESEARCH DESIGN AND METHODOLOGY}

Given the constant climate of school reform and the pressure applied to educational leaders to show student performance at high levels, it is critical that school counselors have the knowledge and confidence to utilize data (Lapan, 2001, 2005; Sink, 2005). School and district data, as well as state and national trends, can support the development of comprehensive school counseling programs, meet the academic and opportunity gap needs of student populations, and assist in the program advocacy needed to keep school counseling a vital part of schools (Lapan, 2001, 2005; Lapan, Gysbers, \& Petroski, 2001; Sink, 2005). My study takes a pragmatic approach to determine if a relationship exists between self-reports of efficacy for school counselor and tendencies for the school counselors to use student achievement data. In this chapter, I discuss the study's research questions as well as the full design of the study, from collection to analysis of data, including a rationale for the design as well as the context of the study are described. Finally, issues of ethics, reliability, validity, and researcher positionality are discussed.

\section{Purpose of the Study}

The purpose of this quantitative survey study is to examine if there is a relationship between school counselor self-efficacy and school counselor's utilization of data to design, implement, and evaluate a comprehensive school counseling program. Previous research on school counselor data use (Young \& Kaffenberger, 2011, 2015) focused on data use in specific subsets of the school counselor population. Young and Kaffenberger's (2011) first study used school counselors in Recognized ASCA Model 
Program (RAMP) certified school counseling programs as the population. RAMP's purpose is to allow individual school counseling programs to demonstrate adherence to the ASCA National Model (2012) through program implementation and evaluation. The application process takes approximately a year to complete all required evaluation and data tools. In Young and Kaffenberger's (2015) second study, they looked at school counselors in Iowa and connected data use within the program to professional development. Respondents to the survey were a convenience sample.

A dissertation (Miller, 2016) inspired by the first article by Young and Kaffenberger (2011) looked at identical questions but used a sample of ASCA members rather than RAMP certified program school counselors. A limitation of this dissertation is the homogeneity of the sample along the characteristic of membership in a professional organization. This limitation allows for an exploration of data use among school counselors regardless of affiliation with the national professional organization.

It is my contention that looking at the self-efficacy of school counselors in the state of Missouri as it relates to data use for the design, implementation, and evaluation of programs describes another factor within the topic. Specifically, I believe my study furthers Young and Kaffenberger's $(2011,2015)$ work by looking through the lens of one's belief about one's own ability. Further, describing this relationship provides information that informs my own practice, the comprehensive school counseling program at my school and district, as well as state initiatives and counselor education programs. 


\section{Research Questions}

The primary question guiding this study is: are there relationships between school counselor self-efficacy and the use of data to drive program advocacy and accountability? Additional questions, to further understand the relationship were: does the direction and strength of the relationship, if one was found to be present, change (1) with report of greater self-efficacy in mathematical processes and (2) depending upon the experience of professional development focused on the topic of data use?

\section{Hypotheses}

For purposes of this study there was one hypothesis set. For the primary question:

1. $\mathrm{H}_{0}=$ No relationship exists between school counselor data usage and the use of data to drive program advocacy and accountability.

2. $\mathrm{H}_{1}=\mathrm{A}$ relationship does exist between school counselor data usage and the use of data to drive program advocacy and accountability.

\section{Design and Methods}

A quantitative, descriptive, and correlational survey design was employed in this study to fully capture the complexity and variety of counselor experiences. I utilized instruments designed and validated by previous studies as well as seven items regarding self-efficacy in math I created for the present study. A self-administered survey was the collection device. The method of collection followed Dillman's (2007) protocol for Tailored Method Design. For example, the opening question applied to all members of the population but did not include basic demographic data. This data was left to the final pages of the survey to allow for potential survey fatigue. 
The survey for the current study opened with selected questions from the School Counselor Self-efficacy Scale (SCSE) developed by Bodenhorn and Skaggs (2005). The SCSE items, through participant self-report, measured on a 43-item Likert scale survey, self-efficacy levels of school counselors. Next, select items from the School Counseling Accountability Needs Assessment (SCANA), also presented on a Likert scale format, were added to the present study's survey. The seven items related to math self-efficacy designed for this study were entered as the third section of the current study's survey. These items were, again, on a Likert Scale. Finally, the survey concluded with basic demographics to identify the potential co-variates of gender and school assignment (i.e., grade level and caseload) as well as the demographics identified as mitigating variables (e.g., years in education, years in school counseling position(s), and participation in professional development). Permission was obtained by the lead authors from both the Bodenhorn and Skaggs (2005) SCSE scale and the Young and Kaffenberger (2015) SCANA scale to use their instruments in this study (N. Bodenhorn, personal communication, July 15, 2016; A. Young, personal communication, September 26, 2016). A complete version of the survey is in Appendix B. The combination of these scales affords the present study the opportunity to examine the interplay of self-efficacy of a school counselor as it relates to the specific nuances of data use.

\section{Variables}

To facilitate the understanding of relationships between school counselor selfefficacy and the use of data for program advocacy and student development, there are several variables. Field (2009) defined variables in social science research as more 
closely defined as predictor (independent) and outcome (dependent) variables. This section outlines the variables studied.

The predictor variable was self-efficacy as defined in Bodenhorn and Skaggs (2005). The authors defined self-efficacy as beliefs held regarding personal accomplishment within a particular behavior or situation. This definition was built on research by Bandura $(1993,2000)$ covering the concept of personal efficacy and agency. The author suggests that this concept adequately explains the erratic as well as the deliberate actions of people (Bandura, 2000). Bodenhorn and Skaggs (2005) as well as Bodenhorn, Wolfe, and Airen (2010) applied this concept to the field of school counseling. The outcome variable was use of data to design, implement and evaluate a comprehensive school counseling program as defined by Young and Kaffenburger (2015).

Mitigating variables included demographic characteristics such as years in the profession of school counseling, years in education in general, self-efficacy in mathematical processes and concepts, and attendance at professional development experiences. These variables were examined as covariates due to the researcher expectation that participants with one, or more, of these characteristics may respond differently on self-efficacy ratings and/or report higher utilization of data for program advocacy. Additionally, this relationship was examined while controlling for the following demographic variables: (a) gender, (b) level of school (i.e., elementary, middle, high, K-8), and (c) size of caseload. Controlling for these characteristics allowed for greater confidence in the data set and added to the generalization of findings. 


\section{Data Collection}

For the purposes of this correlational study, the data collection strategy was survey driven. Surveys are the standard collection method for studies when description of a phenomena are the central focus (Creswell, 2009; Fink, 2009). Additionally, the data provided by surveys allows for comparisons between groups in the population being studied. The survey for this study contains dichotomous questions, Likert scales, and produced data that are nominal and ordinal. Participants self-administered the instrument though an online survey system called Qualtrics. Specific information regarding the instrumentation, pilot testing, and step-by-step procedures for data collection follow.

\section{Instrumentation}

Literature pertaining to the development of survey instruments is clear that researchers must follow a specific set of steps and protocols to create and deploy a reliable and valid product (Dillman, 2007; Field, 2009; Fink, 2009; Mertens, 2010; Punch, 2014). These steps vary slightly depending upon the author, but they are consistent in their intent to create a template for researchers to use. Four instruments were used in this study and were combined into one online survey that participants used to provide data. Two parts of the combined tool were developed using standard protocols for development of surveys by previous authors. The first component is the scale developed by Bodenhorn and Skaggs (2005), The School Counselor Self-Efficacy Scale (SCSE). The second component is the School Counseling Accountability Needs Assessment (SCANA) developed by Young and Kaffenberger (2015). The third component, created by me, was seven items centered on the concept of math selfefficacy. The items related to math self-efficacy were developed to answer a secondary 
question to the research question. Developed with inspiration from Young and Kaffenberger (2015) and is focused on demographic information for respondents, I created the final component. The combined instrument, as it was presented to participants is in Appendix B.

School Counselor Self-Efficacy (SCSE) Scale. Created by Bodenhorn and Skaggs (2005) this scale measures self-efficacy - one's perception of one's own personal skills - for school counselors. The SCSE Scale items are found in Table 1. The authors indicate the use of self-efficacy measures connects with career performance (Bodenhorn \& Skaggs, 2005). Borrowing from Bandura's work $(1986,1995)$, the authors further connect self-efficacy with the setting and achieving of goals as well as higher levels of commitment, resilience, and motivation. Additionally, they highlight the Bandura (1995) study indicating that students with self-efficacious teachers reach higher levels of academic success. The authors (Bodenhorn \& Skaggs, 2005) used, as a foundation, a self-efficacy scale for counselors in all settings and adapted it using ASCA National Model standards. Prototypes of the scale were used in four separate studies to confirm construct validity and reliability. The following section details information about each of the studies conducted by Bodenhorn and Skaggs (2005) in the process of creating the SCSE.

Bodenhorn and Skaggs (2005) Study One. In Study One, the purpose was to develop appropriate items to measure the construct of self-efficacy in school counselors. Participants consisted of a panel of experts in school counseling. Item development flowed from training materials, practice, and the standards of both ASCA and the Council for the Accreditation of Counseling and Related Educational Programs (CACREP). The 
experts examined the scale items and provided feedback. This resulted in the inclusion of 51 items on the scale. Wording of the items was simplified and more consistent with self-efficacy theory.

Bodenhorn and Skaggs (2005) Study Two. Practicing school counselors were the population for Study Two. Participants responded to the scale developed in Study One and responses were used for item analysis and group comparisons. This process resulted in the removal of eight items. This was due to concerns with item omission as well as item discrimination. The sample of 226 school counselors was determined to be representative of the larger population in demographic qualities. Statistical processes indicated high reliability in the items as well as positive correlations on the items. 
Table 1

Items from the School Counselor Self-Efficacy Scale

Item

Advocate for integration of student academic, career, and personal development into the mission of my school. (4)

Recognize situations that impact (both negatively and positively) student learning and achievement. (4)

Analyze data to identify patterns of achievement and behavior that contribute to school success. (2)

Advocate for myself as a professional school counselor and articulate the purposes and goals of school counseling. (4)

Develop measurable outcomes for a school counseling program which would demonstrate accountability. (2)

Consult and collaborate with teachers, staff, administrators and parents to promote student success. (4)

Establish rapport with a student for individual counseling. (4)

Function successfully as a small group leader. (1)

Effectively deliver suitable parts of the school counseling program through large group meetings such as in classrooms. (4)

Conduct interventions with parents, guardians and families in order to resolve problems that impact students' effectiveness and success. (4)

Teach students how to apply time and task management skills. (3)

Foster understanding of the relationship between learning and work. (3)

Offer appropriate explanations to students, parents and teachers of how learning styles affect school performance. (3)

Deliver age-appropriate programs through which students acquire the skills needed to investigate the world of work. (3)

Implement a program which enables all students to make informed career decisions. (3)

Teach students to apply problem-solving skills toward their academic, personal and career success. (3)

Evaluate commercially prepared material designed for school counseling to establish their relevance to my school population. (1)

Model and teach conflict resolution skills. (1)

Ensure a safe environment for all students in my school. (1)

Change situations in which an individual or group treats others in a disrespectful or harassing manner. (1)

Teach students to use effective communication skills with peers, faculty, employers, family, etc. (1)

Follow ethical and legal obligations designed for school counselors. (1)

Guide students in techniques to cope with peer pressure. (1)

Adjust my communication style appropriately to the age and developmental levels of various students. (1)

Incorporate students' developmental stages in establishing and conducting the school counseling program. (1) 
I can find some way of connecting and communicating with any student in my school. (5)

Teach, develop and/or support students' coping mechanisms for dealing with crises in their lives - e.g., peer suicide, parent's death, abuse, etc. (1)

Counsel effectively with students and families from different social/economic statuses. (5)

Understand the viewpoints and experiences of students and parents who are from a different cultural background than myself. (5)

Help teachers improve their effectiveness with students. (2)

Discuss issues of sexuality and sexual orientation in an age appropriate manner with students. (5)

Speak in front of large groups such as faculty or parent meetings. (4)

Use technology designed to support student successes and progress through the educational process. (3)

Communicate in writing with staff, parents, and the external community. (4)

Help students identify and attain attitudes, behaviors, and skills which lead to successful learning. (1)

Select and implement applicable strategies to assess school-wide issues. (2)

Promote the use of counseling and guidance activities by the total school community to enhance a positive school climate. (2)

Develop school improvement plans based on interpreting school-wide assessment results. (2)

Identify aptitude, achievement, interest, values, and personality appraisal resources appropriate for specified situations and populations. (2)

Implement a preventive approach to student problems. (2)

Lead school-wide initiatives which focus on ensuring a positive learning environment. (2)

Consult with external community agencies that provide support services for our students. (4)

Provide resources and guidance to school population in times of crisis. (4)

Note. Numbers in parentheses indicate the factor identified by Bodenhorn and Skaggs (2005): (1) Personal and social development, (2) Leadership and assessment, (3) Career and academic development, (4) Collaboration, and (5) Cultural acceptance. 
Bodenhorn and Skaggs (2005) Study Three. Validity of the scale was the focus of Study Three. Bodenhorn and Skaggs (2005) distributed the SCSE scale along with one, of four, other validity scales to the participants. The four validity scales (as cited in Bodenhorn \& Skaggs, 2005): Counseling Self-Estimate Inventory (COSE; Larson et al., 1992), a 37-item scale that measures several subscales and focuses on the micro-skills of counseling; The Social Desirability Scale (SDS; Crowne \& Marlowe, 1960), a 33-item true/false scale, a measurement of one's attempt to be favorable and earn approval from another person; State-Trait Anxiety Inventory (STAI; Spielberger, 1983), a 40-item Likert scale measuring anxiety level in terms of state versus trait; and the Tennessee SelfConcept Scale, second edition (TSCS:2; Fitts \& Warren, 1996), an 82-item Likert scale measuring general self-confidence. Participants in Study Three were second year master's degree students in school counseling $(n=116)$.

The results of Bodenhorn and Skaggs'(2005) third phase indicated that for the students who took the COSE and the SCSE there exists a correlation in higher levels of self-efficacy on both scales. Participants taking the SCSE and the SDS showed little correlation which indicates that these students were not providing socially desirable answers in a "faking positive" direction. For the portion of the participants completing the STAI along with the SCSE, as anxiety decreased self-efficacy increased. Finally, those with the TSCS: 2 produced no significant correlation with the SCSE. The results on the SCSE in Study Three were compared with those from Study Two. A significant difference comparing the students to the active professionals is reported. This indicates that experience of even just one year contributes to an increase in self-efficacy (Bodenhorn \& Skaggs, 2005). 
Bodenhorn and Skaggs (2005) Study Four. In addition to comparing the results for group differences, the authors in Study Four examined factor analysis in the combined data. Through principal component analysis, Bodenhorn and Skaggs (2005) extracted factors and discovered five components that accounted for over half of the variance. These five components create the subscales of the SCSE: (a) Personal and Social Development (12 items), (b) Leadership and Assessment (9 items), (c) Career and Academic Development (7 items), (d) Collaboration (11 items), and (e) Cultural Acceptance (4 items) (Bodenhorn \& Skaggs, 2005). All components, except Career and Academic Development, positively correlate with each other. Career and Academic Development negatively correlates with the other four components. Internal reliability were calculated and run from .72 to .91 .

The development of the SCSE shows a path to creating a reliable and valid scale to use with school counselors. The validity scales indicate promising results in that the SCSE tends to measure a specific set of skills not completely measured in another scale (COSE), that the items do not lend themselves to a wholesale false positive for social desirability (SDS), and that anxiety is negatively correlated with self-efficacy (STAI). With these results, the SCSE can be utilized with confidence. As each of these factors is directly tied to standards for the ASCA National Model, for the present study, all factors are included in the data collection and analysis. For the purposes of data analysis, the participant's responses to the SCSE items are totaled across all items. This follows the practice of Bodenhorn and Skaggs (2005) as well as Mullen (2014). Scoles (2011) opted to do a grand mean with responses from the SCSE, but as it did not follow the understanding of the original authors, this method was dismissed. 
School Counseling Accountability Needs Assessment (SCANA). Young and Kaffenberger (2015) developed the SCANA over the course of a few years. Originally called Data Beliefs and Practices Survey (DBAPS; Young \& Kaffenberger, 2011), the survey had 20 items and assessed counselors' perception of data practices and uses, measured training levels and data sharing practices, and included open-ended questions about motivation to use and understanding of data. This survey was completed by school counselors who received a specific designation for their school counseling programs from ASCA called Recognized ASCA Model Program (RAMP). RAMP recognition occurs after a school submits a 12-part application. In the application various components assess the elements and themes of the ASCA National Model: Foundation, Management, Delivery, Accountability and Leadership, Advocacy, Collaboration, Systemic Change. Central to the process of RAMP recognition is the use of data. The survey, then, was designed to inform school counselors about the beliefs and practices of school counselors recognized for their use of data in the development and delivery of their program. Information regarding the reliability and validity of the DBAPS was not included in the study (Young \& Kaffenberger, 2011).

In 2015, Young and Kaffenberger modified their initial survey. The School Counseling Accountability Needs Assessment (SCANA) provided a means to measure the use of data in the support of student achievement and college and career readiness. The scale now consists of 19 items and draws from the authors' professional experience, information about and items from the DBAPS, and recommendations from experts in school counseling. In addition to the 19 Likert items, the SCANA includes six open- 
ended questions about use of data and professional development along with demographic questions.

Young and Kaffenberger (2015) produced statistical tests to measure internal consistency as well as completed a factor analysis. The Cronbach's Alpha for the survey was at .89 indicating an internal consistency sufficient for social science research as well as the cohesion of the items as a set. The exploratory factor analysis determined a possible four factors in the instrument. The threshold for the four factors was not firmly met using a guideline of at least three items per unique factor. That is, factors 3 and 4 had two items and one item respectively. Young and Kaffenberger (2015), relying on the high Cronbach's Alpha, decided to proceed with the instrument despite this. The four factors are: (1) student achievement, (2) instrument development, (3) collaboration and professional development, and (4) social justice inequities (Young \& Kaffenberger, 2015). With the decision to include all four factors, further research, including the present study, may apply caution to interpretation of factors two, three, and four.

For purposes of this study, the entire SCANA was not administered. I made this decision based upon the concern of internal consistency on three of the four factors. Table 2 shows the items included for the present study. They are items connected to factors one and two and, as such, may have a higher level of validity and reliability in the final analysis of data given the parameters discussed above. Of the 16 items used, only one of them related to the second factor, instrument development. In addition to the concern with internal consistency, I opted to include the 16 items due to their connection with student achievement, the focus of much of the school-reform debate as outlined in Chapter 2. 
Table 2

Items from the School Counseling Accountability Needs Assessment

Item

To improve school counseling services, I analyze district profiles.

To enhance student achievement, I analyze data to increase college and career readiness for all students.

To improve school counseling services (academic, personal/social, and career), I analyze student progress/report cards.

To improve school counseling services (academic, personal/social, and career), I analyze my school's state data reports.

I use technology to improve student achievement.

I use data to close achievement gaps that exist in my school.

I create surveys as a data collection method to improve school counseling services/programs.*

I analyze program feedback to improve school counseling services.

I regularly use pre and post test when facilitating classroom guidance lessons and workshops.

I facilitate focus groups as a data collection method to improve my school counseling services/programs.

My school counseling department sets strategic goals.

I have a systematic way to share outcome data.

I use data to identify barriers that impede student performance.

I regularly attend professional development trainings to improve my school counseling skills.

I believe it is important to use data to identify issues that impede academic success.

I use evidence-based practices to increase student achievement.

Note. The items in this table represent the selected items for the present study. Each item is related to the primary factor identified in the study.

* Item is related to a second factor, instrument development (Young \& Kaffenburger, 2015).

Items related to math self-efficacy. To facilitate the examination of the relationship between self-efficacy of counselors and their use of data and the potential influence of the counselor's self-efficacy in mathematical concepts, I created seven Likert scaled items (see Table 3). Using the framework as described in Bandura (2006) on how to construct survey items related to self-efficacy and drawing from items in Maras, 
Coleman, Gysbers, Herman and Stanley's (2013) instrument for additional guidance, the items created are designed to collect data related to participants' beliefs around personal efficacy in math. Specifically, I considered the steps of math understanding and calculation that must be completed to reach higher levels of ability. This is consistent with Bandura's (1997) understanding of how to assess personal efficacy in multiple domains. Maras et al. (2013) included items related to specific statistical tests and was helpful as a guide for potential wording and scaffolding of items.

Table 3

Items related to math self-efficacy

Item

I can perform standard mathematical calculations (e.g., addition, subtraction, multiplication, division).

I can evaluate student data to choose the best statistical calculation (e.g., mean, t-test, correlations) to interpret student data.

I can calculate measures of central tendency (e.g., mean, median, and mode) to interpret student data.

I can use t-tests to interpret student data.

I can use computer programs (e.g. Word, Excel, Student Information Systems) to support the management of student data.

I can use computer programs (e.g., Excel, EZAnalyze, SPSS) to support the statistical analysis of student data.

I can explain the results of statistical operations to parents, administration, community members, and other stakeholders.

After a first draft of the items was complete, I solicited responses from counselor educators, practicing school counselors, and students in school counseling programs for feedback. Six of 10 people responded to my inquiry. From their feedback I adjusted vocabulary, split items, and changed ordering of the items for clarity and ease of understanding.

Demographic information tool. Developed for use in an online survey platform, the final part of the instrument contains basic and advanced demographic questions. 
Respondents were asked to supply gender, years in the field of education, years as school counselor, as well as two items regarding professional context (i.e., caseload amount and grade levels within school). More advanced demographic items solicited responses about participation in professional development targeted to use of data within a school counseling program, what data the counselor utilized to improve the school counseling program, and who the counselor collaborated with most often.

The advanced demographic items are included to add depth to the analysis of data. The data created by these questions allowed for between-group-comparisons that assist in a fuller understanding of the interaction between self-efficacy and the use of data within a comprehensive school counseling program. The format of the demographic section is adapted from Young and Kaffenburger (2015).

Administration of the survey. This section focuses on the specific design elements that governed the survey administration. These sections include the Tailored Method of collection as described by Dillman (2007) and information about ethical concerns and how the design will safeguard human subjects.

Self-administrated survey. According to Fink (2009), a researcher must consider several aspects of survey data collection when choosing how to administer the survey. Chief among those concerns are reliability, validity, credibility, and cost. For the purposes of this study, the choice was made to design data collection to occur through self-administration. The population surveyed are college-educated persons with background knowledge of the vocabulary and concepts in school counseling due to their employment as school counselors in Missouri. Because of this, the self-administration decision facilitated data collection that produced quality data that is also cost effective. 
However, without the prompting of a survey administrator participants may enter responses that are incomplete or do not fully communicate the opinion of the respondent due to a lack of ability in understanding the full meaning of open-ended responses (Dillman, 2007). Similarly, data collection can have elements of social desirability on the part of respondents that can lead to faulty responses. Confidentiality and anonymity in responses can help mitigate these threats (Field, 2009; Punch, 2014). Responses to openended questions such as what data does the school counselor use and with whom do they collaborate indicate the condition of anonymity in responses helped in the present study. That is, respondents included answers such as, "None, really," as well as "We do not collect data," and "At this time, nothing particular." Answers such as this could indicate a willingness to be more open given the lack of identifiers connecting participant to response. Likewise, in looking at open-ended responses, no items were out of context to the question posed indicating a basic understanding of the wording of questions on the part of participants.

\section{Conducting the Survey}

In 2007, Dillman provided an update for his survey method called the Tailored Design Method. At the heart, this method has five elements: (a) respondent-friendly questionnaire, (b) up to five contacts for respondents, (c) inclusion of a return method, (d) personalized correspondence, and (e) a token incentive sent with the first request to complete the survey. The goal, according to Dillman, is to provide "positive salience" (p. 155). In doing so, the respondent feels such positive regard for the researcher and feels compelled to respond. To reach high levels of return rate, this study used variations of each element. 
Dillman (2007) further explains the process of survey design for the web including visual paths, highly responsive and interactive pages, and strategic placement of instructions that will also assist in the delivery of the survey as well as the readability, clarity, and likelihood of response. Several sources were consulted for design tools and strategies (Fink, 2009; Toepoel, 2016; Tourangeau, Conrad, \& Couper, 2013).

Specifically, this study included these elements: (1) the Qualtrics survey was designed to be easily read on both computer and phone screens, (2) participants received an initial email with a link to the survey on April 25, 2018. There were three additional email reminders on May 2, 9, and 16, 2018, and (3) an incentive for one of five $\$ 20$ gift certificates to Amazon.com, drawn randomly from participants who clicked through and consented to the capture of their email in a separate survey tool not linked to responses to the present study's survey items.

\section{Pilot of Questions and Survey}

Walliman (2016) speaks to the importance of piloting survey instruments to achieve several goals. Dillman (2007) and Walliman (2016) advocate for a two-tier method of piloting which allows for the evaluation of survey clarity as well as content validity. In this study, the first tier of piloting, was a review by content experts with the purpose of evaluating the flow of the survey as well as demographic elements added for this study. Following the review of this panel and slight revisions to the instrument, the updated survey was sent to a second tier of school counselors and school counseling students. Interviews to collect feedback were conducted. Additional revisions were made to the instrument. As the SCANA and the SCSE are established instruments, this pilot study afforded an opportunity to gather feedback on the online administration and design. 


\section{Participants}

For purposes of this study, the population examined was comprised of all school counselors in the state of Missouri. This population is inclusive of counselors working in public schools across grades K-12 as of the beginning of the school year 2017-18. In the spring of 2018, after a data request to the Missouri Department of Elementary and Secondary Education (DESE), I received a file set with over 3,000 lines. Each line represented a person labeled as a school/guidance counselor from each grade level as reported by school districts to the Missouri Department of Elementary and Secondary Education annually through core data reporting (DESE, personal communication, April, 20, 2018). This initial report was used to create the list of school counselors to include in the study. Specifically, lines with duplicate names were removed (290 lines), lines without email addresses were examined and, where possible, email addresses were obtained through school district web sites. Sixty-nine lines were removed due to lack of email after the attempt to locate. Each member of the population, with a valid email address, received an email with a link to the survey. This strategy was an attempt to preplan for response rate concerns by soliciting the population and receiving a sample big enough to find relationships between variables.

Of the 2,641 school counselors who received an email from Qualtrics, 535 clicked into the survey. A total of 437 completed the survey, including eight indicating a desire to not participate by selecting, "I do NOT agree to participate." While 98 did not complete all questions on the survey. After the process for data collected was completed, as described in the following sections, the sample is the total number of respondents and 
is a convenience sample. Participants responded to the survey between April 25, 2018 and May 31, 2018. The total respondents was 426.

For purposes of this study, the participant number, when speaking of the study in broad terms, is 426 , the number of school counselors who completed all but two survey items - minus the eight who completed by indicating a desire to not participate. When a specific item from the survey is highlighted, the number of participants responding to that item is indicated. The following section describes additional information about the participant set, Institutional Review Board information, survey distribution, and response rate.

\section{Characteristics of Participants}

Demographic questions were asked of participants at the end of the survey. These questions included gender, number of years in the education profession, number of years as a school counselor, current grade level, and size of caseload. Most of these questions were answered by over 420 of the participants. The participant group was overwhelmingly female $(89 \%$; $n=382)$, predominately served in the elementary setting $(45 \% ; n=192)$ and had $2-5$ years of experience in school counseling $(n=117)$. The mean reported number of years in education was 11-15 years. Size of a school counselors' caseload is a topic within the profession. In this survey, the range for caseload size was under 50 to over 600 students. The mode for caseload size was in the range of 301-350. The range of years of experience for both the time spent in education in general and school counseling in general showed a wide range of responses. On the item related to attending professional development focusing on data use and accountability strategies in the previous 12 months, 73\%, or 315 participants, responded "No." Table 4 shows the 
years spent in education as well as years participants report being counselors. Note that while participants are evenly spread throughout experience in education, $34 \%$ of the sample reports being a counselor for less than 5 years. Table 4 also shows the breakdown of demographic information for participants. 
Table 4

Participant numbers, percentages by group

\begin{tabular}{|c|c|c|}
\hline Group & $\mathrm{N}=426$ & Percentage \\
\hline \multicolumn{3}{|l|}{ Teaching experience } \\
\hline 1-3 Years & 38 & $8.9 \%$ \\
\hline 4-6 Years & 52 & $12.2 \%$ \\
\hline 7-18 Years & 180 & $42.3 \%$ \\
\hline 19-31 Years & 139 & $32.6 \%$ \\
\hline $32+$ Years & 16 & $3.8 \%$ \\
\hline Missing & 1 & $0.2 \%$ \\
\hline \multicolumn{3}{|l|}{ School counseling experience } \\
\hline 1-3 Years & 91 & $21.4 \%$ \\
\hline 4-6 Years & 68 & $16 \%$ \\
\hline 7-18 Years & 191 & $44.8 \%$ \\
\hline 19-31 Years & 73 & $17.1 \%$ \\
\hline $32+$ Years & 2 & $0.5 \%$ \\
\hline Missing & 1 & $0.2 \%$ \\
\hline \multicolumn{3}{|c|}{ Professional development participation } \\
\hline No & 314 & $73.7 \%$ \\
\hline Yes & 112 & $26.3 \%$ \\
\hline \multicolumn{3}{|l|}{ Grade level served } \\
\hline Elementary school & 186 & $43.7 \%$ \\
\hline Middle school & 68 & $16 \%$ \\
\hline High school & 76 & $17.8 \%$ \\
\hline $\mathrm{K}-12$ & 28 & $6.6 \%$ \\
\hline $\mathrm{K}-8$ & 15 & $3.5 \%$ \\
\hline Multi-level/other & 52 & $12.2 \%$ \\
\hline Missing & 1 & $0.2 \%$ \\
\hline \multicolumn{3}{|l|}{ Caseload } \\
\hline Less than 200 & 55 & $12.9 \%$ \\
\hline $201-300$ & 104 & $24.4 \%$ \\
\hline $301-400$ & 134 & $31.5 \%$ \\
\hline $401-500$ & 86 & $20.2 \%$ \\
\hline More than 500 & 43 & $10.1 \%$ \\
\hline Missing & 4 & $0.9 \%$ \\
\hline \multicolumn{3}{|l|}{ Gender } \\
\hline Female & 381 & $89.4 \%$ \\
\hline Male & 40 & $9.4 \%$ \\
\hline Non-binary/third option & 2 & $0.5 \%$ \\
\hline Prefer to self-describe & 1 & $0.2 \%$ \\
\hline Prefer not to say & 2 & $0.5 \%$ \\
\hline
\end{tabular}


Consent, access, and the use of human subjects. Prior to the collection of data from the instruments described, the Institutional Review Board of the University of Missouri-Columbia approved the present study and the collection of data. This section describes the elements of this approval that focus on the step-by-step procedures for data collection.

Informed consent. Eight major points, according to Seidman (2006), are necessary to fully describe a study to allow respondents to enter into informed consent. These are: (a) invitation, (b) risks, (c) rights, (d) possible benefits, (e) confidentiality or records, (f) dissemination of results, (g) safeguards for protected populations, and (h) contact information for the researcher. Each of these elements, with the exception of special populations due to my research with adults only, are included in the informed consent documentation. The full text of the agreement was housed on the main landing page of the online survey.

Respondents were informed that their participation was completely voluntary. Further it was acknowledged that some participants may find risks associated with discomfort and vulnerability through the questions, but that everything would be done to mitigate this discomfort. For example, responses were anonymous and were not connected to individuals directly. Participants also received information regarding the academic purpose of the study and that statistical results, not data at the individual level, would be included within this dissertation. Additionally, participants were told how data would be stored. Finally, all respondents received contact information should they have additional questions about the research as well as concerns that need to be addressed by IRB. Documentation from the University of Missouri-Columbia IRB is in Appendix D. 


\section{Distribution of Survey to Study Population}

An initial email was sent to 2,742 participants. The email included an introductory message with a link to the Qualtrics survey. When respondents clicked on the link the first screen was a more detailed description of the study including information about Informed Consent and other Institutional Review Board (IRB) information. The first distribution went to 2,641 identified school counselors; 116 emails from the initial list bounced back.

Subsequent email contacts, via the Qualtrics system, were made to members of the population at the 2, 3, and 4-week marks for a total of four email contacts. These reminder emails were sent only to counselors who did not click the link in a previous email (Appendix C contains the text of the email). Dillman (2007) points to the higher response rates found in making four email contacts. This is also supported by Tourangeau, Conrad, and Couper (2013) who indicate a response rate of more than 14 points higher when multiple email contacts are made to a population. Data collection ended 28 days after the initial administration of the survey.

Response rate. Of the 2,641 potential participants identified and emailed, 539 people used the link found in the email. This number includes 437 who completed the survey and 98 who started, but did not submit, the survey. Of those, 437 entered the survey to respond to the primary question of "I agree to participate" or "I do NOT agree to participate." Eight participants declined to participate. The number of participants for the study, after removing responses where participants missed more than two survey items was 426 . 
Mertens (2010) recommends the use of the response rate formula from the American Association for Public Opinion Research (AAPOR). The minimum response rate, according to the AAPOR is the number of complete interviews divided by the number of interviews plus the number of non-interviews plus all cases of unknown eligibility. When using their formula, I looked at two response rates. The first, Response Rate 1 (RR1) takes the number of completed interviews $(n=426)$ and divides it by all possible participants $n(\operatorname{sub1})=2641$. The RR1 equals 0.161. Fink (2009) uses a similar formula to calculate response rate. The second rate of the AAPOR, Response Rate 2 (RR2) takes all interviews (complete and partial) and divides it by all possible participants. The RR2 for the present study is 0.20 . As partial responses still contribute data to the survey items included in the response, I selected the RR2 calculation of response rate, $20 \%$. When specific items are discussed in the following sections, care was taken to indicate number of respondents to more accurately explain results.

It is important to discuss the response rate and how it contributed to the overall analysis of data as well as bias within the present study. Fink (2009) indicates that one potential area of concern for bias within a convenience sample, such as the sample of participants in this study, is with who chooses to respond. The author contends that participants are often the people willing to complete at the time that they are needed to complete. The concern that follows is that participants may have a motivation in completing a particular survey. For example, participants in the present study may have responded due to a particular viewpoint regarding using data to develop and produce a comprehensive school counseling program. These viewpoints could be either positive or negative. Additionally, Fink (2009) as well as Mertens (2010) point out, the timing of a 
survey could be important in response rate. This is especially true in this sample due to the cyclical nature of the school year for school counselors. There are times in the year that are more, or less, busy (Fink, 2009; Mertens, 2010). I attempted to balance this concern by sending the first email prior to a major time commitment to many school counselors in our state (i.e., state end of course and achievement testing dates). Using Dillman's (2007) protocol as well as recommendations by Fink (2009) and Mertens (2010) around topic salience, multiple reminders, incentives, and precise description of how the data would be used should mitigate some of the potential bias.

\section{Data Analysis}

Analysis of the data for this study follows the responses captured through the online survey tool. This section describes the statistical procedures used as well as coding processes implemented for the limited amount of open-ended questions that are part of the SCANA instrument.

\section{Statistical Procedures for the Study}

At the most basic level the statistical operations for this study began with descriptive statistics to understand the population sample. With a complete understanding of the "who" behind the sample, more sophisticated statistical operations can take place. Due to the number of variables and the type of data that the Likert items produced, the most logical form of statistical process to use is Multiple Linear Regression (MLR). Regression is a process that allows researchers to understand data linearly along a model of best fit (Field, 2009; Tabachnick \& Fidell, 2013). The model to understand the data is based on the equation of a line where slope $\left(b_{1}\right)$, the direction or gradient of 
the line, and intercept $\left(b_{0}\right)$, where the line crosses the vertical, or $\mathrm{y}$, axis, position the data within the space of a plane.

The predictor variables are compared to outcome variable(s) and, ultimately, relative weights are ascribed to the predictor variables. This provides an ability to attribute a certain part of the outcome variable to a particular percentage of predictor variable $X_{1}$ (Field, 2009; Tabachnick \& Fidell, 2013). The equation that describes this model is:

$$
Y_{i}=\left(b_{0}+b_{1} X_{1 i}+b_{2} X_{2 i}+\ldots+b_{n} X_{n i}\right)+\varepsilon_{i}
$$

Utilizing variable labels, the model equation is:

$$
\text { Data use }_{i}=b_{0}+b_{1} \text { self-efficacy } i+b_{2} \text { demographic variable }_{2 i}+\ldots+\text { error }_{i}
$$

SPSS is the computer program that supported the Multiple Regression analysis as well as the basic demographic statistical descriptions.

With all of the statistical procedures, both basic and sophisticated, a code book, or $\log$ of operations, was maintained to assist with the outcomes of the data manipulations and the logging of researcher intention. As appropriate, statistical operations and the resulting tables and graphs are presented to fully explain the data.

\section{Coding of Non-Numerical Data}

Open response items from the SCANA were coded for themes utilizing methods from grounded theory design, specifically constant interaction with data and systemic coding (Birks \& Mills, 2011; Charmaz, 2006; Mertens, 2010, Stern \& Porr, 2011). As with the purely quantitative data analysis, this coding was monitored and recorded through a code book to facilitate the understanding of my processes. 


\section{Reliability, Validity, and Generalizability}

Concerns around reliability, validity, and generalizability are addressed to support the arguments made after data collection and analysis. It is through the acknowledgement of these concerns and the subsequent protections made within the design of a study that the trustworthiness of the results occurs.

\section{Reliability}

Results are reliable when the data is consistent across context and/or time.

Reliability concerns can occur through participant error and bias as well as observer error and bias. The construction of the survey was key in helping mitigate these potential sources of error. Thoughtful design, especially in online methods, facilitates the participant's progress through and understanding of, the survey thus limiting participant error (Dillman, 2007; Singh, Taneja, \& Mangalaraj, 2009; Toepoel, 2016). Bias is a natural limitation in research with humans. Observer error was addressed, partly, through quantitative research in the standardization of scales. Data collection, through the use of these strict survey parameters, leaves little in the way of observer error. Analysis, however, may still produce error due to the observer/researcher. This can be seen in the selection of statistical processes and the understanding of the resulting representations of the data. Observer bias was addressed in the limitations of the study and relies upon the researcher's reflexivity throughout the process of data collections, analysis, and reporting. In the end, reliability is connected with error. The more reliable the survey, the less error that will result in the administration and the subsequent data analysis. Reliable measures allow researchers to separate "noise," or random variance, to uncover actual results (Punch, 2014). 
During the collection and analysis of the data I engaged in reflection. I considered if the information was an accurate representation of the reality of school counselor experiences and if there was any reason to be suspicious of the data gathered. I strived to report findings in such a way that did not overstate them due to a restricted sample or other potential restriction.

\section{Validity}

The concept of validity speaks to the ability of a study and scale to measure what it is determined to measure (Field, 2009; Punch, 2014). In both the SCSE (Bodenhorn \& Skaggs, 2005) and SCANA (Young \& Kaffenberger, 2011) items, the authors report confidence in the validity of the scales, specifically the factors I am including in the analysis. Through expert review, piloting of survey items, and initial data collection they are confident the scales measure the constructs of self-efficacy and data use, respectively. Additionally, Cronbach's alpha $(\alpha)$ is measured to establish internal consistency for the data collection in this study. This measurement shows how closely related the set of items and responses are as a group. That formula is shown in Equation 3:

$$
\propto=\mathrm{N} /(\mathrm{N}-1)\left[1-\frac{\sum_{i=1}^{N} \sigma_{Y_{i}}^{2}}{\sigma_{x}^{2}}\right]
$$

In this formula, $\mathrm{N}=$ number of items, $\sigma_{Y_{i}}^{2}$ is the variance of item $i$, and $\sigma_{x}^{2}$ is the variance of the observed total scores. Finally, when analyzing the data, I reflected upon the statistical operations and considered any factors or intervening variables that might have caused a level of distrust with the data set and/or calculations. 


\section{Generalizability}

Also known as external validity, generalizability is the notion that results from one study can be applied beyond the scope of the original research (Creswell, 2009; Field, 2009; Mertens, 2010, and Punch, 2014). For the present study the question of generalizability asks if the same results, given to counselors identified outside of Missouri, would be the same. Given that counselors in the state of Missouri are educated in the field through programs of study accredited through CACREP there may be some areas where generalizability could occur. However, the size of the population and the myriad of other characteristics that may contribute to the personality, training, and experiences of school counselors in Missouri are limits to potential generalizability.

\section{Researcher Positionality}

Constructivism and interpretivism both resonate with me. In my mind constructivism comes before - people live their life and create schema through experience. When one conducts research, I think that the interpretivism is the lens we use. My study focused on describing the relationships, positive or negative, between counselor self-efficacy and the use of data for program advocacy. Punch (2014) highlights the need for descriptive studies of this sort to help identify and describe elements of a phenomena and by doing this the study attempts to understand and explain larger social constructs.

It is important to note that I am a school counselor in a secondary school in Missouri. This is a position I began over a decade ago. Additionally, I am the leader of the counseling department as well as a leader within my school and, as such, have 
contributed, outside of my role as school counselor, to the design, implementation, and maintenance of a student support system designed to address achievement gaps in my building. Finally, I hold membership in several professional organizations. These characteristics contribute to the potential bias within the design, analysis, and reporting of findings for this study.

\section{Limitations and Assumptions}

Humans seek understanding of phenomena. Through research and analysis we discover ways to conceptualize these phenomena and find answers to our questions. As a human enterprise, research has inherent limitations and basic assumptions. My desire to understand professional self-efficacy of school counselors as it may relate to data use for program design and evaluation is no different.

A few factors may limit this study. First, the limitation of the sample, school counselors from Missouri only, is purposeful. This selection of participants meeting this criterion may limit the transferability of the data and results to other situations.

Additionally, given the location of Missouri in the United States, the sample may be more homogeneous than other parts of the country. Therefore, similarities in participant demographics may limit the ability of findings to generalize to other situations.

Additionally, given the contributions of Department of Elementary and Secondary Education in the State of Missouri to the history of school counseling as a profession (i.e., formation of the Missouri Model of Comprehensive Guidance) as well as the multidecade presence of prominent researchers in the field at the flagship campus of the university system, (e.g., Gysbers, Lapan, Herman), counselors situated in Missouri may 
report different levels of efficacy or demonstrate altered relationships with data use due to exposure to these influences.

Limitations to the interpretation of the data may also arise in the perceptions of participants including mindset at the time of survey completion. Social desirability may provide an additional limitation as participants may reply to survey items in such a way to appear more efficacious in school counseling and/or data use. The reliability and validity of the survey may be another limitation in the study. Finally, my own position as a school counselor in Missouri may be viewed as a limiting factor of this study.

This study is premised on the assumption that school counselors identified through the Missouri State Department of Education's database hold some professional knowledge in data use. An assumption of this knowledge is based on the criterion used by CACREP in the evaluation of programs of study for school counselors. It is further assumed that these school counselors also hold some self-efficacious notion regarding professional duties and responsibilities due to the specific training required through master's degree programs and preparation.

\section{Summary}

Within the context of being a school counselor, I conceived this study to examine the relationship of school counselors with the use of data, specifically to determine if a relationship exists between a professional's self-efficacy and their subsequent use of data to design, implement, and evaluate comprehensive programs. This chapter contains the purpose of the study, the subsequent research questions and hypothesis, as well as the design and method. The selection of the School Counseling Accountability Needs 
Assessment (SCANA) and School Counselor Self-Efficacy Scale (SCSE) is shared as is a description of the development of these scales. Also included is the discussion of design and the statistical operations used. Multiple Linear Regression and descriptive statistical techniques are highlighted. Finally issues of reliability, validity, and significance were addressed. 


\section{CHAPTER 4: FINDINGS}

Throughout the literature on school counselor effectiveness, a call is sounded for practitioners to utilize the types of data available in the school setting to design, deliver, and analyze interventions with students, guardians, faculty, and other stakeholders. Yet, many of these articles are written like a how-to manual rather than examinations of what works suggesting that many school counselors are not utilizing this part of their training (ASCA, 2018; CACREP, 2016; Erford, House, \& Martin, 2003; Lapan, Gysbers, \& Sun, 1997; Shillingford and Lambie, 2010).

This study examined the connection between school counselor self-reports of beliefs about their own professional abilities and self-reports of utilization of data for program design, evaluation, and advocacy. Other factors, such as time in the field of education, knowledge of statistical processes, engagement with professional development, and case load size are also reported. Within this chapter, the findings of the statistical analysis performed on the items created for this study as well as the participant data set are reported through the lens of the research questions.

Data analysis, using sequential multiple regression suggests an ability to reject the null hypotheses for the research question that guided this study. Specifically, this may indicate the use of data in a school counseling program is a function of the school counselor's professional self-efficacy as well as some other factors when controlling for demographic influences. 


\section{Descriptive Statistics}

After receiving one of the emails soliciting participation, 539 school counselors in Missouri clicked through a to the survey. Of this group, 63 answered the first question by selecting one option: (1) I agree to participate or (2) I do NOT agree to participate. Another 50 respondents missed more than two survey items. This leaves 426 , or $79 \%$ of those who clicked through the email to the survey, as the number of participants included in the analysis of data.

\section{Basic Demographic Information}

Table 4 shows the total number and percentage of the sample for each of the demographic questions presented on the survey. As shown in the table, most participants are female (89.4\%) and work with students at the elementary level (43.7\%). High school and multi-level or other placements are the next highest location of work at $17.8 \%$ and $12.2 \%$ respectively. Experience in teaching is high with 335 participants $(78.8 \%)$ reporting 7 or more years in the field of education. Counseling experience is also high with $266(62.4 \%)$ indicating 7 or more years as a school counselor. Caseload sizes are spread among the 5 options with three ranges: (1) 201-300, (2) 301-400, and (3) 401-500 being within $10 \%$ of each other. Put another way, 324 of participants, or $76.1 \%$, have a caseload between 201-500. 
Table 4

Participant numbers, percentages by group

\begin{tabular}{|c|c|c|}
\hline Group & $\mathrm{N}=426$ & Percentage \\
\hline \multicolumn{3}{|l|}{ Teaching experience } \\
\hline 1-3 Years & 38 & $8.9 \%$ \\
\hline 4-6 Years & 52 & $12.2 \%$ \\
\hline 7-18 Years & 180 & $42.3 \%$ \\
\hline 19-31 Years & 139 & $32.6 \%$ \\
\hline $32+$ Years & 16 & $3.8 \%$ \\
\hline Missing & 1 & $0.2 \%$ \\
\hline \multicolumn{3}{|l|}{ School counseling experience } \\
\hline 1-3 Years & 91 & $21.4 \%$ \\
\hline 4-6 Years & 68 & $16 \%$ \\
\hline 7-18 Years & 191 & $44.8 \%$ \\
\hline 19-31 Years & 73 & $17.1 \%$ \\
\hline $32+$ Years & 2 & $0.5 \%$ \\
\hline Missing & 1 & $0.2 \%$ \\
\hline \multicolumn{3}{|c|}{ Professional development participation } \\
\hline No & 314 & $73.7 \%$ \\
\hline Yes & 112 & $26.3 \%$ \\
\hline \multicolumn{3}{|l|}{ Grade level served } \\
\hline Elementary school & 186 & $43.7 \%$ \\
\hline Middle school & 68 & $16 \%$ \\
\hline High school & 76 & $17.8 \%$ \\
\hline $\mathrm{K}-12$ & 28 & $6.6 \%$ \\
\hline $\mathrm{K}-8$ & 15 & $3.5 \%$ \\
\hline Multi-level/other & 52 & $12.2 \%$ \\
\hline Missing & 1 & $0.2 \%$ \\
\hline \multicolumn{3}{|l|}{ Caseload } \\
\hline Less than 200 & 55 & $12.9 \%$ \\
\hline $201-300$ & 104 & $24.4 \%$ \\
\hline $301-400$ & 134 & $31.5 \%$ \\
\hline $401-500$ & 86 & $20.2 \%$ \\
\hline More than 500 & 43 & $10.1 \%$ \\
\hline Missing & 4 & $0.9 \%$ \\
\hline \multicolumn{3}{|l|}{ Gender } \\
\hline Female & 381 & $89.4 \%$ \\
\hline Male & 40 & $9.4 \%$ \\
\hline Non-binary/third option & 2 & $0.5 \%$ \\
\hline Prefer to self-describe & 1 & $0.2 \%$ \\
\hline Prefer not to say & 2 & $0.5 \%$ \\
\hline
\end{tabular}




\section{Screening of the Data}

Following the methods described in Field (2009) as well as Tabachnick and Fidell (2013), data were initially screened to look for any potential concerns in accuracy, missing data, and outliers. One of the first tests was a simple scatter plot of the values of participant SCANA means (z-score) compared to total score on the SCSE (see Figure 2). The bivariate scatterplot did not show outliers that would contribute undue influence on the analysis of participant data. Also, the distribution shown in the figure suggested a normal, linear relationship between the two variables. This indicated that data collected were appropriate for the design of the study.

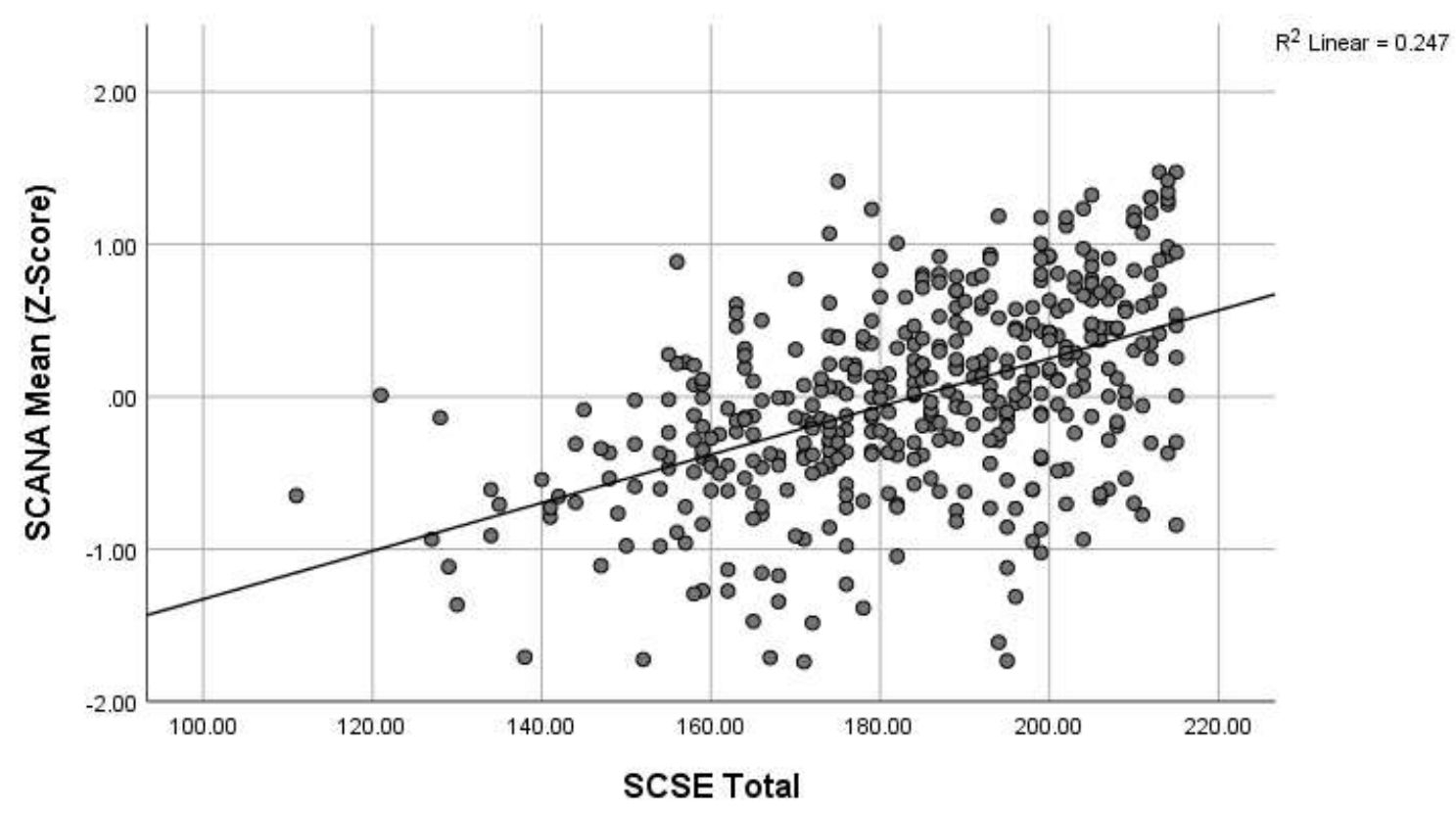

Figure 2. Simple scatterplot of SCANA Mean by SCSE Total with Regression Line for participants.

\section{Check for normality, homogeneity of variance, and multicollinearity.}

Utilizing distribution graphs, P-P and Q-Q Plots as well as variance inflation factor, tests 
for normality, homogeneity of variance, and multicollinearity were conducted on the data.

Tests of normality. Due to the size of the sample $(\mathrm{n}=426)$ values for skew and kurtosis were calculated, but significance levels were not determined. According to Field (2009) as well as Tabachnick and Fidell (2013) larger samples cause distortion to significance levels and it is better to visually inspect histograms of the data and actual values of skew and kurtosis. Included in Figures 3, 4, and 5, are the histograms for the SCANA Mean (z-score), SCSE Total Scores, and Math Self-Efficacy Mean (z-score).

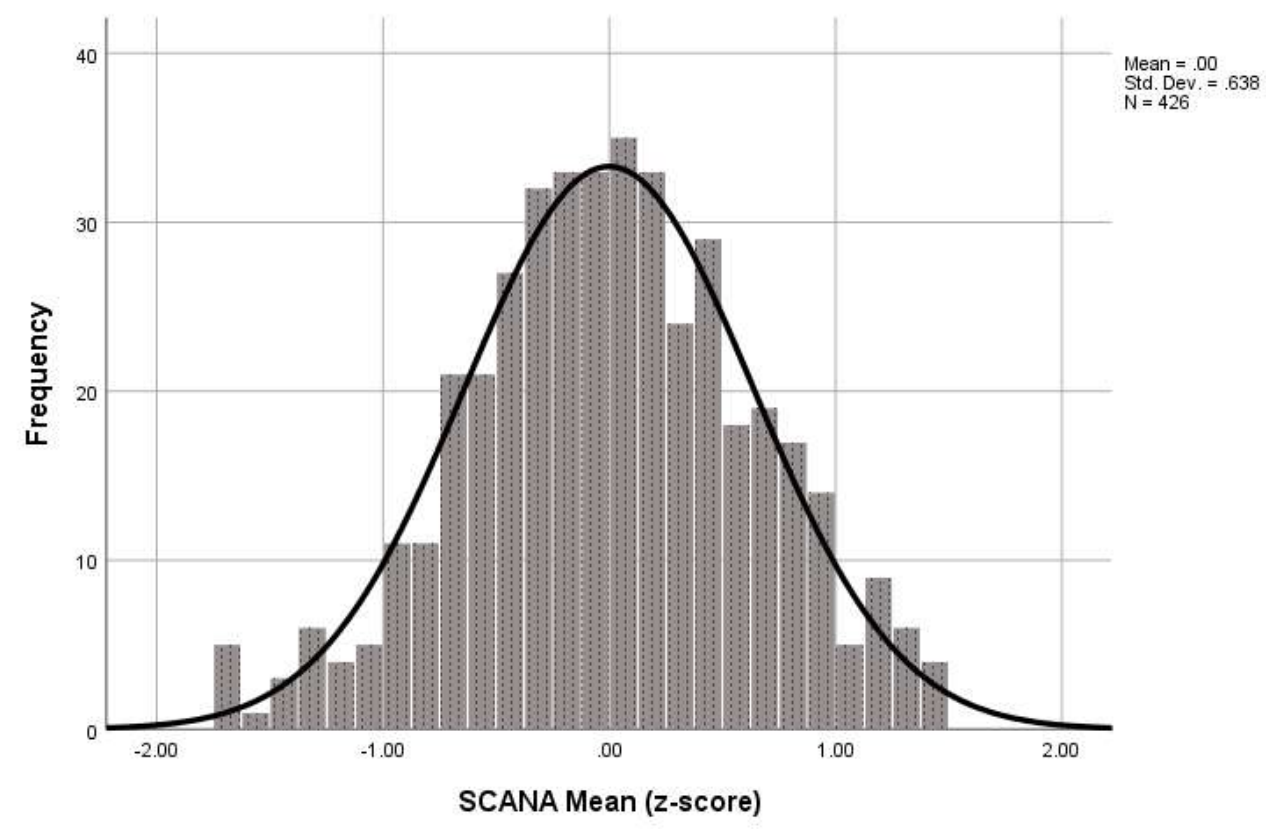

Figure 3. Histogram of SCANA mean scores indicating normal distribution.

In Figure 3, The SCANA Mean scores are distributed in what looks to be a normal curve. The peak of scores occurs at the z-score of " 0 " as indicated in literature and the tails are tapered at approximately the same point (Field, 2009). This contrasts with Figure 4, which shows the distribution of SCSE total scores. The distribution of 
scores shows a negative skew, indicating participants report a higher level of self-efficacy in the area of school counseling than would be expected from a random sample.

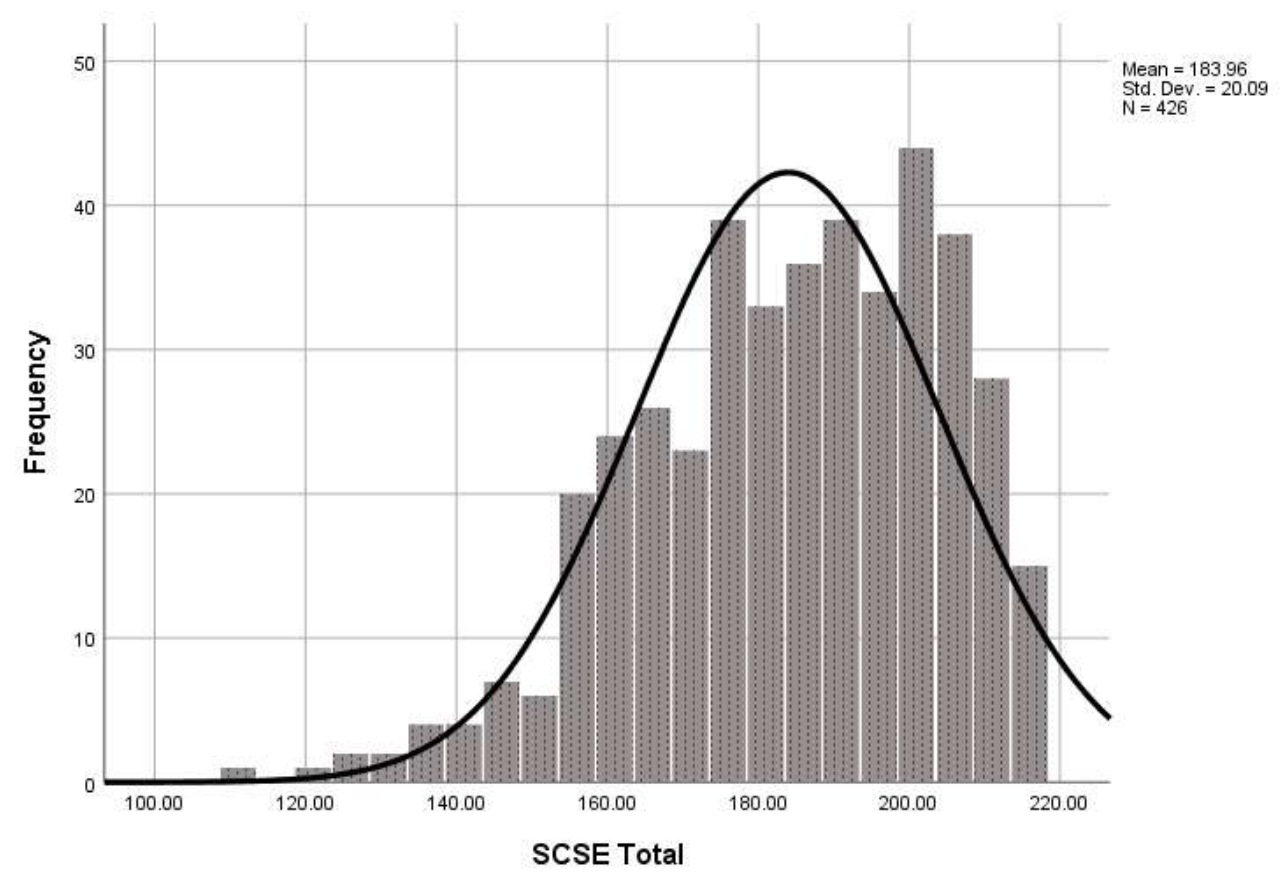

Figure 4. Histogram of total scores on SCSE items with negative skew.

Likewise, in Figure 5, the Math Means (z-scores), the distribution shows a negative skew indicating higher levels of confidence in the responses to the items connected to math self-efficacy in the survey.

The visual inspection of kurtosis - the relative size of peak and tails - on Figures 3, 4, and 5 indicated normality. The presence of kurtosis approaching normal, or mesokurtic, distribution indicates a participant group that conforms to an element of the understanding of scores tending to group around a mid-point (mean) and tapering to extreme values. In all three of these figures there are values on each side of the mean. 


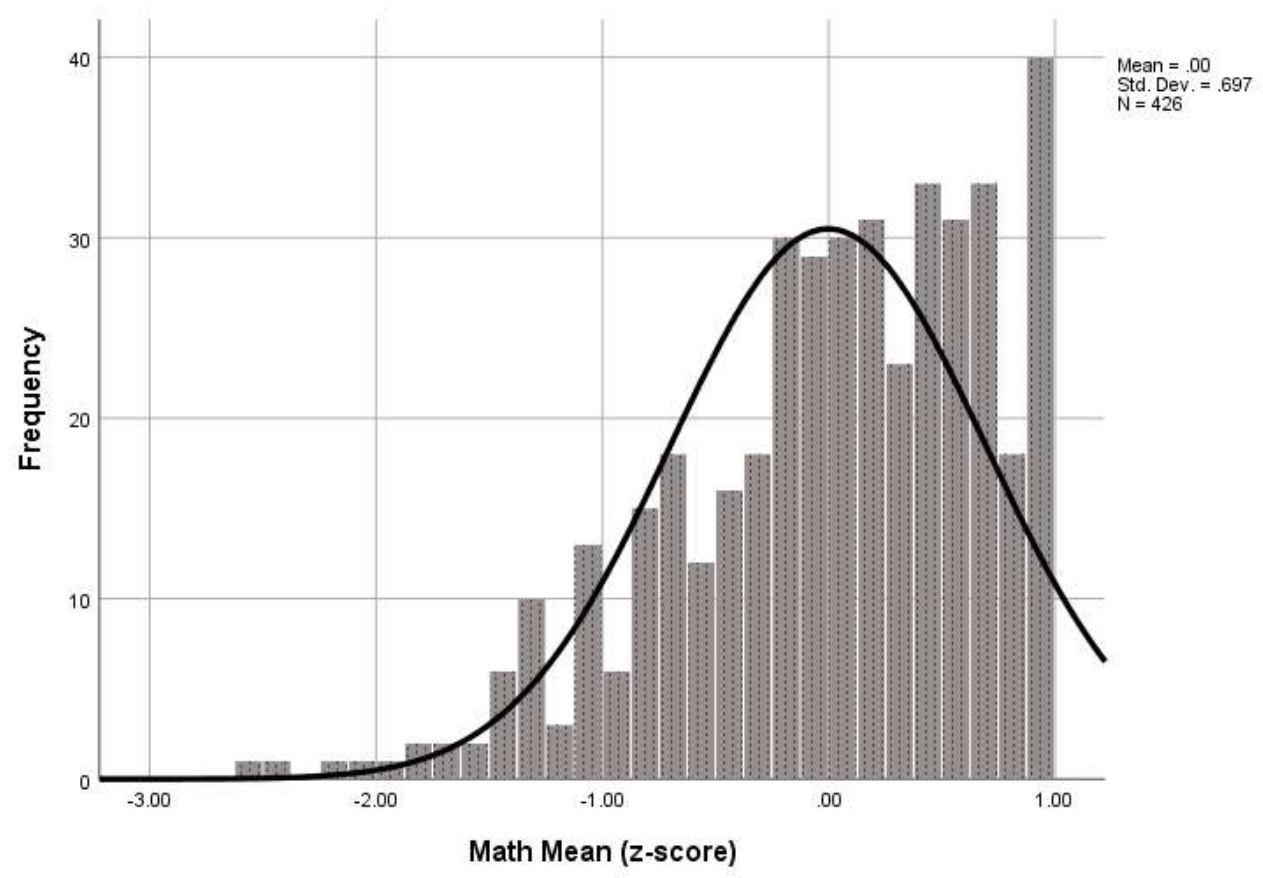

Figure 5. Histogram, with a negative skew, representing mean scores for participants on selfefficacy in math items.

Additionally, probability plots (both P-P and Q-Q) were run. These plots are helpful in finding deviations in the distributions of scores and, when used with histograms, help further understand normality of a data set (Tabachnick \& Fidell, 2013). Probability plots take every observed value in the data set and compare against a normal distribution with the same number of points allowing for a check for how close to expected values the data falls. P-P Plots are related to skew and the mean of the data set while Q-Q plots are concerned with data at the ends of the distributions. The plots confirm the information from the histograms indicating an ability to assume normality in the data.

Tests for homogeneity of variance. The data set were checked for homogeneity of variance using Levene's test in SPSS. The purpose of this test is to see if the data set 
meets the assumption that as levels in one variable change, the variance of the other variable remains stable. Results for the tests are in Table 5. In most cases, variances were equal across groups meaning the assumption of homogeneity of variance can be met for those groups. As noted in the table, Teaching Experience on the SCSE and Counseling Experience on the SCANA violate the assumption.

Table 5

Homogeneity of variance for SCANA and SCSE by groups

\begin{tabular}{lcclcc}
\hline & \multicolumn{2}{c}{ SCANA } & & \multicolumn{2}{c}{ SCSE } \\
\cline { 2 - 3 } \cline { 5 - 6 } Grouped Data & Levene Statistic & Sig. & & Levene Statistic & Sig. \\
\hline Gender is Female & $F(5,834)=1.764$ & .118 & & $F(5,834)=1.112$ & .352 \\
Level is Elem & $F(1,419)=1.096$ & .300 & & $F(1,419)=1.595$ & .207 \\
Caseload Size & $F(4,416)=2.149$ & .074 & & $F(4,416)=.760$ & .552 \\
Teaching Exp & $F(4,416)=.790$ & .532 & & $F(4,416)=2.985$ & $.019^{*}$ \\
Counseling Exp ${ }^{\text {a }}$ & $F(3,419)=3.030$ & $.029^{*}$ & & $F(3,419)=1.582$ & .193 \\
Participated in PD & $F(1,419)=.318$ & .573 & & $F(1,419)=1.564$ & .212 \\
\hline
\end{tabular}

${ }^{\text {a }}$ Participants with counseling experience greater than 32 years excluded from group as there were not enough in the sub-group for the Levene test.

$* \mathrm{p}<.05$

Field (2009) and Tabanchnick and Fidell (2013) indicate that a possible cause of this could be due to the larger sample size. The authors suggest a double check utilizing the $\mathrm{F}_{\mathrm{MAX}}$, or variance, ratio in these cases. The $\mathrm{F}_{\mathrm{MAX}}$ ratio is calculated by dividing the largest variance by the smallest. Then using the result, the group sizes, and the number of variances compared to determine the critical value (Field, 2009; Tabanchnick \& Field, 2013). Field (2009) has a table for critical values. Using that table, Teaching Experience as it relates to SCSE, the ratio is 1.8042 , with the large sized groups and 4 variances, the critical value - the value that the ratio cannot exceed - is 1.0. For Counseling Experience as it relates to SCANA, the ratio is 1.7916 with 5 variances. Again, the critical value is 
1.0. The FMAX ratio confirms Levene's test and these two portions of the data set do not conform to the assumption of stable variation. In contrast, Tabanchnick and Fidell (2013), suggest when group sizes are unequal, as they are in this data set, that a value for F MAX less than 10 is acceptable when the ratio of the group sizes with the largest and smallest variances has a ratio of 4 to 1 in size. For Teacher Experience, the group size ratio is 1.31. For Counselor Experience, the group size ratio is 1.24. By their metric, then, the FMAX ratio is within limits and the assumption of homogeneity is met.

Tests for multicollinearity. Multicollinearity, and the accompanying concept of singularity, are instances when variables are too highly correlated and, as such, become problematic in analysis due to redundancies (Field, 2009; Tabachnick \& Fidell, 2013). According to Field (2009), multicollinearity is determined by looking at the value of the variance inflation factor (VIF). In the process of running a simple regression model for participant SCSE totals and SCANA means - explained in a later section - the VIF was produced by SPSS. For these variables VIF was 1.000. Another check, called tolerance (1/VIF), was also 1.000. The levels for each of these, as stated by Field (2009) are such that multicollinearity was not found.

\section{Creating Dummy Variables to Support Analysis}

Utilizing guidance from Cohen, Cohen, West, and Aiken (2003), I created

dummy-variable coding systems for the categorical demographic variables of gender and grade level served to make them appear dichotomous in the statistical operations. New variables were also created for the categorical demographic variables of years of experience (both in teaching and counseling) as well as caseload size. This allows for the new variable to appear as a continuous variable. Means and the standard deviations of 
the descriptive statistics, as well as correlations between them are shown in Table 6 . Asterisks indicate significant correlations between variables in the table. As the legend indicates, some variables correlated at $p<.05$ with others correlating at $p<.01$.

Significant correlations of demographic statistics. Bivariate correlations were calculated using Pearson's r. On row 2 of Table $6, r=.49$ at the $\mathrm{p}<.01$ level indicating a significant, positive, relationship between the SCSE Total and SCANA Means for participants. Additional highlights from Table 6 include the significant correlations between Counselor Experience (measured in years) and SCSE Total $(r=.09, p<.05)$, Female participants $(\mathrm{r}=-.10, \mathrm{p}<.05)$, and Teaching Experience $(\mathrm{r}=.70, \mathrm{p}<.01)$. These values suggest a complex relationship between female counselors with experience in the counseling field and reports of school counseling self-efficacy.

Female participants also correlated in statistically significant ways with Elementary Level $(r=.11, p<.05)$ and High School Level $(r=-.11, p<.05)$. This suggests that more women are represented in the elementary schools than in high schools in the field of counseling. Elementary Level was significantly related to with Caseload Size $(r=.25, p<.01)$. Scores on the SCSE were significantly related to Teaching Experience, $r=.12$, and service in the high school level, $r=.13$ (all $p \mathrm{~s}<.01$ ).

Finally of note in Table 6 are the relationships between Math Self-Efficacy and Participation in Professional Development with other variables. There was a significant correlation between Math Self-Efficacy and SCSE Total $(r=.31)$, SCANA Mean $(r$ $=.45)$, and participation in professional development $(r=.15)$. The significance level of all three relationships was $p<.01$. Participation in training was also correlated with higher SCSE Totals $(r=.16, p<.01)$ and higher SCANA Means $(r=.28, p<.01)$. 
Table 6

Descriptive statistics and correlations

\begin{tabular}{|c|c|c|c|c|c|c|c|c|c|c|c|}
\hline & Mean & SD & 1 & 2 & 3 & 4 & 5 & 6 & 7 & 8 & 9 \\
\hline 1. SCSE Total & 183.9577 & 20.09022 & & & & & & & & & \\
\hline 2. SCANA Z Mean & -0.0016 & 0.63791 & $.497^{* *}$ & & & & & & & & \\
\hline 3. Gender is Female & 0.89 & 0.308 & -0.014 & -0.016 & & & & & & & \\
\hline 4. Level is Elementary & 0.4366 & 0.49655 & 0.075 & -0.072 & $.118^{*}$ & & & & & & \\
\hline 5. Level is High School & 0.1784 & 0.38330 & 0.008 & 0.011 & $-.119^{*}$ & $-.410^{* *}$ & & & & & \\
\hline 6. Caseload Size & 341.4692 & 98.37503 & 0.015 & -0.064 & -0.010 & $.257^{* *}$ & -0.088 & & & & \\
\hline 7. Teaching Exp & 15.4659 & 8.57524 & $.128^{* *}$ & 0.004 & -0.089 & 0.029 & $.132^{* *}$ & 0.079 & & & \\
\hline 8. Counseling Exp & 11.2906 & 7.74031 & $.095^{*}$ & -0.041 & $-.105^{*}$ & 0.024 & 0.069 & 0.081 & $.708^{* *}$ & & \\
\hline 9. Math Self-Efficacy & -0.0022 & 0.69673 & $.318^{* *}$ & $.454^{* *}$ & -0.077 & -0.081 & 0.010 & 0.042 & 0.046 & 0.036 & \\
\hline 10. Participated in PD & 0.26 & 0.441 & $.169^{* *}$ & $.288^{* *}$ & 0.032 & 0.001 & -0.028 & -0.030 & -0.038 & 0.019 & $.152^{* *}$ \\
\hline
\end{tabular}


It is important to note correlations are not causal relationships and should not be inferred at such (Field, 2009; Tabachnick \& Fidell, 2013). The information from the bivariate correlations further confirmed the data set to be appropriate for use in the proposed statistical analysis and to answer the research question posed.

\section{Research Questions}

This study has one primary research question with two additional sub-questions. The following section describes the data from the survey as it relates to these. Data to answer these questions, and the statistical operations to help understand the story of the data, are presented in the following sections.

\section{The Primary Research Question}

The central question of this study is: are there relationships between school counselor self-efficacy and the use of data to drive program advocacy and accountability? For this question the hypothesis set was:

1. $\mathrm{H}_{0}=$ No relationship exists between school counselor self-efficacy and the use of data to drive program advocacy and accountability.

2. $\mathrm{H}_{1}=\mathrm{A}$ relationship does exist between school counselor self-efficacy and the use of data to drive program advocacy and accountability.

Simple Regression. To understand my question, does self-efficacy in school counseling predict the use of data to promote program advocacy, I ran a simple regression using the participant totals on the School Counselor Self-Efficacy (SCSE, Bodenhorn \& Skaggs, 2005) scale as the independent variable and the participant means 
of the items included from the School Counselor Accountability Needs Assessment (SCANA, Young \& Kaffenburger, 2015) as the dependent variable.

In this simple regression, the participant's SCSE Total score was used to mirror the analysis performed by Bodenhorn and Skaggs (2005) as well as Mullen (2014). Young and Kaffenburger (2015) in their study analyzed data regressed on individual "data activities" rather than utilizing an overall total or mean score on the SCANA. For their purposes, "data activities" were defined with the wording of the SCANA items. It is important to note, as reported in Chapter 3, only 16 of the SCANA items were included: 15 of the items loaded into the factor called "Student Achievement" the other item was labeled "Instrument Development." Responses from participants on SCANA items, for this study, were converted to $z$-scores which, in turn, were averaged together across the 16 items to create a standardized mean response to be used for the initial simple regression calculations.

Regression is a statistical process that allows researchers to understand data linearly along a model of best fit (Field, 2009; Tabachnick \& Fidell, 2013). The model is based on the equation of a line where slope $\left(b_{1}\right)$, the direction or gradient of the line, and intercept $\left(b_{0}\right)$, where the line crosses the y (vertical) axis, position the data within the space of a plane. Utilizing the data from the participants of my study, a simple regression model allows predictions to be made based on knowing a person's total score on the SCSE. Equation 4 shows the equation for simple regression.

$$
\mathrm{Y}_{\mathrm{i}}=b_{0}+b_{1} \mathrm{X}_{\mathrm{i}}+\varepsilon_{\mathrm{i}}
$$


where $\mathrm{Y}_{\mathrm{i}}$ is the mean value on the SCANA, $\mathrm{X}_{\mathrm{i}}$ is the participant's total value on the $\mathrm{SCSE}$, and $\varepsilon_{\mathrm{i}}$ represents the residual difference between what is predicted and what is observed.

Table 7

Results for Simple Regression Analysis for Data Use Regressed on Self-Efficacy

\begin{tabular}{|c|c|c|c|}
\hline \multirow{2}{*}{ Model } & \multicolumn{2}{|c|}{ Unstandardized Coefficients } & \multirow{2}{*}{ Sig. } \\
\hline & B & Std. Error & \\
\hline (Intercept) & -2.906 & 0.248 & 0.000 \\
\hline Self-Efficacy & 0.016 & 0.001 & 0.000 \\
\hline
\end{tabular}

Using SPSS, I ran the simple regression as described. The equation of the model, based on my data set becomes: $Y_{i}=\left(-2.906+0.016 \mathrm{X}_{\mathrm{i}}\right)+\varepsilon_{\mathrm{i}}$. The intercept of the line is 2.906 which means when X (the participant's total value on SCSE) is 0 , the expected value of Y (mean value on SCANA) is -2.906 . Further, the slope of the model is 0.016 . As participants' total on the SCSE increases by one unit, the $z$-score mean on the SCANA increases by 0.0016 units. With significance set at the $p<.01$ level, these coefficients are statistically significant (Table 7).

The SCSE mean is based on ratings produced on a Likert scale of 1 to 5 with 1 being "Not Confident" and 5 indicating "Highly Confident." The SCANA's scale is 1 to 6 where 1 is "Never" and 6 is "Always." As indicated previously, I transformed participant scores on the SCANA into standardized z-scores and so the participant means on that scale are z-score means. This model suggests when a participant increases 1 unit in total SCSE score - indicating higher self-efficacy as a school counselor - the resulting 
change in the mean on the SCANA would increase .016 unit closer to "Always implementing data for program advocacy and accountability."

Overall, the basic model described by simple regression in this analysis significantly explains, at a $p<.001$ level, nearly a quarter of the variance $\left(\mathrm{R}^{2}=0.247\right)$ found in the mean of the SCANA as being connected to the total score from a participant's SCSE responses. The results suggest a positive relationship where as school counselors report higher levels of professional self-efficacy, the reported use of data for program advocacy and accountability increases at a rate of .016 . This allows for the rejection of the null hypotheses. There is, as seen through simple regression, a significant, positive relationship that exists between school counselor self-efficacy and the use of data to drive program advocacy and accountability. The variance explained is only $24.7 \%$ of the total variance so to consistently increase data use among school counselors, it is necessary to look at what other factors contribute to the variance and strengthen the model.

Sub-questions in the study. To advance the understanding of the primary question through the lens of Bandura's work, the two sub-questions for the study ask if specific experiences, as reported by the school counselors, contribute to the understanding of the relationship between self-efficacy and the use of data. To best answer this question, as outlined in Chapter 3, multiple regression was used.

In contrast to simple regression, multiple regression allows for the isolation of the relationship between dependent and independent variables separate from the effects of one or more other variables (Field, 2009; Tabachnick \& Fidell, 2013; Tolmie, Muijs, \& 
McAteer, 2011). These other variables are called co-variates. Equation 1, previously mentioned in Chapter 3 and shown again here, is the expression of multiple regression.

$$
\mathrm{Y}_{\mathrm{i}}=b_{0}+b_{1} \mathrm{X}_{1 \mathrm{i}}+b_{2} \mathrm{X}_{2 \mathrm{i}}+\ldots+b_{n} \mathrm{X}_{n i}+\varepsilon_{\mathrm{i}}
$$

$\mathrm{Y}_{\mathrm{i}}$ remains the outcome variable, or mean value on the SCANA, $b_{0}$ is the $\mathrm{Y}$ intercept when all $\mathrm{X}$ values are 0 , and all other $b$ s are the coefficient of the $\mathrm{X}$, or co-variate, that follows, and $\varepsilon_{\mathrm{i}}$ represents the residual difference between what is predicted and what is observed. Another term for $b_{1}, b_{2}, \ldots b_{n}$ is regression coefficients.

Multiple regression allows for an answer to the question: how does self-efficacy in school counseling contribute to the use of data, after accounting for some other measured quality (i.e., demographic characteristics, self-efficacy in math, and participation in professional development)?

Adding co-variates to the model. Following a sequential multiple regression strategy, the decision of when to include specific covariates was based upon Bandura's (1997, 2009, 2012) four builders of self-efficacy. Those were: (1) early mastery experiences, (2) observational learning, (3) social persuasion, and (4) process of choice. With this in mind, the covariates were added to the model to answer, does self-efficacy in school counseling predict the use of data to promote program advocacy, in the following order: (1) years in the field of education, (2) years as a school counselor, and (3) grade level served. The reasoning for this order, and the subsequent models, is that years of experience ties to Bandura's concept of early mastery experiences and for observational learning whereas grade level severed is a matter of choice of which the participant is an agent. Finally, data from this multiple regression analysis is reported with information about case load size and gender. 
Sequential multiple regression. Table 8 shows six models created through sequential multiple regression. The regression process was used to determine if the addition of demographic variables improved the prediction of SCANA mean over the use of SCSE Total score alone. After the variables were added to the model and the analysis was run in SPSS, assumptions were checked to insure none were violated: linear relationships were found in relevant variables, and homoscedasticity and multicollinearity were met. Case-wise diagnostics indicated two cases as potential outliers as the standardized residual for each case was just over -3 standard deviations. As the values are just barely out of the bounds set, the cases were kept. Next, five cases were identified as potential concerns for leverage points. In looking at the data more closely, these five cases were also kept. The cases had in common a response to the Gender question that was other than Male or Female. Cook's Distance, a measure of a specific case's influence on the results, were all within acceptable limits. Normality in distribution, as determined by histogram and P-P Plot of the standardized residual, was also met.

Changes in the model by adding demographic variables. The addition of demographic variables to the model contributed little in terms of the variability of SCANA scores (Table 8). From Model 1 to Model $6, \mathrm{R}^{2}$ changed .031 . That is, the variation of the SCANA mean that can be correlated to the various demographic variables is only $3.1 \%$. The full model with SCSE and all demographic variables (Model 6) was statistically significant, $\mathrm{R}^{2}=.287, \mathrm{~F}(13,407)=12.631, \mathrm{p}<.001$, adjusted $\mathrm{R}^{2}=$ .265 .

After adding demographic information to the model and controlling for their influence, the influence of the covariates of greater self-efficacy in mathematical 
Table 8

Sequential Multiple Regression Analysis Results for Data Use Regressed on Self-Efficacy

SCANA Mean

\begin{tabular}{|c|c|c|c|c|c|c|c|c|c|c|c|c|c|}
\hline \multirow[b]{2}{*}{ Model } & \multirow[b]{2}{*}{ Variable } & \multicolumn{2}{|c|}{ Model 1} & \multicolumn{2}{|c|}{ Model 2} & \multicolumn{2}{|c|}{ Model 3} & \multicolumn{2}{|c|}{ Model 4} & \multicolumn{2}{|c|}{ Model 5} & \multicolumn{2}{|c|}{ Model 6} \\
\hline & & B & $\begin{array}{c}\text { Std. } \\
\text { Error }\end{array}$ & B & $\begin{array}{c}\text { Std. } \\
\text { Error }\end{array}$ & B & $\begin{array}{c}\text { Std. } \\
\text { Error }\end{array}$ & B & $\begin{array}{c}\text { Std. } \\
\text { Error }\end{array}$ & B & $\begin{array}{c}\text { Std. } \\
\text { Error }\end{array}$ & B & $\begin{array}{c}\text { Std. } \\
\text { Error }\end{array}$ \\
\hline 1 & (Constant) & $-2.952 * *$ & 0.247 & $-2.928 * *$ & 0.248 & $-2.919 * *$ & 0.247 & $-3.034 * *$ & 0.254 & $-2.950 * *$ & 0.273 & $-2.969 * *$ & 0.273 \\
\hline & SCSE Total & $0.016 * *$ & 0.001 & $0.016^{* *}$ & 0.001 & $0.016^{* *}$ & 0.001 & $0.016 * *$ & 0.001 & $0.0164 * *$ & 0.001 & $0.016 * *$ & 0.001 \\
\hline 2 & Teach Exp & & & -0.004 & 0.003 & 0.001 & 0.004 & 0.001 & 0.004 & 0.001 & 0.004 & 0.001 & 0.004 \\
\hline 3 & Counsel Exp & & & & & -0.008 & 0.005 & -0.008 & 0.005 & -0.008 & 0.005 & -0.008 & 0.005 \\
\hline 4 & Middle & & & & & & & 0.135 & 0.079 & 0.129 & 0.079 & 0.125 & 0.079 \\
\hline & High & & & & & & & 0.101 & 0.076 & 0.089 & 0.077 & 0.085 & 0.079 \\
\hline & K12 & & & & & & & 0.206 & 0.111 & 0.180 & 0.115 & 0.176 & 0.116 \\
\hline & K8 & & & & & & & -0.008 & 0.152 & -0.020 & 0.153 & -0.022 & 0.153 \\
\hline & Other Level & & & & & & & $0.201 *$ & 0.086 & $0.189^{*}$ & 0.087 & $0.199 *$ & 0.088 \\
\hline 5 & Caseload & & & & & & & & & 0.000 & 0.000 & 0.000 & 0.000 \\
\hline 6 & Male & & & & & & & & & & & 0.018 & 0.095 \\
\hline & Non-Binary & & & & & & & & & & & -0.736 & 0.391 \\
\hline & $\begin{array}{l}\text { Self-Describe } \\
\text { Gender }\end{array}$ & & & & & & & & & & & 0.076 & 0.553 \\
\hline & $\begin{array}{l}\text { Not Say } \\
\text { Gender }\end{array}$ & & & & & & & & & & & -0.031 & 0.396 \\
\hline & $R^{2}$ & 0.256 & & 0.259 & & 0.264 & & 0.280 & & 0.281 & & 0.287 & \\
\hline & $F$ & $144.09 * *$ & & $73.15 * *$ & & $49.83 * *$ & & $20.014^{* *}$ & & $17.86^{* *}$ & & $12.63 * *$ & \\
\hline & $\Delta \mathrm{R}^{2}$ & 0.256 & & 0.003 & & 0.005 & & 0.016 & & 0.001 & & 0.006 & \\
\hline & $\Delta F$ & $144.08 * *$ & & 1.899 & & 2.628 & & 1.827 & & 0.716 & & 0.909 & \\
\hline
\end{tabular}

$* p<.05, * * p<.01$ 
processes and participation in professional development designed to support the use of data within a school counseling program was examined.

\section{Sub-Question One}

In addition to the primary research question, this study also examined the question: if a relationship does exist, does the direction and strength of the relationship change depending upon the self-efficacy of participants in mathematical processes? To help answer this question, items were included in the survey that loaded into two factors: (1) Statistical Comfort and (2) Computer Comfort.

Math items created for this study. Seven items related to math in general, statistical operations, and the maintenance of student data were created for this study. After data collection concluded with the participants for the study, a factor analysis was conducted using principal component analysis (PCA) with varimax rotation on the seven items (Table 3). Results from this analysis indicated sampling adequacy, Kaiser-MeyerOlkin (KMO) was .825 with individual KMO values greater than .74 which is above the accept limit of .5 (Field, 2009). According to Field (2009), the KMO test demonstrates a pattern of correlations in the data. Values in this statistic range from 0 to 1 . As they near 1, this indicates a tight correlation pattern and distinct and reliable factors. Bartlett's test of sphericity $\mathrm{X}^{2}(15)=1120.645, \mathrm{p}<.001$, indicated that items were correlated sufficiently for PCA. An initial analysis for eigenvalues was conducted. Two components had values over Kaiser's criterion of 1 and together explained $73.9 \%$ of the variance. The scree plot demonstrated a point of inflexion at two components confirming the result of the PCA. Table 9 shows the factor loadings after rotation. Items 2, 3, 4 and 7 loaded into Factor 1, which I labeled "Statistical Comfort" and items 5 and 6 loaded 
into Factor 2, called "Computer Comfort." Finally, a reliability analysis was conducted on these factors. The Statistical Comfort scale had a high reliability with a Cronbach's $\alpha$ $=.87$. The Computer Comfort scale, however, had low reliability, Cronbach's $\alpha=.59$. Due to the low reliability and the small number of items, I did not include items that loaded into Factor 2 in the analysis of data. Item 1, a general question about basic mathematical operations (see Table 3), was excluded after it did not load into either factor.

Table 9

Summary of exploratory factor analysis of items related to math $(n=428)$

\begin{tabular}{|c|c|c|c|}
\hline \multirow[b]{2}{*}{ Item } & \multirow[b]{2}{*}{$\mathrm{KMO}$} & \multicolumn{2}{|c|}{ Rotated Factor Loadings } \\
\hline & & $\begin{array}{l}\text { Statistical } \\
\text { Comfort }\end{array}$ & $\begin{array}{c}\text { Computer } \\
\text { Comfort }\end{array}$ \\
\hline $\begin{array}{l}\text { I can evaluate student data to choose the best statistical calculation } \\
\text { (e.g., mean, t-test, correlations) to interpret student data. }\end{array}$ & .828 & .86 & \\
\hline $\begin{array}{l}\text { I can calculate measures of central tendency (e.g., mean, median, } \\
\text { and mode) to interpret student data. }\end{array}$ & .860 & .80 & \\
\hline I can use t-tests to interpret student data. & .818 & .87 & \\
\hline $\begin{array}{l}\text { I can use computer programs (e.g. Word, Excel, Student } \\
\text { Information Systems) to support the management of student data. }\end{array}$ & .744 & & .89 \\
\hline $\begin{array}{l}\text { I can use computer programs (e.g., Excel, EZAnalyze, SPSS) to } \\
\text { support the statistical analysis of student data. }\end{array}$ & .781 & & .77 \\
\hline $\begin{array}{l}\text { I can explain the results of statistical operations to parents, } \\
\text { administration, community members, and other stakeholders. }\end{array}$ & .870 & .70 & \\
\hline Eigenvalues & & 3.41 & 1.01 \\
\hline Percent of variance & & $56.9 \%$ & $16.9 \%$ \\
\hline A & & .87 & .59 \\
\hline
\end{tabular}

As with the scores calculated for the SCANA, I calculated scores for participants on the Statistical Comfort items. Participants rated their beliefs in their abilities on a 
scale of 1 to 5 with 1 meaning "Cannot do at all" and a 5 meaning "Highly certain I can do." The mean score for the participants $(n=428)$ was 3.72 with a standard deviation of 0.91 and a range in mean scores of 1.0 to 5.0 .

Continuing the sequential multiple regression process, the mean score on participants' responses to the survey items dealing with self-efficacy in math was added to the model. Table 10 contains the results of the analysis.

Table 10

Regression Analysis Results for Data Use Regressed on Self-Efficacy with Math and PD

\begin{tabular}{|c|c|c|c|c|c|c|c|}
\hline \multirow[b]{2}{*}{ Model } & \multirow[b]{2}{*}{ Variable } & \multicolumn{2}{|c|}{ Model 6} & \multicolumn{2}{|c|}{ Model 7} & \multicolumn{2}{|c|}{ Model 8} \\
\hline & & B & $\begin{array}{c}\text { Std. } \\
\text { Error }\end{array}$ & B & $\begin{array}{c}\text { Std. } \\
\text { Error }\end{array}$ & B & $\begin{array}{c}\text { Std. } \\
\text { Error }\end{array}$ \\
\hline \multirow[t]{2}{*}{1} & (Constant) & $-2.969 * *$ & 0.273 & $-2.297^{* *}$ & 0.273 & $-1.981 * *$ & 0.276 \\
\hline & SCSE Total & $0.016^{* *}$ & 0.001 & "0.013** & 0.001 & $0.013^{* *}$ & 0.001 \\
\hline 2 & Teach Exp & 0.001 & 0.004 & 0.001 & 0.004 & 0.003 & 0.004 \\
\hline 3 & Counsel Exp & -0.008 & 0.005 & -0.008 & 0.005 & $-0.009 *$ & 0.005 \\
\hline \multirow[t]{5}{*}{4} & Middle & 0.125 & 0.079 & 0.087 & 0.075 & 0.082 & 0.073 \\
\hline & High & 0.085 & 0.079 & 0.058 & 0.074 & 0.066 & 0.072 \\
\hline & $\mathrm{K} 12$ & 0.176 & 0.116 & 0.085 & 0.110 & 0.103 & 0.107 \\
\hline & $\mathrm{K} 8$ & -0.022 & 0.153 & -0.005 & 0.144 & -0.008 & 0.141 \\
\hline & Other Level & $0.199^{*}$ & 0.088 & 0.136 & 0.083 & 0.128 & 0.081 \\
\hline 5 & Caseload & 0.000 & 0.000 & 0.000 & 0.000 & 0.000 & 0.000 \\
\hline \multirow[t]{4}{*}{6} & Male & 0.018 & 0.095 & -0.022 & 0.089 & -0.005 & 0.087 \\
\hline & Non-Binary & -0.736 & 0.391 & -0.550 & 0.369 & -0.476 & 0.361 \\
\hline & Self-Describe Gender & 0.076 & 0.553 & -0.148 & 0.521 & -0.342 & 0.511 \\
\hline & Not Say Gender & -0.031 & 0.396 & 0.132 & 0.373 & 0.057 & 0.365 \\
\hline 7 & Math Self-Efficacy & & & $0.286^{* *}$ & 0.039 & $0.267^{* *}$ & 0.038 \\
\hline 8 & $\begin{array}{l}\text { Did Not Participate in } \\
\text { PD }\end{array}$ & & & & & $-0.257 * *$ & 0.057 \\
\hline & $R^{2}$ & 0.287 & & 0.370 & & 0.400 & \\
\hline & $F$ & $12.63 * *$ & & $17.04^{* *}$ & & $17.99 * *$ & \\
\hline & $\Delta \mathrm{R}^{2}$ & 0.006 & & 0.083 & & 0.030 & \\
\hline & $\Delta F$ & 0.909 & & $53.242 * *$ & & $20.088 * *$ & \\
\hline
\end{tabular}

\footnotetext{
$* p<.05, * * p<.01$
} 
By adding the mean of the Math Self-Efficacy Items to the model led to a statistically significant increase in $R^{2}$ of $.083, F(1,406)=53.242, p<.01$. A one-unit change in a counselor's self-efficacy in math results in an increase of SCANA Mean by 0.286 units.

\section{Sub-Question Two}

The final aspect of the question examined in this study was: does the direction and strength of the relationship, if one is found to be present, change depending upon the experience of professional development focused on the topic of data use. The simple regression demonstrated that a relationship between school counselor self-efficacy and use of data is present in this data set. For the final step of the sequential multiple regression, participation in targeted professional development was added to the model. Model 8 further increases $R^{2}$ in a statistically significant way by $.03, F(1,405)=20.088$, $p<.01$. This means participating in professional development that is perceived to be related to data use for program advocacy is correlated with an increase in SCANA Mean by .257 units. Additionally, Model 8 accounts for $40 \%$ of the variation in SCANA which indicates other variables, not measured in this study, contribute to the use of data for school counselors.

\section{Qualitative Data}

While this study was not designed as a mixed-methods project, in addition to the quantitative data analyzed by regression, the survey included three free-response, shortanswer items supplying qualitative data (see Table 11, Appendix B). 
Table 11

Free-response items included in the survey

Item

What data do you rely on the most to improve your school counseling services?

Briefly describe who you collaborate with most often.

If participant responded "Yes" to participating in PD:

Please explain what was the title or scope of the professional development training.

Note. These items came from Young and Kaffenburger (2015).

These data were examined and coded using principles and methods from grounded theory construction (Birks \& Mills, 2011; Charmaz, 2006; Mertens, 2010; Stern \& Porr, 2011).

Common themes, ideas, or topics were created by going through each participant's freeresponse and combining responses with common key words or concepts.

\section{Types of Data Used}

After answering the SCSE and SCANA items, participants indicated, through free-response, what types of data they used most often within the school counseling program. Table 12 displays the information provided by participants and is organized by larger categories of student information, survey data, testing data, data related to student outcomes, data to examine intervention effectiveness, and process data. As noted in the table, participants often identified multiple types of data used within the school counseling program. On this item, 366 participants responded with some type of data identified. The average number of data types identified was 2.76 with a range of 1-10. The mode number of data types was 1 with a median of 2 types of data.

The categories of data displayed in Table 12 show a wide variety of information types that school counselors use to shape the program within the schools in Missouri. 
These data are used to determine needs within a program to design services, measure effectiveness of these services/interventions, and also describe the program to all

Table 12

Types of Data School Counselors Rely On

\begin{tabular}{|c|c|}
\hline & $\mathrm{n}$ \\
\hline \multicolumn{2}{|l|}{ Student Information } \\
\hline Attendance & 88 \\
\hline Behavior & 98 \\
\hline Gradebook/Assignments & 7 \\
\hline Race/Ethnicity & 18 \\
\hline Report Card/Transcript & 84 \\
\hline Socio-Economic Status & 18 \\
\hline \multicolumn{2}{|l|}{ Survey } \\
\hline Anecdotal Information (Informal) & 21 \\
\hline Parent & 98 \\
\hline Referrals & 39 \\
\hline Staff & 116 \\
\hline Student & 127 \\
\hline Student Screening Tools & 14 \\
\hline \multicolumn{2}{|l|}{ Testing } \\
\hline District & 40 \\
\hline Special Education & 3 \\
\hline State & 46 \\
\hline \multicolumn{2}{|l|}{ Outcome } \\
\hline College/Career Readiness & 7 \\
\hline Graduation Rates & 7 \\
\hline \multicolumn{2}{|l|}{ Intervention } \\
\hline Pre-Test & 34 \\
\hline Post-Test & 65 \\
\hline Observations & 14 \\
\hline \multicolumn{2}{|l|}{ Process } \\
\hline Check In Sheet & 1 \\
\hline Counselor Experience & 3 \\
\hline Internal Improvement Review & 15 \\
\hline Time on Task & 18 \\
\hline Other & 38 \\
\hline Nothing & 5 \\
\hline No Response & 61 \\
\hline
\end{tabular}


stakeholders. Data of the types found in this table are used at the individual, small group, and building/district levels. Student surveys comprise the largest type of data used by school counselors.

As seen in Table 12, school counselors utilized a wide variety of types of data. Some of the data like those found under Student Information are more demographic data points that are retrieved from student information systems in most schools. Other types of data like those found under Intervention and Process categories, are reliant upon school counselor creation of data tracking tools. For the data points shown under Intervention, for example, counselors typically create instruments for pre- and postsurvey of each lesson or intervention on their own. When created by the school counselor, the reliability and validity of such surveys may be vastly divergent depending upon the training and confidence of the school counselor. Some interventions, specifically those that are established, evidence-based practices, come with standardized pre- and post- measures for counselors to use. Under the Process category it is interesting to note the number of school counselors utilizing the Internal Improvement Review (IIR) as a data point for their program. The IIR is a Missouri Department of Elementary and Secondary Education created document designed to measure the effectiveness and degree of implementation of a school counseling program within the public schools in the state (DESE, 2020). Of the total participants of the study ( $\mathrm{n}=426)$, only 15 , or $3.5 \%$, indicated the IIR as a data they rely upon.

Opinions, thoughts, and feelings shared on data type question. As freeresponse items, each participant shared information without the constraints of a 
standardized format. While most participants gave specific answers to the question, participants could also comment with thoughts, opinions, and feelings related to the question in particular and the study or practice of data use in general.

In response to the first question, what types of data do you rely on as a school counselor, there were a few comments that deviated from the categorical responses. Quotes from these participants are in Table 13.

Quotes from individual participants that were beyond the labeling of data types fell into five themes: (1) Confidence, (2) Professional Instinct, (3) Qualitative Data, (4) Reliance on Others, and (5) Specific Plans for Data. These 15 responses shown in Table 13 indicate the narrative of school counselors as they relate to data. It is key to recall these items were presented after all Likert items of the survey. There are positive, negative, and neutral emotions captured in the table.

In the theme called Professional Instinct, one participant referred to membership within the national professional organization and how that contributes to their understanding of what data to use and when. The other four responses highlighted in this theme could, perhaps, be labeled as "gut instinct" or "intuition." One participant said, "I do not have time to bury myself in data. I can look in a kids eyes and tell when there is a problem. I can not do that sitting at my computer analyzing data." These four responses read, at least partially, with a negative impression connected to the use of data within a school counseling program. 
Table 13

Qualitative responses indicating opinion, thought, or feeling of school counselor

\begin{tabular}{ll}
\hline Theme & Participant Response \\
\hline Confidence $(n=1)$ & $\begin{array}{l}\text { I am not confident about how to select which statistical measure to use } \\
\text { to ensure validity and reliability. }\end{array}$ \\
Professional Instinct $(\mathrm{n}=5)$ & $\begin{array}{l}\text { As a member of ASCA, I research effective ways to handle } \\
\text { counseling related issues. Support Team meetings are held each } \\
\text { month to discuss individual student data of struggling students. }\end{array}$ \\
& $\begin{array}{l}\text { Based on what I have learned works best for students over the past } 11 \\
\text { years }\end{array}$
\end{tabular}

Creating relationships with all of my students. I do not have time to bury myself in data. I can look in a kids eyes and tell when there is a problem. I can not do that sitting at my computer analyzing data.

My knowledge and experience in building student rapport

Trial and Error.

Qualitative Data $(\mathrm{n}=1) \quad$ I rely more on qualitative data (reports of improvement from teachers, students, parents, etc.) more than quantitative data.

Reliance on Others ( $\mathrm{n}=4) \quad$ I count on our building director to interpret relevant data and share with our team rather than analyzing it personally.

I rely heavily on data reports which are ran and analyzed by another school employee. We do not run our own data reports.

The teachers telling me what the needs are for their students.

We give a climate survey twice a year-all counselors in our district give the same one. The data is reviewed but nothing is ever done with the information at the building or district level.

Specific Plans for Data

I look at a correlation between tier 2 students and their attendance and $(n=4)$ try to bridge that gap through individual counseling to improve attendance, academics and behaviors

I look at academic data, such as, report card grades, progress monitoring of skills, and formal assessments. I look at formal behavior screeners and progress monitor weekly. I look at office discipline data. Graphs based off of research based behavior interventions.

I set goals at the beginning of a school year to address the needs of the students. This is done by collaborating with the previous building and learning about the students, forming relationships with them through the mentor program that we established two years ago.

Typically grades, attendance, starting to use surveys a lot more, and looking at time/task data. Will also try to get reviews/feedback from all presentations. 
Four participants, as seen in Table 13, rely upon others to run data and reports related to students and the school counseling program. The participants diverge at that point on who conducts the interpretation of those reports with some school counselors being active and analysts of the data while others are more consumers of the data reports. One participant noted that nothing is done with the data at the building or district level even as it is collected twice yearly.

Finally, four counselors in their response to the first free-response item, indicated a detailed and specific plan for utilizing data within the school counseling program. These plans identified the comparing of data from both quantitative Student Information sources and Testing as well as qualitative data in the form of perceptual data from students, teachers, and other stakeholders. One participant specifically mentioned using data as a way to set goals and determine program outcomes.

\section{Collaborative Relationships}

In the second free-responses item, participants $(\mathrm{n}=410)$ responded with the groups most often participating in collaboration with them. Table 14 displays the responses, grouped by colleagues within the school counselor's building, colleagues outside of a particular building, and other stakeholders. 
Table 14

Who School Counselors Collaborate with by Group

Colleagues within building

Administrators 262

Counselors/Social Workers 198

Nurse 11

Special Education Department 26

Student Services Team 20

Support Staff 9

Teachers 185

Colleagues outside of building

Counselors in other districts 9

Outside Agencies 11

Stakeholders

Parents/Families $\quad 40$

Students 18

Other collaborators $\quad 17$

Note. Participants answered with a free-response and could identify several groups of collaborators.

Collaboration, as seen in this table, is wide-ranging. Counselors make connections with partners in various areas of influence to help inform the counseling program within the school. This table highlights other professionals within the school culture as well as stakeholders who are consumers of the counseling program. School counselors identified an average of 1.97 collaborative group types. Administrators, other counselors, and teachers are the main types of people school counselors identified.

\section{Types of Professional Development}

Participants were asked if, in the previous 12 months, they participated in professional development related to using data and accountability strategies. Those who responded with "Yes" were further asked to explain the scope of, or provide the title for, the professional development. Of the participants, 112 , or $26.2 \%$, responded in the affirmative. Ninety-one of the school counselors provided information regarding the 
training. Within the answers provided by school counselors there were two types of data contained in many of the responses. First, some counselors identified the location of the professional development session(s). Then, some counselors identified the topic, or scope, of the training. Many responses contained both pieces of information which were tabulated into categories.

Where school counselors receive professional development. Many of those responding to the follow-up question included information about the location or host of professional development. Table 15 shows the various locations.

Table 15

Where Professional Development Occurred

\begin{tabular}{lr} 
Graduate School & 6 \\
Building/District & 31 \\
State or National School Counselor Conference & 25 \\
Other Conference & 9 \\
Other & 16 \\
Don't remember & 4 \\
No response & 20 \\
\hline
\end{tabular}

Note. Of the 112 indicating "Yes" to the PD question, for this item $\mathrm{n}=92$; some gave more than one answer

The most often cited location for professional development was within the school counselor's own building or district. A close second was training provided through state or national school counselor conferences.

Professional development topic and scope. Of the 91 school counselors who responded to the question about topic and scope of professional development, several common themes of training appeared. These topics are shown in Table 16. 
Table 16

Topic or Focus of Professional Development

\begin{tabular}{lr}
\hline Achievement Gap & 2 \\
Annual Performance Report & 4 \\
ASCA Data Specialist Training & 2 \\
Attendance & 2 \\
Behavior Intervention Support Team & 8 \\
Data Collection for Program Support & 13 \\
Outcome Data on Interventions & 9 \\
Specific Computer Program & 11 \\
Student Learning Objectives/Assessment & 5 \\
Testing & 4 \\
Nothing Specified & 33 \\
\hline
\end{tabular}

Note. Of the 112 indicating "Yes" to the PD question, for this item $\mathrm{n}=92$; some gave more than one answer

The largest group of participants responded without giving a specific topic or indicated they did not recall the title or scope $(n=33)$. Of the remaining counselors, the trainings with the highest level of participation were focused on data collection as it relates to program support and training on specific computer programs that either house student data or can be used in the collection and analysis of data. Counselors also report attending professional development on tracking outcome data for interventions specifically as it related to students with suicidal or self-harm tendencies.

\section{Summary}

In the spring of 2018, 426 school counselors in the State of Missouri responded to a request for a survey regarding their professional self-efficacy beliefs and practices. Through both simple and sequential multiple regression, this chapter shared the findings of those survey responses. Descriptive statistics placed the participants in the survey in context. Factorial analysis was also conducted on items created for this study. Finally, 
findings related to the primary research question as well as the two sub-questions were discussed. For the primary research question, the null hypothesis was rejected, and the alternate hypothesis was accepted. This indicates that there is a positive relationship between school counselor self-efficacy and the use of data. Further, multiple regression indicates a relationship between the use of data in school counseling programs with the counselor's self-efficacy in math and their participation in targeted professional development. Additionally, qualitative data, collected through free-response questions were presented for additional depth in the analysis. 


\section{CHAPTER 5: DISCUSSION, CONCLUSIONS, AND IMPLICATIONS}

With a rich and long history, the school counseling profession in the United States is a specialized field within education focused on the welfare of children and adolescents within the areas of academic support, social and emotional learning, and career development. School counselors operate within schools as educational leaders, advocates, and clinicians. The history of the profession parallels the educational reform movements in the United States. Most recently, educational reform is seen in the form of executive reauthorization of the Elementary and Secondary Education Act ([ESEA], 1965). In 2015, the Every Student Succeeds Act (ESSA), passed and is the current understanding of educational accountability law.

It is within an understanding of ESSA as the litmus for measuring student proficiency and the health of school districts this study is grounded. ESSA requires the examination of student and school level data to set goals and develop programs and strategies to increase the proficiency of all students (Education Trust, 2016b; ESSA, 2015; Klein, 2015). School counselor training programs, certification requirements, and the American School Counselor Association (ASCA) National Model (2012), focus on the use of data to address the same questions and challenges as ESSA while simultaneously contributing to the health and development of a comprehensive school counseling program (Adelman \& Taylor, 2002; ASCA, 2012; Carey \& Dimmitt, 2006; Council for Accreditation of Counseling \& Related Educational Programs, 2016; Dahir \& Stone, 2009; Dimmitt \& Carey, 2007; Erford, House, \& Martin, 2003; House \& Hayes, 2002; Militello \& Janson, 2014). 
Yet, with the calls from the federal government to produce information about the proficiency levels of students alongside the academic community promoting the utilization of data to support the growth and development of students as well as the comprehensive school counseling program, several studies (Astramovich \& Corker, 2007; Dahir \& Stone, 2009; Dimmitt, 2009; Mitiello \& Janson, 2014) indicate current practice for school counselors does not include a prevalence of data use. These studies looked to possible reasons as to why school counselors do not include a consistent use of data within their program development and advocacy. One suggestion was the selfefficacy of school counselors.

The purpose of this quantitative survey study is to examine if there is a relationship between school counselor self-efficacy and school counselor's utilization of data to support a comprehensive school counseling program. Bodenhorn and Skaggs (2005) developed a scale to measure general self-efficacy of school counselors. This scale, SCSE, combined with several items from Young and Kaffenberger's (2015) SCANA - designed to assess the use of data in school counseling programs - are the foundational elements of the present study's data collection.

\section{Interpretation of Findings}

At a preliminary level, the results of this study suggest a positive relationship exists between a school counselor's self-efficacy and their reported use of data within their counseling program. Pulling the results to the additional questions of specific experiences, expands the model to encompass an understanding that mirrors the work of Bandura $(1977,1986,1993,1995,1997,2000,2001,2006,2009,2012)$ as well as 
Bodenhorn, Wolfe, and Airen (2010). That is, the results further indicate this correlation supports the notion that self-efficaciousness in professional identities is created through a specific exposure of the person to a variety of experiences: (1) early mastery experiences, (2) observational learning, (3) social persuasion, and (4) process of choice.

\section{Primary Research Question}

The focal research question of this study was: are there relationships between school counselor self-efficacy and the use of data to drive program advocacy and accountability? The simple regression model, as described in Chapter 4, indicates selfefficacy is responsible for nearly a quarter of the variance found in the use of data by school counselors.

This result, and the subsequent ability to reject the null hypothesis, is not surprising. In the simple regression model, the participant's score on the SCSE - a tool designed to measure self-efficacy in school counselors - is the independent variable used. The simple regression, then, in some ways, confirms the analysis completed by Bodenhorn and Skaggs (2005) when creating the SCSE as a valid and reliable instrument and then correlates that response to a positive change in a school counselor's report on data use. Further, it stands to reason, given Bandura's (1993, 1995, 1997, 2009) framework of efficacy builders, that a person identified as a school counselor would report self-efficaciousness around the qualities and activities ascribed to the role of school counselor. School counselor training programs, especially those governed by CACREP (2016) competencies and/or steeped in understanding of the ASCA National Model (2012), would necessarily provide mastery experiences, opportunities for observational learning, and social persuasion through evaluation in coursework and 
practicum experiences. In the end, however, simple regression only describes a small amount of variance and does not provide a rich understanding of the relationship of school counselors to the utilization of data within a program. With only a quarter of the variance explained in the model, looking at other factors is necessary.

\section{Self-Efficacy in Mathematical Concepts}

An additional question, to further understand the relationship between school counselor professional efficacy and the use of data within their program was: does the direction and strength of the relationship, if one was found to be present, change with higher levels of self-reported self-efficacy in mathematical processes?. To answer this question, multiple linear regression was used. Inclusion of this question extends Bandura's $(1993,1995,1997,2009)$ theoretical framework. Specifically, multiple regression allowed for additional consideration of the four builders of self-efficacy as noted by Bandura (1997, 2009, 2012). Those were: (1) early mastery experiences, (2) observational learning, (3) social persuasion, and (4) process of choice.

In looking at the simple regression results, it stands to reason that participant scores were influenced by the self-efficacy builder of social persuasion. The training covered in graduate school for school counselors focused on the competencies of CACREP (e.g., design and evaluation of school counseling program, use of accountability data to inform decision making, use of data to advocate for program and students), could influence participant responses to the SCANA and the SCSE. That is, school counselors "know" the right answers to questions about their duties and activities that will show their skill in a positive light, but when the model includes participant responses to the items about mathematical concepts, do early mastery experience - and 
subsequent self-efficacy around the concepts - hold a greater amount of sway in the results and ultimate variance in the model? Perhaps school counselors, when presented with the math items, become more open and reflective about personal strengths in the specific skills presented rather than presenting the "right" responses. In Bandura's (1977, 1986) Social Learning Theory - which became Social Cognitive Theory with the inclusion of self-efficacy in his theory - the author describes other constructs necessary to help shape human behavior. In looking at school counselors and their professional self-efficacy, the addition of the math items adds a layer of previous experiences that may influence the relationship to how they use data within their program.

Social Cognitive Theory, as shown in Chapter 2, contains six constructs: (1) reciprocal determinism, (2) behavioral capability, (3) observational learning, (4) reinforcements, (5) expectations of behavior, and (6) self-efficacy. It is the school counselor's behavioral capability - their actual ability - in mathematics combined with the elements of self-efficacy that are measured with the seven items created for the present study.

When added to the model, through multiple regression, school counselor's responses to the math self-efficacy items led to a statistically significant increase in $R^{2}$ of $.083, F(1,406)=53.242, p<.01$. A one-unit change in a counselor's self-efficacy in math results in an increase of SCANA Mean by 0.286 units. The model now described $37 \%$ of the variance.

\section{Participation in Targeted Professional Development}

Finally, the additional question regarding participation in professional development was: does the direction and strength of the relationship, if one was found to 
be present, change depending upon the experience of professional development focused on the topic of data use? This question, again, connects directly to Bandura's (1997, 2001, 2009, 2012) understanding of how self-efficacy is constructed. Specifically, professional development provides not only observational learning experiences where school counselors are able to view the results of another person's use of data and make connections on how using a similar process could benefit professional growth, but training opportunities also expose participants to social persuasion. It is the combination of seeing how the use of data might work to improve one's practice as a school counselor with the added persuasion and pressure within the training session and any resulting sessions where the school counselor must report on their learning, that the self-efficacy around the topic of professional development increases.

Additionally, looking again to Bandura's Social Cognitive Theory $(1977,1986)$, professional development experiences also provide reinforcements and expectations to the participant. In the theory, reinforcements of behavior are those internal and/or external responses that serve as a mechanism to support the continuance or extinction of a particular behavior. Considering the participation of school counselors in professional development in this light, gives an added depth. Counselors who learn more about data use could, in an environment that nurtures the use of data for evaluation and advocacy, lead to reinforcements that continue the use of data. In the climate of accountability as seen in the reauthorizations of the ESEA (1965), the environment is, at a macro level, designed to support the continuing behavior of data utilization. Expectations, as viewed in Bandura's Social Cognitive Theory $(1977,1986)$, are those consequences that people anticipate given previous experiences. This also connects to the participation in targeted 
professional development for school counselors. As counselors experience professional development and the subsequent reinforcements, the expectation of the counselor on what consequences will occur is also set. School counselors who observe the changes made by colleagues and peers after a training session, or reflect on personal past experiences of the same, can reasonably predict an outcome of their own actions as they continue to utilize data for program advocacy and evaluation.

In this study, the addition of participation in professional development experiences targeted to school counselor data use described an additional $3 \%$ of the variance in the model. This result was statistically significant at the $p<.01$ level and takes the total amount of variance of the responses to the SCANA explained through multiple regression to $40 \%$.

\section{More than Half of the Variance Remains Unattributed}

Even with statistically significant results that account for $40 \%$ of the variance, the model is incomplete. What about the other $60 \%$ of the variance? What could the lack of results mean? Participants, in addition to the Likert items of the SCANA, SCSE, and Math Self-Efficacy items, responded to open-ended questions as noted in Chapter 4. The responses to these questions are instructive on where additional sources of variance may be located and can lead to further understands of practice and research.

\section{Targeted professional development, diverse collaboration, and identified}

data types. In the qualitative data collected from participants, several themes presented and could add depth to the understanding of the model. School counselors identified 10 professional development training topics related to data use (see Table 16) hosted in five different location types (see Table 15) as well as 12 different groups of professionals with 
whom the counselor collaborates (see Table 14). The variety found in these tables would, necessarily, contribute to the understanding of why school counselors do or do not utilize data within their program. Perhaps even more explanatory is that of the total participants ( $\mathrm{n}=426$ ), nearly $74 \%$ report not attending training focused on data use in the previous 12 months.

Bandura's $(1997,2001,2009,2012)$ notions of self-efficacy and agentic behavior are seen in these data too. His contention of observational experiences with social persuasion as being key elements to the formation of professional self-efficacy can be observed in the responses provided by school counselors to these questions. In Table 13, the quotes from participants who identified a reliance on others to collect and analyze data are informative here. School counselors in these situations may not feel the control over their own context that Bandura indicates as an essential part of self-efficacy.

Additionally, self-efficacy contributes to the concept of mindset (Bandura 1997, 2001, 2009, 2012). While measured through the responses to all Likert items, a complete understanding of school counselor mindset is not captured in this study. Again, in Table 13 participant responses to free-response items indicating opinion, thought, or feeling of school counselor were highlighted. Understanding the remaining variance in this model could be based upon the comments in that table. Specifically looking at the correlating demographic data of counselors who identify "Professional Instinct" as a method of data collection could show additional dimensions to the model. 


\section{Implications for Practice}

The findings of this study indicate a few interesting implications for practice. The next section highlights these implications. Practice for school counselors as well as those involved in the training and evaluation of school counselors is addressed. Finally, implications for how the findings of this study might connect to school counselor advocacy groups as well as opportunities for leadership within the profession.

\section{Individual School Counselor Practice}

School counselors reflecting upon personal practice could see the results of this study and consider professional self-efficacy as it relates to program goals and advocacy efforts. Specifically, school counselors can examine self-efficacy within mathematical concepts, the utilization of professional development to understand the importance of -and support the tasks related to -- utilization of data within a school counseling program, develop personal development plans to maintain skills within this area, and seek out accountability partners who support the use of data within the comprehensive school counseling program.

Training in math self-efficacy as well as the utilization of data for school counseling begins in the counselor educator programs. Participants in this study indicated graduate school as the last time they received training on these topics. School counselors can seek ways to continue this professional development through continuing education opportunities. Participants in this study indicated building and district professional development as being supportive of the practice of using data within school improvement. Some indicated that this type of training was typically targeted for other professionals within the building and not easily transferable to school counselors. If this 
is the case, counselors should advocate for sessions that are targeted to their unique concerns.

Additionally, professional development that focuses on the ways in which school counselors can use data within a school and a program to ultimately advocate for students and the profession, while supporting the accountability efforts of the school and/or district for which they serve is needed. This professional development would center on topics of why, when, and how to use data as well as the communication piece that is necessary. In this type of training, school counselors would learn skills in the collection, interpretation, and communication of data.

Professional development with these topics can occur at all levels and locations. Given the information provided by participants in this study, trainings located within a counselor's building or district would have the greatest impact. In Missouri, this is followed by targeted professional development hosted by the state professional organization. Currently there are a handful of nationally recognized training opportunities that align with this vision. One, sponsored by ASCA, is a virtual training program available to all school counselors. Completion of the training results in a certification that counselors can add to their resume. Another, connected to researcher and speaker Trish Hatch, offers an annual conference and online trainings as well as facilitators for buildings and districts (Hatching Results, 2020).

\section{Implications for Those Involved in Training School Counselors}

School counselor educators as well as those practicing professionals who support interns and newly certified professionals could find guidance within the results of this study. If, as Astramoich and Coker (2007) posit, one element of why school counselors 
do not use data relates to a lack of confidence, then Bandura's (1997, 2002, 2012) response would be to look at the ways self-efficacy is established and supported. Then provide those environments and contexts to build school counselor self-efficacy. The results of this study would indicate this is an appropriate direction given the $3 \%$ of the variance explained through targeted professional development. School counselor educators and mentors for new professionals could examine additional, orchestrated experiences that could support the continued development of self-efficacy in school counselors as it supports the use of data within the program. Doing so would foster early mastery experiences, the foundation of self-efficacy, as well as provide the necessary social persuasion through collegial reflection and evaluation during practicum experiences (Bandura, 1977; 1986; 1993; 1995; 1997).

\section{Implications for Those Working Alongside School Counselors}

All signs point to a continued emphasis on accountability measures for schools in the United States. Those persons collaborating with, and evaluating the professional lives of, should take note of the findings in this study for at least two reasons: (1) to be aware of the ways mastery experiences, as seen in teaching and counseling experience, inform the utilization of data within a school program and (2) support the growth of school counselors through professional development.

Both of these reasons, supported in Bandura's $(1993,1995,1997)$ conceptualization of the development of self-efficacy, allow an administrator and/or counselor leader to utilize the instruments in the present study to perform a survey of practicing counselors and use that data for specific and targeted professional development for a particular department or counselor. This would allow for a drill-down to learn what 
areas a particular counselor's beliefs may lead to greater or lesser self-efficacy in their professional lives. Then, develop a professional development plan to support the growth of counselors in those areas that will help increase the use of data. Similarly, being aware of which counselors received initial training in the elements of the profession before the first introduction of the ASCA National Model in 2003, would help in the development of support and training programs. As seen in the data analysis in Chapter 4, counseling experience positively correlated in statistically significant way with the participant's total score on the SCSE (at the $p<.05$ level). The mean of counseling experience was just over 11 years. ASCA introduced the first National Model in 2003. If counselor training programs taught the model beginning the next school year that would indicate that counselors in 2018, when the survey was administered for the present study, with 12 or fewer years of experience had a reasonable expectation to know the elements of the model and the importance of using data within a program's development and assessment. The correlation with the years of experience and the SCSE total support this idea.

\section{Implications for Advocacy Groups Focused on School Counselors}

In the time since the present study began, The American School Counselor Association released an updated version of The ASCA National Model $(2012,2019)$ the primary elements remain the same. The diamond of the new model removes the outer edge and the themes of leadership, collaboration, systemic change, and advocacy. The developers also changed the wording of the elements to utilize verbs rather than nouns. They explain the purpose to spur counselors to action. The elements are now conceptualized as: (1) Define (previously foundation), (2) Manage (management system), (3) Deliver (delivery system), and (4) Assess (accountability) (ASCA, 2019). The revised 
model includes a set of mindsets for school counselors as well as three professional responsibilities, or behaviors. One of them, planning and assessment, specifically highlights the intentional use of data for identification of macro and micro level student needs, development of annual goals for the program and students, creation of action plans tied to these goals, and a complete program evaluation shared with various stakeholders (ASCA, 2019).

\section{Implications for School Counselors and Leadership}

With the release of A National at Risk in 1983, the "accountability movement" in education began (Cinotti, 2014). It was no longer considered enough that most of the students were prepared for some of the jobs. There was recognition of an achievement gap accompanied with a call to address the discrepancy. No Child Left Behind continued this emphasis on "real" change that addressed needs for all students. A key element of school reform in the past 40 years is the use of data to identify problems, research solutions, and measure effects. So called, "data-driven decisions," "Decision Making for Results," and "S.M.A.R.T. Goals" are phrases and processes adopted by school districts and personnel to focus on the learning of all students.

Data connected with student performance must go beyond enumeration.

Educational professionals, school counselors in particular, must employ analysis through statistical processes to show the effectiveness of educational initiatives. Indeed, it is the use of data that best answers the first question of the ASCA Model: How are students different because of the program delivery in school counseling?

In the state of Missouri, school counselors must have coursework focused on program evaluation (DESE, n.d.). Likewise, counselors trained in a CACREP accredited 
program are trained in the competencies around data collection and analysis (CACREP, 2016). The school counselor can, therefore, use profession specific training and competencies to solidify their role within the school community while supporting the success of students. It is as an active participant of this student support/data team where the school counselor can offer expertise in the collection, analysis, and dissemination of data. Through the use of normative and individual data, the team can then make informed decisions and create models of intervention

\section{An Opportunity for Leadership}

Within the structure of the ASCA National Model is a call for school counselors to be a leader for change within a system when that system does not meet the needs of all students (ASCA, 2012). Erford, House and Martin (2003) as well as Shillingford and Lambie (2010) point to the accountability mandates and the conceptualization of the National Model as a call to leadership to support academic achievement and the holistic development of students. "Professional school counseling must evolve into a model that will both fit the needs of the students in this rapidly changing society and conform to demands by school reform and accountability mandates" (Erford, House, \& Martin, 2003, p.3). These authors are echoing a concern of others (Carey \& Dimmit, 2006, 2007; Bemak, 2000; Bemak \& Chung, 2005; Bemak, Williams, \& Chung, 2014) that school counselors, when not included in the leadership initiatives within a school, are left out of the story of accountability and to the detriment of the individual and the profession. Shillingford and Lambie (2010) go on to highlight the leadership practices that make up an effective leader within the school counselor role. There are five fundamental practices: (1) challenging the process, (2) inspiring the vision, (3) enabling others, (4) 
modeling, and (5) encouraging. School counselors with the knowledge and background for data utilization within the counseling program have an opportunity to utilize Bandura's (1993, 1995, 1997) understanding of how self-efficacy increases and apply that to the fundamental practice of modeling described by Shillingford and Lambie (2010). Modeling allows for observational learning and that leads to greater selfefficacy.

\section{Recommendations for Further Research}

With more than half of the variance of the relationship between school counselor self-efficacy and use of data still unexplained, there are several areas yet to explore. Additional demographic information like counseling model of choice (e.g., Missouri Comprehensive Counseling Program, ASCA National Model, or another), or items such as professional memberships, participation in structured mentoring programs during early years of career development, the characteristics of the school where the counselor earned their Masters, and/or role within leadership in school or district.

Additional areas of research connect with the perceptions of school counselors, those that educate them, and the schools that employ counselors. Examining the perceived need for counselors to engage in the utilization and interpretation of data for each of these groups would extend an understanding as to the rationale for why more school counselors do not utilize data, if that is still a concern as listed in the literature (Astramovich \& Coker, 2007; Holcomb-McCoy, Gonzalez, Johnston, 2009;) School counselor perceptions would also be important in looking at the agentic nature of their work. Self-agency, a concept tied to Bandura's $(1986,1993,1995,1997)$ work in social 
cognitive theory and self-efficacy deals with the person's perceived ability to exert control over their own situation. Examining this concept within the model of the relationship between school counselor self-efficacy and data use could expand the model. Responses from a study looking at this element could provide another aspect of why a counselor either is not confident in using data or does not have the professional autonomy to make use of skills in this area.

To accomplish these new areas of exploration, researchers could utilize the information in the present study and, through factor analysis of the SCSE and SCANA, identify redundant items. Merging repetitive items allows for the length of the survey to remain the same as more demographic items are added. There is also benefit in expanding the methods in the study to include additional depth in school counselor voice. Additional qualitative items in the survey, focus groups, or individual interviews with school counselors could add a richness and understanding of the nuances of the model.

\section{Conclusions and Summary}

House and Hayes (2002) assert, “An effective school counselor hears more, knows more, and understands more about teachers, parents, students, and the community than anyone in the school.” (p. 252). It is this level of knowledge that cuts across all venues in a school as well as all stakeholders in a school that uniquely set school counselors in a role to advocate for students, determine needs, explain those needs to the community at large, and then report on any designed interventions and their outcomes. School counselors, through the use of data within their program, can answer the question, how are students different because of what happens in school? 
As seen in Chapter 2, the history of school counselors is often a story of a profession where the clearest objective is "all other duties as assigned." (ASCA, 2012; Gysbers, 2010; Gysbers \& Henderson, 2005; Lambie \& Williamson, 2004; Paisley, 2001; Sink, 2005). Using the standards from both ASCA and CACREP as a benchmark, it is clear that school counselors must learn those skills pertaining to data (i.e., collection, analysis, and description) to provide excellence within the profession (ASCA, 2012; CACREP, 2016). Authors (Blacher, Murray-Ward, \& Uellendahl, 2005; Isaacs, 2003; Militello \& Janson, 2014; Poynton, 2009; Poynton \& Carey, 2006) agree with this assertion and indicate that by utilizing intentional data collection methods with a goal of analysis of those data is key to the profession's ability to address issues of both academic and opportunity gaps as this is the ultimate goal of data use.

It is through a deeper understanding of why school counselors either do, or do not, use data within the school counseling program that the people who educate, lead, and evaluate them are best equipped to support the professionals. Ultimately, when school counselors are supported in the use of data the students connected to them during school years benefit (Young \& Kneale, 2013). The work of school counseling, viewed through the lens of data use, as it relates to identifying achievement and opportunity gaps and the evaluation of interventions designed to address those gaps, is a matter of social justice.

Students facing systemic obstacles to educational attainment and success are best served by school counselors who are able to adequately advocate in the climate of accountability (Carey \& Dimmit, 2006; Dahir \& Stone, 2003, 2009; Gibson \& Dembo, 1984; Isaacs, 2003; Lapan, 2005; Young \& Kneale, 2013). In a climate where notions that the only "things" that matter are those that can be measured, school counselors, 
equipped with the ability and self-efficacy to use data, can share the story of education within today's schools and the conditions that nurture student growth as well as the obstacles for the same. 


\section{REFERENCES}

Adelman, H. S., \& Taylor, L. (2002). School counselors and school reform: New directions. Professional School Counseling, 5(4), 235-248.

ACT for Youth Center of Excellence. (2016). U.S. teen demographics. Retrieved from http://www.actforyouth.net/adolescence/demographics/

American School Counselor Association. (2012). The ASCA National Model: A framework for school counseling programs (3rd ed.). Alexandria, VA: Author.

American School Counselor Association. (2017). RAMP recipients. Retrieved from https://www.schoolcounselor.org/school-counselors/recognized-asca-modelprogram-(ramp)/current-ramp-schools

American School Counselor Association. (2018). ASCA School Counselor Competencies. Retrieved from https://www.schoolcounselor.org/asca/media/asca/home/SCCompetencies.pdf

American School Counselor Association. (2019). The ASCA National Model: A framework for school counseling programs (4th ed.). Alexandria, VA: Author.

Astramovich, R. L., \& Coker, J. K. (2007). Program evaluation: The accountability bridge model for counselors. Journal of Counseling \& Development, 85, 162-172.

Bandura, A. (1977). Social learning theory. Englewood Cliffs, NJ: Prentice-Hall.

Bandura, A. (1986). Social foundations of thoughts and actions: A social cognitive theory. Englewood Cliffs, NJ: Prentice Hall.

Bandura, A. (1993). Perceived self-efficacy in cognitive development and functions. Educational Psychologist, 28(2), 117-148. 
Bandura, A. (1995). Exercise of personal and collective efficacy in changing societies. In A. Bandura (Ed.), Self-efficacy in changing societies (pp. 1-45). New York, NY: Cambridge University Press.

Bandura, A. (1997). Self-efficacy: The exercise of control. New York, NY: W. H. Freeman and Company.

Bandura, A. (2000). Exercise of human agency through collective efficacy. Current Directions in Psychological Science, 9(3), 75-78.

Bandura, A. (2001). Social cognitive theory: An agentic perspective. Annual Review of Psychology, 52, 1-26.

Bandura, A. (2006). Guide for constructing self-efficacy scales. In F. Pajares \& T. Urdan (Eds.), Self-efficacy beliefs of adolescents. (pp.307-377). Charlotte, NC: Information Age Publishing.

Bandura, A. (2009). Cultivate self-efficacy for personal and organizational effectiveness. In E. A. Locke (Ed.), Handbook of principles of organization behavior. (2nd ed.) (pp. 179-200). New York, NY: Wiley.

Bandura, A. (2012). On the functional properties of perceived self-efficacy revisited. Journal of Management, 38(1), 9-44. doi: 10.1177/0149206311410606

Bemak, F. (2000). Transforming the role of the counselor to provide leadership in educational reform through collaboration. Professional School Counseling, 3(5), 323-331.

Bemak, F., \& Chung, R. C-Y. (2005). Advocacy as a critical role for urban school counselors: Working toward equity and social justice. Professional School Counseling, 8(3), 196-202. 
Bemak, F., Williams, J.M., \& Chung, R. C-Y. (2014). Four critical domains of accountability for school counselors. Professional School Counseling 18 (1), 100110.

Blacher, J. H., Murray-Ward, M., \& Uellendahl, G. E. (2005). School counselors and student assessment. Professional School Counseling, 8(4), 337-343.

Birks, M., \& Mills, J. (2011). Grounded theory: A practical guide. London, England: Sage.

Bodenhorn, N., \& Skaggs, G. (2005). Development of the school counselor self-efficacy scale. Measurement and Evaluation in Counseling and Development, 38, 14-28.

Bodenhorn, N., Wolfe, E., \& Airen, O. (2010). School counselor program choice and self-efficacy: Relationship to achievement gap and equity. Professional School Counseling, 13, 165-174. doi 10.5330/PSC.n.2010-13.165

Bolman, L. G., \& Deal, T. E. (2008). Reframing organizations: Artistry, choice, and leadership (4th ed.). San Francisco, CA: Jossey-Bass.

Carey, J. C., \& Dimmitt, C. (2006). Resources for school counselors and counselor educators: The Center for School Counseling Outcome Research. Professional School Counseling, 9(5), 416-420.

Centers for Disease Control and Prevention. (2013). Mental health surveillance among children - United States, 2005-2011. Morbidity and Mortality Weekly Report, $62(2), 1-35$.

Charmaz, K. (2006). Constructing grounded theory: A practical guide through qualitative analysis. Thousand Oaks, CA: Sage. 
Cinotti, D. (2014). Competing professional identity models in school counseling: A historical perspective and commentary. The Professional Counselor, 4, 417-425. doi:10.15241/dc.4.5.417

Cohen, J., Cohen, P., West, S. G., \& Aiken, L. S. (2003). Applied multiple regression/correlation analysis for the behavioral sciences (3rd ed.). Mahwah, NJ: Lawrence Erlbaum Associates, Publishers.

Council for Accreditation of Counseling \& Related Educational Programs. (2016). Section 5G. 2016 CACREP Standards. Retrieved from http://www.cacrep.org/section-5-entry-level-specialty-areas-school-counseling/

Creswell, J. W. (2009). Research design: Qualitative, quantitative, and mixed method approaches (3rd ed.). Thousand Oaks, CA: Sage.

Crowne, D. P., \& Marlowe, D. (1960). A new scale of social desirability independent of psychopathology. Journal of Consulting Psychology, 24, 349-354.

Dahir, C. A., \& Stone, C. B. (2003). Accountability: A M.E.A.S.U.R.E. of the impact school counselors have on student achievement. Professional School Counseling, $6(3), 214-221$.

Dahir, C. A., \& Stone, C. B. (2009). School counselor accountability: The path to social justice and systemic change. Journal of Counseling and Development, 87, 12-20.

Dillman, D. A. (2007). Mail and internet surveys: The tailored design method (2nd ed.). Hoboken, NJ: John Wiley \& Sons.

Dimmit, C. (2009). Why evaluation matters: Determining effective school counseling practices. Professional School Counseling, 12(6), 395-399. 
Dimmitt, C., \& Carey, J. (2007). Using the ASCA national model to facilitate school transition. Professional School Counseling, 10, 227-232.

Education Trust. (2007). Transforming school counseling: Benefits of becoming a transforming school counselor preparation program. Retrieved from http://www2.edtrust.org

Education Trust. (2014). Accountability. Retrieved from https://edtrust.org/issue/accountability-for-raising-achievements-closing-gaps/ Education Trust. (2016a). The Every Student Succeeds Act: What's in it? What does it mean for equity? Overview. Retrieved from https://edtrust.org/wpcontent/uploads/2014/09/what-is-in-ESSA-Overview.pdf

Education Trust. (2016b). Detailed overview of Every Student Succeeds Act. Retrieved from https://edtrust.org/wp-content/uploads/2014/09/Detailed-Overview-ofEvery-Student-Succeeds-Act.pdf

Education Trust. (2016c). The Every Student Succeeds Act: What's in it? What does it mean for equity? Standards. Retrieved from https://edtrust.org/resource/whats-inthe-every-student-succeeds-act-standards/

Education Trust. (2016d). The Every Student Succeeds Act: What's in it? What does it mean for equity? Assessments. Retrieved from https://edtrust.org/resource/whatsin-the-every-student-succeeds-act-assessments/

Education Trust. (2016e). The Every Student Succeeds Act: What's in it? What does it mean for equity? Accountability. Retrieved from https://edtrust.org/resource/whats-in-the-every-student-succeeds-actaccountability/ 
Education Week. (2011). Research Center: Adequate yearly progress. Retrieved from http://edweek.org/ew/issues/adequate-yearly-progress

Elementary and Secondary Education Act of 1965, Pub. L. No. 89-10 Stat. 27 (1965).

Retrieved from https://www.gpo.gov/fdsys/pkg/STATUTE-79/pdf/STATUTE-79Pg27.pdf

Erford, B. T., House, R., \& Martin, P. (2003). Transforming the school counseling profession. In B. T. Erford (Ed.), Transforming the school counseling profession (pp. 1-20). Upper Saddle River, NJ: Pearson Education.

Every Student Succeeds Act, Pub. L. No. 114-95 Stat. 1802 (2015). Retrieved from https://www.gpo.gov/fdsys/pkg/PLAW-114pub195/pdf/PLAW-114pub195.pdf

Federal Interagency Forum on Child and Family Statistics. (2016). America's children in brief: Key national indicators of well-being, 2016. Washington, DC: U.S. Government Printing Office.

Field, A. (2009). Discovering statistics using SPSS (3rd ed.). Thousand Oaks, CA: Sage.

Fink, A. (2009). How to conduct surveys: A step-by-step guide (4th ed.). Thousand Oaks, CA: Sage.

Fitts, W. H., \& Warren, W. L. (1996). Tennessee Self-Concept Scale: TSCS: 2. Los Angeles, CA: Western Psychological Services.

Gibson, S., \& Dembo, M. H. (1984). Teacher efficacy: A construct validation. Journal of Educational Psychology, 76, 569-582. doi: 10.1037/0022-0663.76.4.569

Gysbers, N. C. (2010). Remembering the past, shaping the future: A history of school counseling. Alexandria, VA: American School Counselor Association. 
Gysbers, N. C., \& Henderson, P. (2005). Designing, implementing, and managing a comprehensive school guidance and counseling program. In C. Sink (Ed.), Contemporary school counseling: Theory, research, and practice (pp. 151-188). Boston, MA: Houghton Mifflin Company.

Hatching Results. (2020). Professional development by Hatching Results. Retrieved from https://www.hatchingresults.com/pd/services

Herr, E. L. (2003). Historical roots and future issues. In B. T. Erford (Ed.), Transforming the school counseling profession (pp. 21-38). Upper Saddle River, NJ: Pearson Education.

Holcomb-McCoy, C., Gonzalez, I., \& Johnston, G. (2009). School counselor dispositions as predictors of data usage. Professional School Counseling, 12(5), 343-351.

House, R. M., \& Hayes, R. L. (2002). School counselors: Becoming key players in school reform. Professional School Counseling, 5, 249-256.

Isaacs, M. L. (2003). Data-driven decision making: The engine of accountability. Professional School Counseling 6(4), 288-295.

Kena, G., Musu-Gillette, L., Robinson, J., Wang, X., Rathbun, A., Zhang, J., WilkinsonFlicker, S., Barmer, A., \& Dunlop Velez, E. (2015). The condition of education 2015 (NCES 2015-144). U.S. Department of Education, National Center for Education Statistics. Washington, DC. Retrieved from http://nces.ed.gov/pubsearch

Keys, S. G., Green, A., Lockhart, E., \& Luongo, P.F. (2003). Consultation and collaboration. In B. T. Erford (Ed.), Transforming the school counseling profession (pp. 171-190). Upper Saddle River, NJ: Pearson Education. 
Kim, J. S., \& Sunderman, G. L. (2005). Measuring academic proficiency under the No Child Left Behind Act: Implications for educational equity. Educational Researcher, 34(8), 3-13.

Klein, A. (2015). ESEA Reauthorization: The Every Student Succeeds Act explained. Retrieved from http://blogs.edweek.org/edweek/campain-k12/2015/11/esea_reauthorization_the_every.html

Lambie, G. W., \& Williamson, L. L. (2004). The challenge to change from guidance counseling to school counseling: A historical proposition. Professional School Counseling, 8, 124-131.

Lapan, R. T., (2001). Results-based comprehensive guidance and counseling programs: A framework for planning and evaluation. Professional School Counseling, 4, 289299.

Lapan, R. T. (2005) Evaluating school counseling programs. In C. Sink (Ed.), Contemporary school counseling: Theory, research, and practice (pp. 257-293). Boston, MA: Houghton Mifflin Company.

Lapan, R. T., Gysbers, N. C., \& Petroski, G. F. (2001). Helping seventh graders be safe and successful: A statewide study of the impact of comprehensive guidance and counseling programs. Journal of Counseling and Development, 79, 320-330.

Lapan, R. T., Gysbers, N. C., \& Sun, Y. (1997). The impact of more fully implemented guidance programs on the school experiences of high school students: A statewide evaluation study. Journal of Counseling \& Development, 76, 292-302.

Larson, L. M. (1998). The social cognitive model of counselor training. The Counseling Psychologist, 26(2), 219-273. 
Larson, L. M., \& Daniels, J. A. (1998). Review of the counseling self-efficacy literature. The Counseling Psychologist, 26(2), 179-218.

Larson, L. M., Suzuki, L. A., Gillespie, K. N., Potenza, M. T., Bechtel, M. A., \& Toulouse, A. L. (1992). Development and validation of the Counseling SelfEstimate Inventory. Journal of Counseling Psychology, 39, 105-120.

Linn, R. (2003). Accountability: Responsibility and reasonable expectations. Educational Researcher, 32(7), 3-13.

Maras, M. A., Coleman, S. L., Gysbers, N. C., Herman, K. C., \& Stanley, B. (2013). Measuring evaluation competency among school counselors. Counseling Outcome Research and Evaluation, 4(2), 99-111.

Martin, P. J., \& House, R. M. (2002). Transforming school counseling in the transforming school counseling initiative. Washington, DC: The Education Trust.

Mertens, D. M. (2010). Research and evaluation in education and psychology: Integrating diversity with quantitative, qualitative, and mixed methods (3rd ed.). Thousand Oaks, CA: Sage.

Militello, M., \& Janson, C. (2014). The urban school reform opera: The obstructions to transforming school counseling practices. Education and Urban Society, 46(7), 743-772. doi: 10.1177/0013124512468007

Miller, B. J. (2016). No school counselor left behind: Counselors use of data and their perceived obstacles and facilitators (Doctoral dissertation). Retrieved from https://etda.libraries.psu.edu/catalog/db78tc00b

Missouri Department of Elementary and Secondary Education. (n.d.). School counseling. Retrieved from https://dese.mo.gov/college-career-readiness/school-counseling 
Missouri Department of Elementary and Secondary Education. (2010). Program evaluation: Determining the level of implementation. Retrieved from https://dese.mo.gov/college-career-readiness/school-counseling\#mini-panelschool-counseling4

Mullen, P. (2014). The contribution of school counselor self-efficacy and professional quality of life to their programmatic service delivery (Doctoral dissertation). Electronic Theses and Dissertations, 4793. Retrieved from https://stars.library.ucf.edu/etd/4793/

Mullen, P. R., \& Lambie, G. W. (2016). The contribution of school counselors'selfefficacy to their programmatic service delivery. Psychology in the Schools, 53(3), 306-320. doi: 10.1002/pits

National Commission on Excellence in Education. (1983). A nation at risk: The imperative for educational reform. Retrieved from https://www.edreform.com/wp-content/uploads/2013/02/A_Nation_At_ Risk_1983.pdf

National Defense Education Act of 1958, Pub. L. No. 85-864 Stat. 72 (1958). Retrieved from https://www.gpo.gov/fdsys/pkg/STATUTE-72/pdf/STATUTE-72Pg1580.pdf

NDEA, impacted areas. (1965). CQ almanac 1964 (20th ed.). Washington, DC: Congressional Quarterly. Retrieved from http://library.cqpress.com/cqalmanac/cqal64-1304318 
No Child Left Behind Act of 2001, Pub. L. No. 107-110 Stat. 1425 (2001). Retrieved from https://www.gpo.gov/fdsys/pkg/PLAW-107publ110/html/PLAW107publ110.htm

Paisley, P. O. (2001). School counseling for the 21st century: Challenges and opportunities. Professional School Counseling, 5, 106-116.

Paisley, P. O., \& Borders, L. D. (1995). School counseling: An evolving specialty. Journal of Counseling and Development, 74, 150-153.

Poynton, T. A. (2009). Evaluating the effectiveness of a professional development workshop to increase school counselors' use of data: The role of technology. The Journal of Counselor Preparation and Supervision 1(1). doi: 10.7729/11.0107

Poynton, T. A. \& Carey, J. C. (2006). An integrative model of data-based decision making for school counseling. Professional School Counseling, 10(2), 121-130.

Punch, K. F. (2014). Introduction to social research. London, England: Sage.

Robson, C., \& McCartan, K. (2016). Real world research: A resource for users of social research methods in applied settings (4th ed.). Hoboken, NJ: Wiley.

Scoles, M. A. (2011). Examination of the impact of prior teaching experience on the selfefficacy of school counselors in the state of Ohio. (Electronic Thesis or Dissertation). Retrieved from https://etd.ohiolink.edu/pg_10?::NO:10:P10_ETD_SUBID:49813

Seidman, I. (2006). Interviewing as qualitative research (3rd ed.). New York, NY: Teachers College Press. 
Shillingford, M. A., \& Lambie, G. W. (2010). Contribution of professional school counselors' values and leadership practices to their programmatic service delivery. Professional School Counseling, 13(4), 208-217.

Singh, A., Taneja, A., \& Mangalaraj, G. (2009). Creating online surveys: Some wisdom from the trenches tutorial. IEEE Transactions on professional communication, 52(2), 197-212.

Sink, C. A. (2005). The contemporary school counselor. In C. Sink (Ed.), Contemporary school counseling: Theory, research, and practice (pp. 1-42). Boston, MA: Houghton Mifflin Company.

Smith, E. (2005). Raising standards in American schools: The case of No Child Left Behind. Journal of Education Policy, 20(4), 507-524.

Spielberger, C. (1983). State-trait anxiety (Form Y). Redwood City, CA: Mind Garden.

Stern, P. N., \& Porr, C. J. (2011). Essentials of accessible grounded theory. Walnut Creek, CA: Left Coast Press.

Sutton, J. M., \& Fall, M. (1995). The relationship of school climate factors to counselor self-efficacy. Journal of Counseling Psychology, 34, 414-424.

Tabachnick, B. G., \& Fidell, L. S. (2013). Using multivariate statistics (6th ed.). Boston, MA: Pearson.

Tolmie, A., Muijs, D., \& McAteer, E. (2011). Quantitative methods in educational and social research: Using SPSS. New York: McGraw Hill.

Toepoel, V. (2016). Doing surveys online. Los Angeles, CA: Sage.

Tourangeau, R., Conrad, F. G., \& Couper, M. P. (2013). The science of web surveys. New York, NY: Oxford. 
U. S. Department of Education. (2008). Fiscal year 2009 budget summary - February 4, 2008. Retrieved from http://www2.ed.gov/about/overview/budget/budget09/summary/edlitesection1.html

U.S. Department of Education. (2012). Title I - Improving the academic achievement of the disadvantaged. Retrieved from http://www2.ed.gov/nclb/landing.jhtml

U.S. Department of Education. (2016). Every student succeeds act. Retrieved from https://www2.ed.gov/policy/elsec/leg/essa/index.html

U.S. Senate. (n.d.). 1941-1963. Retrieved from https://www.senate.gov/artandhistory/history/minute/Sputnik_Spurs_Passage_of_ National_Defense_Education_Act.htm

Walliman, N. (2016). Social research methods: The essentials. Thousand Oaks, CA: Sage.

Young, A., \& Kaffenberger, C. (2011). The beliefs and practices of school counselors who use data to implement comprehensive school counseling programs. Professional School Counseling (15)2, 67-76.

Young, A., \& Kaffenberger, C. (2015). School counseling professional development: Assessing the use of data to inform school counseling services. Professional School Counseling, 19(1), 46-56. 


\section{Appendix A:}

The ASCA National Model Diamond (2012). The diamond visually describes the interplay of the four elements: Foundation, Management, Delivery, and Accountability as well as the themes of Leadership, Advocacy, Collaboration and Systemic Change. From ASCA National Model: A Framework for School Counseling Programs by American School Counselors Association (2012) Alexandria, VA: Author, Copyright 2012 by American School Counselor Association. Reprinted with permission.

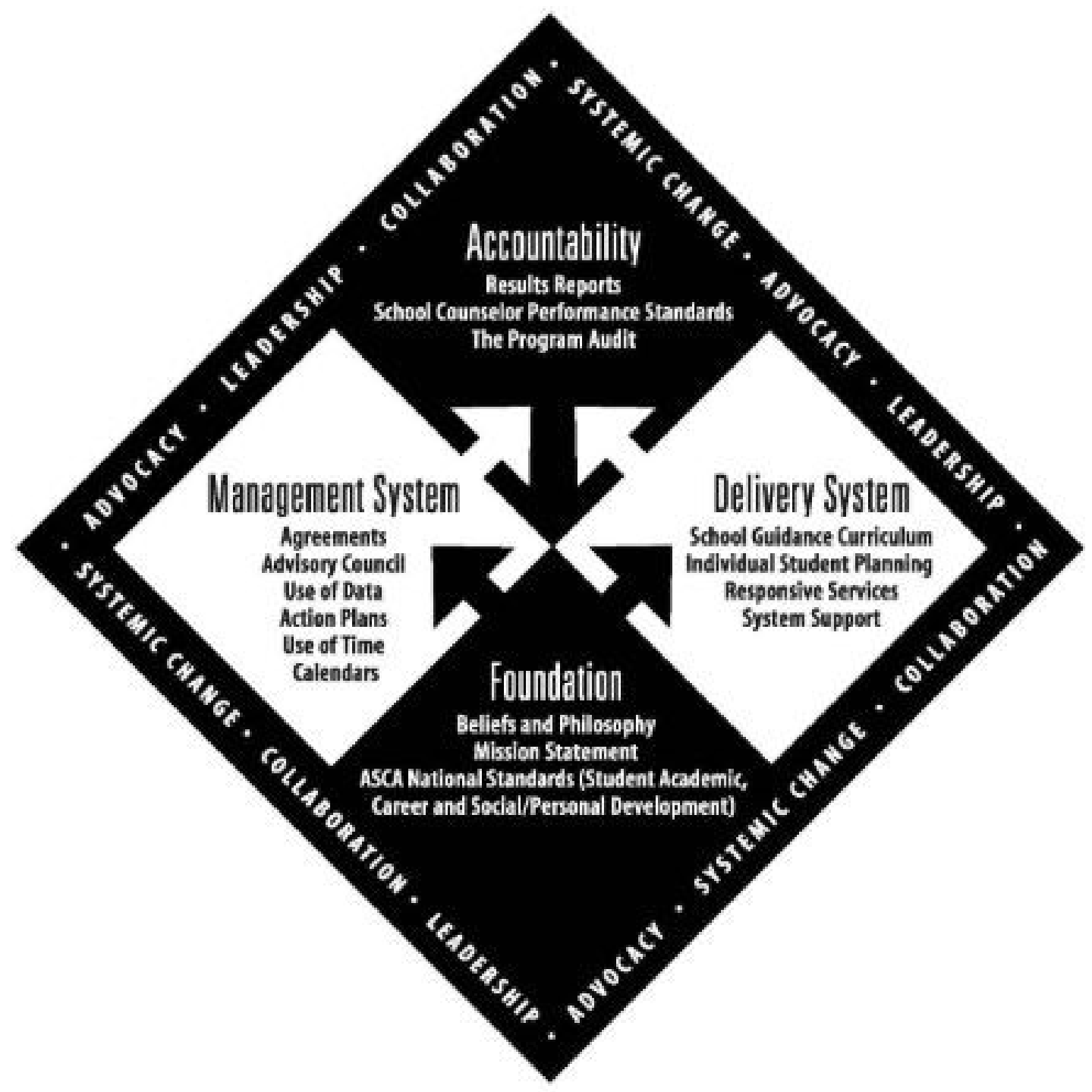


Appendix B:

\section{Survey for the present study}

\section{School Counselor Data Use and Self-Efficacy Survey}

Thank you for your willingness to consider participating in this survey. Below is information regarding informed consent and this study.

\section{Consent Form to Participate in a Research Study}

Researcher's Name(s): Susan E. Matthews

Project Number: 2008294

Project Title: Accountability in school counseling: The interplay of data use and self-efficacy in a climate of school reform

\section{INTRODUCTION}

This consent may contain words that you do not understand. Please ask the investigator or the study staff to explain any words or information that you do not clearly understand. You are being asked to participate in a research study. This research is being conducted to look at patterns of data use among school counselors. When you are invited to participate in research, you have the right to be informed about the study procedures so that you can decide whether you want to consent to participation.

This form may contain words that you do not know. Please ask the researcher to explain any words or information that you do not understand. You have the right to know what you will be asked to do so that you can decide whether or not to be in the study. Your participation is voluntary. You do not have to be in the study id you do not want to. You may refuse to be in the study and nothing will happen. If you do not want to continue to 
be in the study, you may stop at any time without penalty or loss of benefits to which you are otherwise entitled.

WHY IS THIS STUDY BEING DONE? The purpose of this research is to examine how use of data in school counseling may or may not be related to perception of personal ability as a school counselor and as part of the investigator's doctoral studies.

HOW MANY PEOPLE WILL BE IN THE STUDY? About 2,000 people will receive an invitation to take part in this study in the state of Missouri.

WHAT AM I BEING ASKED TO DO? You will be asked to complete a survey on the computer.

HOW LONG WILL I BE IN THE STUDY? This study will take approximately 20 minutes to complete. You can stop participating at any time without penalty.

WHAT ARE THE BENEFITS OF BEING IN THE STUDY? Your participation will benefit the study of data use among school counselors.

WHAT ARE THE RISKS OF BEING IN THE STUDY? There are limited risks associated with this study. The questions on the computer-based survey may prompt reflection on professional practices and this may lead to discomfort.

WHAT ARE THE COSTS OF BEING IN THE STUDY? There is no cost to you.

WHAT OTHER OPTIONS ARE THERE? An alternative is to not participate in this research study

CONFIDENTIALITY Your responses to this survey will be anonymous. At the conclusion of the survey you will be directed to a separate survey to submit your name and contact information to be eligible for one of five, \$20 gift certificates for Amazon.com.

WILL I BE COMPENSATED FOR PARTICIPATING IN THE STUDY? You will receive no payment for taking part in this study. However, there are five, \$20 gift certificates to Amazon.com that will be given randomly to participants who complete the survey.

WHAT ARE MY RIGHTS AS A PARTICIPANT? Participation in this study is voluntary. You do not have to participate in this study. You will also be informed of any new information discovered during the course of this study that might influence your health, welfare, or willingness to be in this study. 


\section{WHO DO I CONTACT IF I HAVE QUESTIONS, CONCERNS, OR COMPLAINTS? Please contact Susan Matthews, (573) 864-8197, if you have} questions about the research. Additionally, you may ask questions, voice concerns or complaints to the research team:

Susan Matthews, M.Ed.

Doctoral Student

University of Missouri - Columbia

(573) 864-8197

SMatthews@cpsk12.org
Sarah Diem, Ph.D.,

Advisor

Associate Professor

Director of Graduate Studies

Ph.D. Program Coordinator

Educational Leadership and Policy Analysis

Faculty Affiliate, Harry S. Truman School

of Public Affairs

University of Missouri

202 Hill Hall (mailing)

307 Hill Hall (office)

Columbia, MO 65211

Phone: 573-884-4907

Fax: 573-884-5714

diems@missouri.edu

WHOM DO I CALL IF I HAVE QUESTIONS OR PROBLEMS? If you have any questions regarding your rights as a participant in this research and/or concerns about the study, or if you feel under any pressure to enroll or to continue to participate in this study, you may contact the University of Missouri Campus Institutional Review Board (which is a group of people who review the research studies to protect participants' rights) at (573) 882-3181 or umcresearchcirb@missouri.edu.

Please save or print a copy of this Informed Consent before you participate in the research.

Please select an option:

I agree to participate I do NOT agree to participate

\section{Skip To: End of Survey If Q30 = I do NOT agree to participate}

Below is a list of activities representing many school counselor responsibilities. Indicate your confidence in your current ability to perform each activity by selecting the appropriate answer next to each item according to the scale defined below. Please answer each item based on one current school, and based on how you feel now, not on your anticipated (or previous) ability or school(s). Remember, this is not a test and there are no right answers. 
Select the choice that best represents your response for each item.

$\begin{array}{ccccc}\text { Not } & \text { Slightly } & \text { Moderately } & \text { Generally } & \text { Highly } \\ \text { Confident } & \text { Confident } & \text { Confident } & \text { Confident } & \text { Confident } \\ (1) & (2) & (3) & (4) & (5)\end{array}$

Advocate for integration of student academic, career, and personal development into the mission of my school.

Recognize situations that impact (both negatively and positively) student learning and achievement.

Analyze data to identify patterns of achievement and behavior that contribute to school success.

Advocate for myself as a professional school counselor and articulate the purposes and goals of school counseling.

Develop measurable outcomes for a school counseling program which would demonstrate accountability.

Consult and collaborate with teachers, staff, administrators and parents to promote student success.

\section{New web page}

Establish rapport with a student for individual counseling.

Function successfully as a small group leader.

Effectively deliver suitable parts of the school counseling program through large group meetings such as in classrooms.

Conduct interventions with parents, guardians and families in order to resolve problems that impact students' effectiveness and success.

Teach students how to apply time and task management skills. 
New web page

Foster understanding of the relationship between learning and work.

Offer appropriate explanations to students, parents and teachers of how learning styles affect school performance.

Deliver age-appropriate programs through which students acquire the skills needed to investigate the world of work.

Implement a program which enables all students to make informed career decisions.

Teach students to apply problemsolving skills toward their academic, personal and career success.

\section{New web page}

Evaluate commercially prepared material designed for school counseling to establish their relevance to my school population.

Model and teach conflict resolution skills.

Ensure a safe environment for all students in my school.

Change situations in which an individual or group treats others in disrespectful or harassing manner.

Teach students to use effective communication skills with peers, faculty, employers, family, etc. 
New web page

Follow ethical and legal obligations designed for school counselors.

Guide students in techniques to cope with peer pressure.

Adjust my communication style appropriately to the age and developmental levels of various students.

Incorporate students' developmental stages in establishing and conducting the school counseling program.

I can find some way of connecting and communicating with any student in my school.

New web page

Teach, develop and/or support students' coping mechanisms for dealing with crises in their lives -e.g., peer suicide, parent's death, abuse, etc.

Counsel effectively with students and families from different social/economic statuses.

Understand the viewpoints and experiences of students and parents who are from a different cultural background than myself.

Help teachers improve their effectiveness with students.

Discuss issues of sexuality and sexual orientation in an age appropriate manner with students. 


\section{New web page}

Speak in front of large groups such as faculty or parent meetings.

Use technology designed to support student successes and progress through the educational process.

Communicate in writing with staff, parents, and the external community.

Help students identify and attain attitudes, behaviors, and skills which lead to successful learning.

Select and implement applicable strategies to assess school-wide issues.

\section{New web page}

Promote the use of counseling and guidance activities by the total school community to enhance a positive school climate.

Develop school improvement plans based on interpreting school-wide assessment results.

Identify aptitude, achievement, interest, values, and personality appraisal resources appropriate for specified situations and populations.

Implement a preventative approach to student problems.

Lead school-wide initiatives which focus on ensuring a positive learning environment.

Consult with external community agencies that provide support services for our students.

Provide resources and guidance to school population in times of crisis. 
Responses to statements in the following section will help measure the impact of data and accountability strategies to close achievement and opportunity gaps, measure student progress, and foster student success at all levels.

As before, please respond to the items based on your current behavior and/or practices, not what you have done or would like to do.

Select the choice that best represents your response for each item. *

$\begin{array}{cccccc}\text { Never } & \text { Seldom } & \text { Sometimes } & \text { Often } & \text { Usually } & \text { Always } \\ (1) & (2) & (3) & (4) & (5) & (6)\end{array}$

To improve school counseling services, I analyze district profiles.

To enhance student achievement, I analyze data to increase college and career readiness for all students.

To improve school counseling services (academic, personal/social, and career), I analyze student progress/report cards.

To improve school counseling services (academic, personal/social, and career), I analyze my school's state data reports.

I use technology to improve student achievement.

* On these five items, I followed the scale of the original researchers as 1-6. In the following sets of items, the scale reverts to 1-5. This was an error and was accounted for by transforming participant scores on these items into z-scores. 
New web page

$\begin{array}{ccccc}\text { Never } & \text { Seldom } & \text { Sometimes } & \text { Usually } & \text { Always } \\ (1) & (2) & (3) & (4) & (5)\end{array}$

I use data to close achievement gaps that exist in my school.

I create surveys as a data collection method to improve school counseling services/programs.

I analyze program feedback to improve school counseling services.

I regularly use pre and post-test when facilitating classroom guidance lessons and workshops.

I facilitate focus groups as a data collection method to improve my school counseling services/programs.

New web page

My school counseling department sets strategic goals.

I have a systematic way to share outcome data.

I use data to identify barriers that impede student performance.

I regularly attend professional development trainings to improve my school counseling skills.

I believe it is important to use data to identify issues that impede academic success.

I use evidence-based practices to increase student achievement. 
The following questions are designed to get a better understanding of the kinds of things that are difficult for school counselors.

If you were asked to complete the following tasks right now, how certain are you that you could complete the task with accuracy?

Rate your degree of confidence by marking the number from 1 to 5 using the scale below:

\begin{tabular}{|c|c|c|}
\hline $\begin{array}{l}\text { Cannot do } \\
\text { at all (1) }\end{array}$ & 2 & $\begin{array}{l}\text { Moderately certain } \\
\text { I can do ( } 3)\end{array}$ \\
\hline
\end{tabular}

I can perform standard mathematical calculations (e.g., addition,

subtraction, multiplication, division).

I can evaluate student data to choose the best statistical calculation (e.g. mean, t-test, correlations) to interpret student data.

I can calculate measures of central tendency (e.g., mean, median, and mode) to interpret student data.

I can use t-tests to interpret student data.

I can use computer programs (e.g., Word, Excel, Student Information Systems) to support the management of student data.

I can use computer programs (e.g., Excel, EZAnalyze, SPSS) to support the statistical analysis of student data.

I can explain the results of statistical operations to parents, administration, community members, and other stakeholders.

The following open-ended questions give you the opportunity to share additional information about your current behavior and/or practices. 
What data do you rely on the most to improve your school counseling services?

Briefly describe who you collaborate with most often.

Have you participated in professional development training related to using data and accountability strategies during the past 12 months?

No (1)

Yes. Please explain what was the title or scope of the professional development training. (2)

Finally, please respond to the following demographic questions.

What level(s) do you serve? (Check all that apply)

Elementary (1)

Middle (2)

High (3)

K-12 (4)

K-8 (5)

Other (please explain): (6)

How many years have you worked in the school counseling profession?

How many years have you worked in the education profession?

Approximately how many students are on your caseload? 
What is your gender

Female (1)

Male (2)

Non-binary/third gender (3)

Prefer to self-describe: (4)

Prefer not to say (5) 


\section{Appendix C:}

\section{Emails soliciting participation from participants}

Message sent to DESE list of School Counselors in Missouri on the following dates:

1. April 26, 2018

2. May 2, 2018

3. May 9,2018

4. May 16,2018

Dear Potential Survey Participant,

As a school counselor in the state of Missouri, you are invited to participate in a quantitative research study. This study examines the connection between school counselor self-efficacy and the ways counselors use data. Your participation involves taking an online survey that will last approximately 20 minutes.

Responses to this survey will be anonymous. Any identifying information will not be linked to your responses.

The potential benefit of your participation includes contributing to knowledge and understanding in the school counseling field. Potential risks may include discomfort or embarrassment from the nature of the questions. Your participation is voluntary and can be ended at any point.

Your rights are important. If you have questions about this study please contact me, Susan Matthews, at 573-864-8197 or SMatthews@cpsk12.org, or my committee chair, Sarah Diem, atdiems@missouri.edu.

Your time is also important. As a thank you, I am offering $\$ 20$ gift certificates from Amazon.com to five participants. If you choose to take the survey, you'll be directed to a separate survey where you can enter your demographic information. Five participants will be randomly selected to receive the $\$ 20$ certificates.

Thank you for taking the time to participate.

Sincerely,

Susan E. Matthews, M.Ed.

Doctoral Candidate 
Department of Educational Leadership and Policy Analysis

University of Missouri - Columbia

Dr. Sarah Diem

Dissertation Chair

Department of Educational Leadership and Policy Analysis

University of Missouri - Columbia

\section{Follow this link to the Survey:}

Link to Qualtrics Survey

Or copy and paste the URL below into your internet browser:

Address of the Qualtrics Survey

Follow the link to opt out of future emails:

Link to allow for opting out of reminder emails 


\section{Appendix D:}

\section{붕

Documentation from the IRB of the University of Missouri - Columbia

April 25, 2018

Principal Investigator: Susan Matthews

Department: Educational Leadership-EDD

Your IRB Application to project entitled Accountability in school counseling: The interplay of data use and self-efficacy in a climate of school reform was reviewed and approved by the MU Institutional Review Board according to the terms and conditions described below:

$\begin{array}{ll}\text { IRB Project Number } & 2008294 \\ \text { IRB Review Number } & 225582 \\ \text { Initial Application Approval Date } & \text { April 25, 2018 } \\ \text { IRB Expiration Date } & \text { April 25, 2019 } \\ \text { Level of Review } & \text { Exempt } \\ \text { Project Status } & \text { Active - Open to } \\ \text { Exempt Categories } & \text { Enrollment } \\ \text { Risk Level } & 45 \text { CFR 46.101b(2) } \\ \text { Internal Funding } & \text { Minimal Risk } \\ & \text { Personal funds }\end{array}$

The principal investigator (PI) is responsible for all aspects and conduct of this study. The PI must comply with the following conditions of the approval:

1. No subjects may be involved in any study procedure prior to the IRB approval date or after the expiration date.

2. All unanticipated problems and deviations must be reported to the IRB within 5 business days.

3. All changes must be IRB approved prior to implementation unless they are intended to reduce immediate risk.

4. All recruitment materials and methods must be approved by the IRB prior to being used.

5. The Annual Exempt Form must be submitted to the IRB for review and approval at least 30 days prior to the project expiration date. If the study is complete, the Completion/Withdrawal Form may be submitted in lieu of the Annual Exempt Form

6. Maintain all research records for a period of seven years from the project completion date.

7. Utilize all approved research documents located within the attached files section of eCompliance. These documents are highlighted green.

If you are offering subject payments and would like more information about research participant payments, please click here to view the MU Business Policy and Procedure:

http://bppm.missouri.edu/chapter2/2_250.html 
If you have any questions, please contact the IRB at 573-882-3181 or irb@missouri.edu. Thank you, MU Institutional Review Board 


\section{VITA}

Susan Evans Matthews is a school counselor who believes the mission of her work is to connect adolescents to the skills and strategies necessary to meet the opportunities and challenges that await in life. The daughter and granddaughter of educators, Dr. Matthews fought against joining the family business and earned her undergraduate degree in Psychology (Drury University) and then did a year of work as an AmeriCorps*VISTA volunteer at Warren Village in Denver, Colorado. Dr. Matthews realized that the true song of her heart was best performed in public education and she moved to Columbia, Missouri and earned her M.Ed. in Counseling Psychology with an emphasis in School Counseling at the University of Missouri - Columbia. She also earned the Doctorate of Education in Organizational Leadership at Mizzou. She serves as the Director of Counseling at David H. Hickman High School (Go Kewpies!).

Dr. Matthews remains a resident of Columbia, the place where she met and married her husband, Marty, and they raise their four children: Eilish, Elora, Rowen, and Scarlett Grace. 